\title{
Towards efficient cardiac surgery
}

Citation for published version (APA):

Haanschoten, M. C. (2016). Towards efficient cardiac surgery: the integrating role of anesthesiology and intensive care. [Doctoral Thesis, Maastricht University]. Universiteit Maastricht. https://doi.org/10.26481/dis.20161013mh

Document status and date:

Published: 01/01/2016

DOI:

10.26481/dis.20161013mh

Document Version:

Publisher's PDF, also known as Version of record

\section{Please check the document version of this publication:}

- A submitted manuscript is the version of the article upon submission and before peer-review. There can be important differences between the submitted version and the official published version of record.

People interested in the research are advised to contact the author for the final version of the publication, or visit the DOI to the publisher's website.

- The final author version and the galley proof are versions of the publication after peer review.

- The final published version features the final layout of the paper including the volume, issue and page numbers.

Link to publication

\footnotetext{
General rights rights.

- You may freely distribute the URL identifying the publication in the public portal. please follow below link for the End User Agreement:

www.umlib.nl/taverne-license

Take down policy

If you believe that this document breaches copyright please contact us at:

repository@maastrichtuniversity.nl

providing details and we will investigate your claim.
}

Copyright and moral rights for the publications made accessible in the public portal are retained by the authors and/or other copyright owners and it is a condition of accessing publications that users recognise and abide by the legal requirements associated with these

- Users may download and print one copy of any publication from the public portal for the purpose of private study or research.

- You may not further distribute the material or use it for any profit-making activity or commercial gain

If the publication is distributed under the terms of Article $25 \mathrm{fa}$ of the Dutch Copyright Act, indicated by the "Taverne" license above, 


\title{
Towards efficient cardiac surgery - The integrating role of
} anesthesiology and intensive care

\author{
MARCO HAANSCHOTEN
}



(c) 2016 Marco Haanschoten
ISBN 978-90-9029808-5
PAINTING Marcel Bastiaans (www.marcelbastiaans.com)
DESIGN Sofie den Ouden (www.vissencom.nl)
PRINTING Frans van Meltvoort (wWW.vanmeltvoort.nl)

All rights reserved. No part of this thesis may be reproduces, stored or transmitted without prior permission of the author.

Printing of this thesis was financially supported by Abbvie B.V., Catharina Ziekenhuis Eindhoven, Eurocept B.V., Vygon N.V. 


\section{Towards efficient cardiac surgery The integrating role of}

anesthesiology and intensive care

\section{Proefschrift}

ter verkrijging van de graad van doctor aan de Universiteit Maastricht, op gezag van Rector Magnificus, prof.dr. R.M. Letschert volgens het besluit van het College van Decanen,

in het openbaar te verdedigen op donderdag 13 oktober 2016 om 14.00 uur

door

Marco Haanschoten

geboren te Oostzaan op 2 juli 1961 


\section{PROMOTIECOMMISSIE}

\section{PROMOTORES}

- Prof.dr. W.F.F.A. Buhre, MD, PhD, hoogleraar Anesthesiologie, Universiteit Maastricht

- Prof.dr. A. van Zundert, MD, PhD, FRCA, EDRA, FANZCA, hoogleraar Anesthesiologie, Universiteit Maastricht, University of Queensland, Australia

\section{CO-PROMOTORES}

- Dr. Mohamed A. Soliman Hamad, MD, PhD, afdeling Cardio Thoracale Chirurgie, Catharina Ziekenhuis Eindhoven

- Dr. A.H.M. van Straten, MD, PhD, afdeling Cardio Thoracale Chirurgie, Catharina Ziekenhuis Eindhoven

\section{BEOORDELINGSCOMMISSIE}

- Prof.dr. J.G. Maessen, Hoogleraar Cardiochirurgie, Universiteit Maastricht (voorzitter)

- Prof.dr. H. Crijns, Hoogleraar Cardiologie, Universiteit Maastricht

- Prof.dr. P.M.H.J. Roekaerts, Hoogleraar Intensive Care Geneeskunde, Universiteit Maastricht

- Prof.dr. V. Scharnhorst, Hoogleraar Klinische Chemie, Technische Universiteit Eindhoven

- Prof.dr. R.J. Stolker, Hoogleraar Anesthesiologie, Erasmus Universitair Medisch Centrum Rotterdam 
Aan mijn ouders

Voor Esther, Daniëlle, Rutger en Yvonne 



\section{PART 1 - RESOURCES}

CHAPTER 2 Fast-track practice in cardiac surgery: results and predictors of outcome Interactive Cardiovascular and Thoracic Surgery 2012;0:1-6

CHAPTER 3 Reducing the immediate availability of red blood cells in cardiac surgery, a single-centre experience Netherlands Heart Journal 2015;23:28-32

CHAPTER 4. Red blood transfusion in patients undergoing cardiac surgery; letter to the editor. Reply Netherlands Heart Journal 2015;23(6):346

PART 2 - IMPACT OF COMPLICATIONS

CHAPTER 5 The impact of postoperative renal replacement therapy on Long-term outcome after cardiac surgery increases with age Journal of cardiac surgery 2014;29:464-9

\section{PART 3 - SUPPORT IN OUTCOME PREDICTION}

CHAPTER 6 Use of Postoperative Peak Arterial Lactate Level to Predict Outcome after Cardiac Surgery Journal of cardiothoracic and Vascular Anesthesia accepted

CHAPTER 7 Total Cholesterol levels as a predictor of early outcome after cardiac surgery submitted 

Introduction and objectives

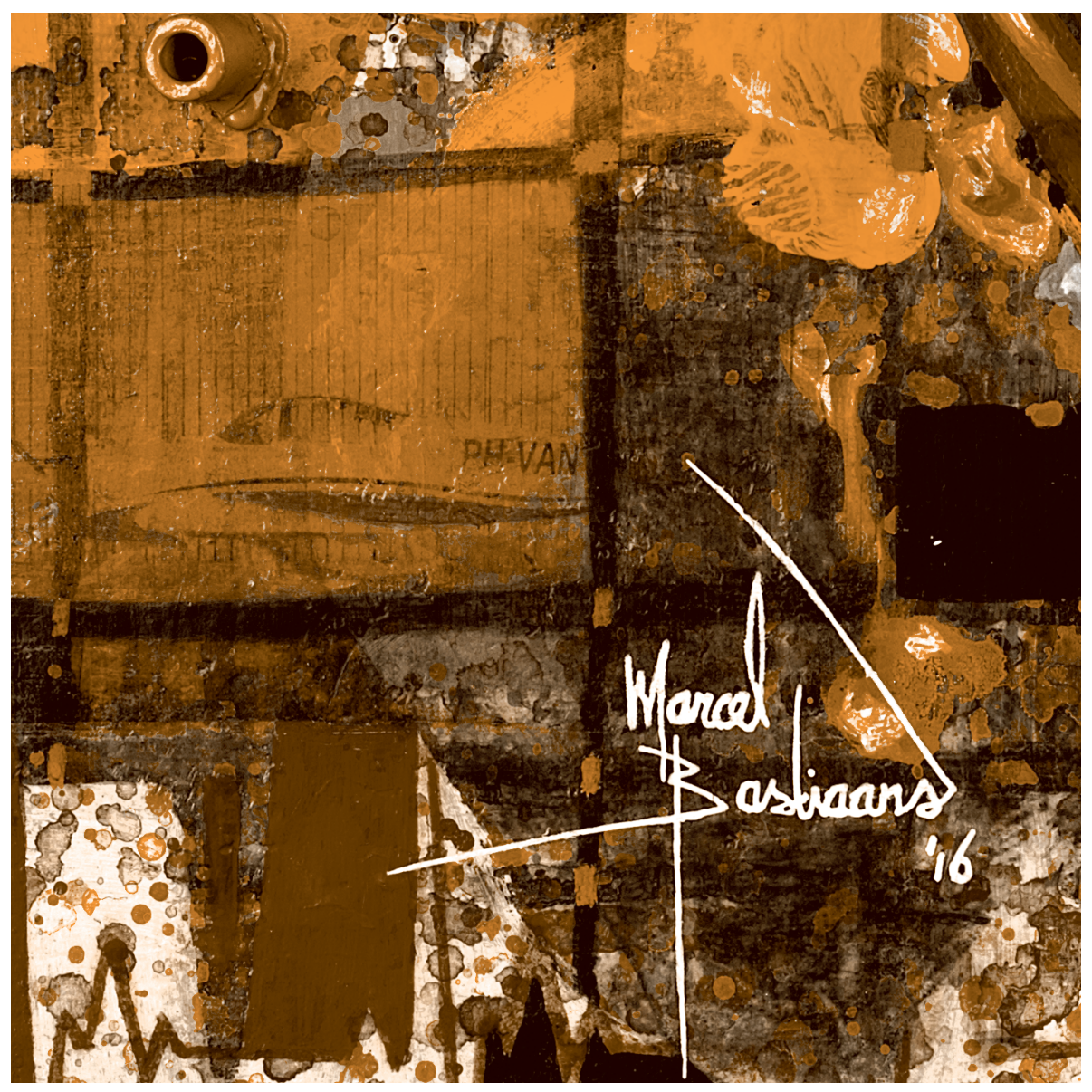





\section{Introduction}

Cardiovascular disease (CVD) is worldwide a leading cause of death $[1,2]$ and consequently poses a large burden on health care resources. Health care faces important future challenges as it is expected that the western population will suffer from increasing incidence of some form of cardiovascular disease.[2]

While technical developments rapidly expand the therapeutic arsenal for intervention, epidemiologic trends - such as aging, obesity and diabetes - will change the patient population presenting for cardiac surgery. ${ }^{[3,4]}$ As a consequence, more complex procedures will be performed in older and frail patients with more concomitant disease. These developments urge the need to optimize perioperative care and clinical decisionmaking to ensure optimal outcome.

A combination of population demographics, prevalence of comorbidity and improvement of medical care has changed the composition of elderly patients who are admitted to the intensive care unit (ICU) after cardiac surgery ${ }^{[5,6]}$ Moreover, $^{[7]}$ the percentage of ICU admissions following cardiac surgery is increasing, a trend, seen in The Netherlands and other European countries. This is mainly attributable to patients aged 80 years or older, who are presented for cardiac surgery. $[8,9]$

Specialized multidisciplinary care in combination with careful selection of patients are basic requirements for the better survival rates with acceptable quality of life. [10, 11] Trends toward off pump coronary artery surgery, hybrid revascularization, minimal invasive valve implantation and repair, ventricular assist devices, refined techniques for treatment of atrial fibrillation and resynchronization therapy have their contribution to outcome. ${ }^{[12,13]}$ Developments in modern anesthesiology practice include appropriate tailor made hemodynamic monitoring, ventilation techniques, fluid management, potent intravenous opioids and relaxants, blood management, invasive and noninvasive diagnostics and advanced cardiopulmonary bypass. ${ }^{[14,15]}$

The impact of clinical decision-making on the patients' outcome and the application of a safe and reliable policy in the management of high-risk cardiac surgery patients seems to be a great challenge. The investment of the anesthesiologist-intensivist in this issue is important and plays a substantial role in future investigation on this subject.[16] 


\section{VALUE OF FAST-TRACK CARDIAC SURGERY}

Fine tuning the balance between safe and effective practise and the available resources combined with increasing presentation of patients with more comorbidity for cardiac surgery asks for innovative solutions. ${ }^{[17,18,19,20]}$ Complications after cardiac surgery influence the length of stay in the intensive care units (ICU) and consequently increase hospital costs. ${ }^{[21]}$ Therefore, the introduction of fast-track protocols since 1990 has gained a growing interest and has become accepted as a safe practice in cardiac surgery. ${ }^{[22]}$ To advance recovery after cardiac surgery, the use of short acting anesthetic drugs, early extubation, sufficient pain control, strict infectious control measures and optimal normothermic policy has been integrated in clinical pathways. Introduction of guidelines, validation of risk indexes and execution of clinical pathways have led to early discharge. $\left.{ }^{17}, 18,19,21,22,23\right]$ By concentrating on the process of anesthesia care handover from operation room to post-anesthesia care units, the morbidity and mortality after cardiac surgery can be decreased. [24] Preoperative secure decisionmaking and patient selection determine the success of these protocols. [25, 26, 27, 28, 29] An evaluation of the results of our early experience with fast-track anesthesia policy in patients undergoing cardiac surgery is addressed in this thesis. The patient-related factors that predict the success of this policy are investigated. (Chapter 2)

\section{BLOOD RESOURCES IN CARDIAC SURGERY}

Perioperative transfusion of red blood cells (RBCs) is associated with increased mortality, morbidity and costs after cardiac surgery. [29] Policies to reduce blood transfusion have priority because excessive transfusions might cause postoperative complications and hospitalisation costs. [30] Intraoperative and postoperative bleeding and the need for blood transfusions in cardiac surgery varies substantially and it is known that $60 \%$ of patients receive allogenic blood products, accounting for $20 \%$ of annual transfusions in the United states. ${ }^{[31]}$ Survival is influenced, even if one or two units are administered and additive with each additional unit of red blood cells. ${ }^{[32]}$ A restrictive transfusion strategy not only decreases blood utilization but also decreases costs, resource use and complications. [33, 34]

The need for red blood cells in daily practise is not predictable. Therefore a logistical fine-tuned protocol for blood management focussed on restriction of blood resources on a routine basis during surgery and direct availability if needed, would be desired. In order to reduce blood use, we redefined our criteria for direct availability of red blood units during cardiac surgery. Introduction of a safe clinical protocol seems to be possible through focussing on preoperative restrictive factors and patient criteria. The importance of taking care of the quality of red blood cells and the advantage of this protocol for clinical practise is discussed. (Chapter 3 and 4 ) 


\section{RISK PREDICTION AND THE PERIOPERATIVE PROCESS}

Risk stratification models, such as EuroSCORE are frequently used to provide a guide for clinical decision-making in the preoperative period of cardiac surgery. However, the validation of such models to predict outcome for patients and their use in clinical practice have extensively been discussed.[35] To produce better clinical survival data, a diversity of both preoperative and postoperative measurements in daily practice are needed to meet all kinds of patient-related factors.[36] Older age, higher body mass index, concomitant diseases of neurological, renal, vascular and pulmonary origin are proved factors that determine risk for adverse outcome and are included in most risk prediction models. ${ }^{20}$, 36, 37, 38, 39, 40] The EuroSCORE was developed to predict surgical risk and helps guide preoperative patient selection in cardiac surgery. [35] The validity of the EuroSCORE is decreased in elderly patients; the predicted risks overestimate mortality and do not correlate with postoperative morbidity. [41] Frailty is a geriatric syndrome of loss of physical and cognitive reserve. $[41,42,43]$ This results in an increased vulnerability to adverse events such as cardiac surgery. [44, 45] Disability is defined as an impaired ability to carry out functional tasks. Various scales exist to measure frailty and disability. While there is significant overlap between frailty, disability and co-morbidity, it is found that frailty and disability are complementary to the existing risk scores for predicting mortality and morbidity in elderly patients undergoing cardiac surgery. ${ }^{[42,43]}$ In our hospital, a multidisciplinary team consisting of a cardiac surgeon, a cardiologist, an anesthesiologist and an intensivist evaluates and decides about the acceptance of a high-risk surgical procedure. Decisions of such multidisciplinary teams should carefully weigh all risk factors, which should in our opinion also include frailty and disability in addition to other more traditional risk factors. Multiple factors in the total perioperative conversion of the patients' physical and cognitive function will determine outcome. However while preoperative risk assessment is important, outcome depends on the result of both the surgical procedure and the postoperative process respectively.

\section{POSTOPERATIVE CRITICAL CARE AND QUALITY IMPROVEMENT}

Long intensive care unit stay after cardiac surgery is mostly due to the occurrence of complications such as renal failure. ${ }^{[46]}$ The prognosis of these patients can be impaired if associated with other comorbidities like old age. Once complications occur, sometimes unpredicted, it is important to guide patient management with adequate care and constant self-examination of the medical staff.[44, 45, 47,48] One of the known and frequent complications is the need for renal replacement therapy because of kidney failure, which has substantial impact on outcome. ${ }^{[46]}$ We investigated the incidence of renal replacement therapy with the aim to identify patient factors with influence on early and late mortality. (Chapter 5) 
An ongoing quality improvement process on the intensive care with focus on enhancing prognosis is shown to be possible through paying attention to all facets of care.[48] In this context, the presence of easy and accessible biomarkers are welcome. Monitoring patient's performance and rapid identification of trends by the use of exact determining parameters can lead to improvement of care. [48] In this thesis, the value and the distinctive quality for prediction of outcome of some biomarkers is evaluated. Lactate is of clinical importance for prediction of early and late mortality after cardiac surgery. Furthermore, the contribution of cholesterol, as another biomarker, is discussed in relation to the operative insult on the patient, resulting in an estimation of early mortality after cardiac surgery. (Chapter 6 and 7 )

\section{OBJECTIVES IN THIS THESIS}

The aim of this thesis is to evaluate the impact of specific perioperative measures on morbidity and mortality and the influence of optimal balanced care on outcome in the patient undergoing cardiac surgery.

Improvement of health care, focusing on cardiac surgery can be achieved through a multidisciplinary balanced navigation of the patient through the cardiac surgery pathway. A preoperative, perioperative and postoperative careful decision-making process, based on clear markers and proven safe protocols are needed to obtain a successful cardiac surgery program in an ageing and sicker population.

The following issues are discussed:

\section{Risk prediction:}

1. What is the impact of renal failure on outcome and postoperative renal replacement therapy on cardiac surgery?

2. Is age a limiting factor for survival in case of postoperative kidney injury in cardiac surgery patients?

3. What are the outcome predictors that are useful and easy to monitor in daily practice in the intensive care after cardiac surgery? Can these parameters be used to predict long-term mortality?

\section{Care and Resources:}

4. Is fast-track cardiac surgery safe? And which patient-related factors are important for the success rate?

5. Should age influence perioperative decision-making for the type of postoperative care? 
6. Is it safe to apply a restrictive logistical policy for blood transfusion after cardiac surgery?

7. Which cardiac procedures are suitable to imply a restrictive blood transfusion policy?

8. Which patient-related factors have significant counteracting influence on this suggested policy? 


\section{REFERENCES}

1. Townsend N, Nichols M, Scarborough P, Rayner M. Cardiovascular disease in Europeepidemiological update 2015. Eur Heart J 2015;36:2696-705

2. Lloyd-Jones D, Adams RJ, Brown TM et al. Heart disease and stroke statistics--2010 update: a report from the American Heart Association. Circulation 2010;121:e46-e215

3. Kones R. Primary prevention of coronary heart disease: integration of new data, evolving views, revised goals, and role of rosuvastatine in management. A comprehensive survey. Drug Des Devel Ther 2011;5:325-80

4. Heidenreich PA Forecasting the future of cardiovascular disease in the United States: a policy statement from the American Heart Association. Circulation 2011;123:933-44

5. Sjoding MW, Prescott HC, Wunsch H, Iwashyna TJ, Cooke CR. Longitudinal changes in ICU admissions among elderly patients in the United States. Crit Care Med 2016;44:1353-60

6. Cleveland JC Jr. Frailty, aging, and cardiac surgery outcomes: the stopwatch tells the story. J Am Coll Cardiol 2010;56:1677-8

7. Schmidt M, Ulrichsen SP, Pedersen L, Bøtker HE, Sørensen HT. Thirty-year trends in heart failure hospitalization and mortality rates and the prognostic impact of co-morbidity: a Danish nationwide cohort study. Eur J Heart Fail 2016;18:490-9

8. Haas LE, Karakus A, Holman R et al. Trends in hospital and intensive care admissions in the Netherlands attributable to the very elderly in an ageing population. Crit Care 2015;19:353

9. Kozian A, Kretzschmar MA, Schilling T. Thoracic anesthesia in the elderly. Curr Opin Anaesthesiol 2015;28:2-9

10. Nicolini F, Agostinelli A, Vezzani A et al. The evolution of cardiovascular surgery in elderly patients: a review of current options and outcomes. Biomed Res Int 2014;ID:736298

11. Jaklitsch M, Billmeier S. Preoperative evaluation and risk assessment for elderly thoracic surgery patients. Thor Surg Clin 2009;19:301-12

12. Drury NE, Nashef SA. Outcomes of cardiac surgery in the elderly. Expert Rev Cardiovasc Ther 2006;4:535-42

13. Sridhar AR, Yarlagadda V, Parasa S et al. Cardiac Resynchronization Therapy: US Trends and disparities in utilization and outcome. Circ Arrhythm Electrophysiol 2016;9:e003108

14. Barry AE, Chaney MA, London MJ. Anesthetic management during cardiopulmonary bypass: a systematic review. Anesth Analg 2015;120:749-69

15. Guarracino F, Baldassarri R. Transesophageal echocardiography in the OR and ICU. Minerva Anesthesiol 2009;75:518-29

16. Glance LG, Kellermann AL, Hannan EL et al. The impact of anesthesiologists on coronary artery bypass graft surgery outcomes. Anesth Analg 2015;120:526-33 
17. Cheng DC, Karski J, Peniston $C$ et al. Early tracheal extubation after coronary artery bypass graft surgery reduces costs and improves resource use: A prospective, randomized, controlled trial. Anesthesiology 1996;85:1300-10

18. Svircevic V, Nierich AP, Moons KG, Brandon Bravo Bruinsma GJ, Kalkman CJ, van Dijk D. Fast-track anesthesia and cardiac surgery: a retrospective cohort study of 7989 patients. Anesth Analg 2009;108:727-33

19. Cheng DCH. Fast-Track Cardiac Surgery: Economic implications in postoperative care. Journal of Cardiothoracic and Vascular Anesthesia 1998;12:72-9

20. Engelman DT, Adams DH, Byrne JG et al. Impact of body mass index and albumin on morbidity and mortality after cardiac surgery. J Thorac Cardiovasc Surg 1999;118:866-73

21. Royston D. Patient selection and anesthetic management for early extubation and hospital discharge: CABG. J Cardiothorac Vasc Anesth 1998;12:11-9

22. Carl M, Alms A, Braun J et al. Guidelines for intensive care in cardiac surgery patients: haemodynamic monitoring and cardio-circulatory treatment guidelines of the German Society for Thoracic and Cardiovascular Surgery and the German Society of Anaesthesiology and Intensive Care Medicine. J Thorac Cardiovasc Surg 2007;55:130-48

23. Tu JV, Jaglal SB, Naylor CD. Multicenter validation of a risk index for mortality, intensive care unit stay, and overall hospital length of stay after cardiac surgery Circulation 1995;91:677-84

24. Hudson CC, McDonald B, Hudson JK, Tran D, Boodhwani M. Impact of anesthetic handover on mortality and morbidity in cardiac surgery: a cohort study. J Cardiothorac Vasc Anesth 2015;29:11-6

25. Geissler HJ, Hölzl P, Marohl S et al. Risk stratification in heart surgery: comparison of six score systems. Eur J Cardiothorac Surg 2000;17:400-6

26. Millar K, Asbury AJ, Murray GD. Pre-existing cognitive impairment as a factor influencing outcome after cardiac surgery. Br J Anaesth 2001;86:63-7

27. Nussmeier NA. A review of risk factors for adverse neurologic outcome after cardiac surgery. The Journal of Extra-corporeal Technology 2002;34:4-10

28. Tuman KJ, McCarthy RJ, March RJ, Najafi H, Ivankovich AD. Morbidity and duration of ICU stay after cardiac surgery. A model for preoperative risk assessment. Chest 1992;102:36-44

29. Murphy GJ, Reeves BC, Rogers CA, Rizvi SI, Culliford L, Angelini GD. Increased mortality, postoperative morbidity, and cost after red blood cell transfusion in patients having cardiac surgery. Circulation 2007;116:2544-52

30. Kilic A, Whitman GJ. Blood transfusions in cardiac surgery: Indications, risks, and conservation strategies. Ann Thorac Surg 2014;97:726-34

31. Van Straten AH, Bekker MW, Soliman Hamad MA et al. Transfusion of red blood cells: The impact on short-term and long-term survival after coronary artery bypass grafting, a ten-year follow-up. Interact Cardiovasc Thorac Surg 2010;10:37-42 
32. Paone G, Likosky DS, Brewer R et al. Membership of the Michigan Society of Thoracic and Cardiovascular Surgeons: Transfusion of 1 and 2 units of red blood cells is associated with increased morbidity and mortality. Ann Thorac Surg 2014;97:87-93

33. Murphy GJ, Pike K, Rogers CA et al. Liberal or restrictive transfusion after cardiac surgery. N Engl J Med 2015;372:997-1008

34. Yaffee DW, Smith DE 3rd, Ursomanno PA et al. Management of blood transfusion in aortic valve surgery: Impact of a blood conservation strategy. Ann Thorac Surg 2014;97:95-101

35. Roques F, Nashef SA, Michel P et al. Risk factors and outcome in European cardiac surgery: analysis of the EuroSCORE multinational database of 19030 patients. Eur J Cardiothorac Surg 1999;15:816-22

36. Karkouti K, Wijeysundera DN, Yau TM et al. Acute kidney injury after cardiac surgery: focus on modifiable risk factors. Circulation 2009;119:495-502

37. Schneider EL, Guralnik JM. The aging of America Impact on health care costs. JAMA 1990;263:2335-40

38. Stewart S, Maclntyre K, Capewell S, McMurray JJ. Heart failure and the aging population: an increasing burden in the 21st century? Heart 2003;89:49-53

39. Leontyev S, Walther T, Borger MA et al. Aortic valve replacement in octogenarians: utility of risk stratification with EuroSCORE. Ann Thorac Surg 2009;87:1440-5

40. Speziale G, Nasso G, Barattoni MC et al. Operative and middle-term results of cardiac surgery in nonagenarians: a bridge toward routine practice. Circulation 2010;121:208-13

41. Afilalo J, Mottillo S, Eisenberg MJ et al. Addition of frailty and disability to cardiac surgery risk scores identifies elderly patients at high risk of mortality or major morbidity. Circ Cardiovasc Qual Outcomes 2012;5:222-8

42. Bergman H, Ferrucci L, Guralnik J et al. Frailty: an emerging research and clinical paradigm issues and controversies. J Gerontol A Biol Sci Med Sci 2007;62:731-7

43. Afilalo J, Karunananthan S, Eisenberg MJ, Alexander KP, Bergman H. Role of frailty in patients with cardiovascular disease. Am J Cardiol 2009;103:1616-21

44. Stephens RS, Whitman GJ. Postoperative critical care of the adult cardiac surgical patient. Part I: Routine postoperative care. Crit Care Med 2015;43:1477-97

45. Stephens RS, Whitman GJ. Postoperative critical care of the adult cardiac surgical patient. Part II: Procedure-specific considerations, management of complications and quality improvement. Crit Care Med 2015;43:1995-2014

46. Chertow GM, Levy EM, Hammermeister KE, Grover F, Daley J. Independent association between acute renal failure and mortality following cardiac surgery. Am J Med 1998;104:343-8

47. Shake JG, Pronovost PJ, Whitman GJ. Cardiac surgical ICU care: Eliminating "preventable" complications. J Card Surg 2013;28:406-13

48. Stamou SC, Camp SL, Stiegel RM et al: Quality improvement program decreases mortality after cardiac surgery. J Thorac Cardiovasc Surg 2008;136:494-9 



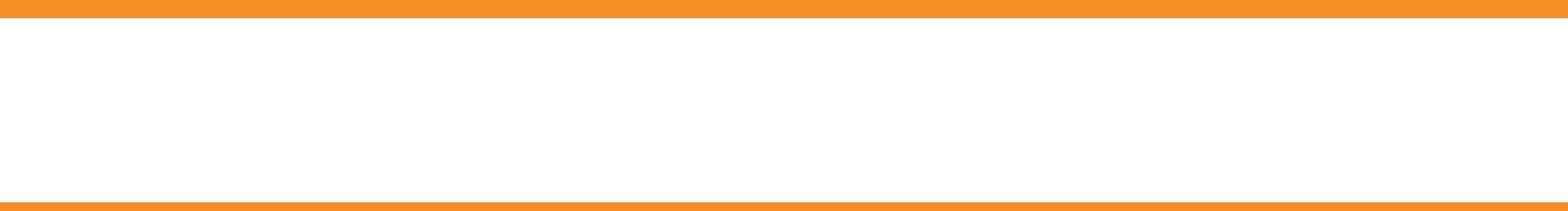


Part 1 - RESOURCES 

Fast-track practice in cardiac surgery:

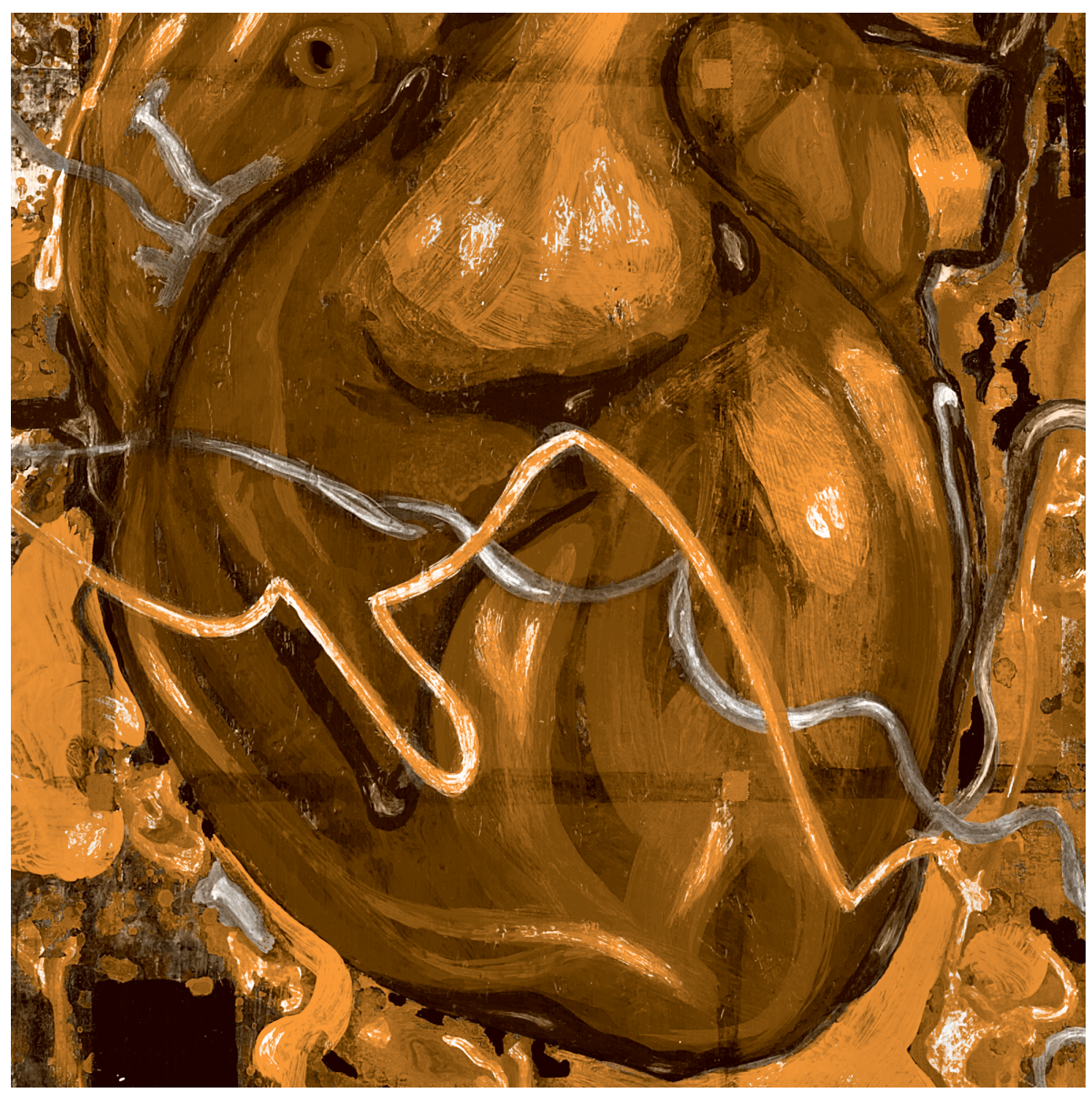





\section{FAST-TRACK PRACTICE IN \\ CARDIAC SURGERY, RESULTS AND PREDICTORS OF OUTCOME}

Marco C. Haanschoten [1, 2], Albert H.M. van Straten[3], Joost F. ter Woorst ${ }^{[3]}$, Pieter S. Stepaniak[4], Auke-Dick van der Meer ${ }^{[1]}$, André A.J. van Zundert ${ }^{[1,5]}$ and Mohamed A. Soliman Hamad[3]

1. Department of Anesthesiology and

2. Intensive care unit, Catharina Hospital, Eindhoven, The Netherlands.

3. Department of Cardio-Thoracic Surgery, Catharina Hospital, Eindhoven, The Netherlands

4. Econometric Institute, University of Rotterdam, Rotterdam, The Netherlands

5. Department of Anesthesiology, University Hospital Ghent, Ghent, Belgium 


\section{ABSTRACT}

Objectives: Various studies showed different parameters as independent risk factors in predicting success of fast-track postoperative management in cardiac surgery. In the present study, we evaluated our seven-year experience with the fast-track protocol and investigated the preoperative predictors of successful outcome.

Methods: Between 2004 and 2010, 5367 consecutive patients undergoing cardiac surgery were preoperatively selected for postoperative admission in the postanesthesia care unit (PACU) and were included in this study. These patients were then transferred to the ordinary ward on the same day of the operation. The primary end-point of the study was success of the PACU protocol, defined as discharge to the ward on the same day, no further admission to the ICU and no operative mortality. Logistic regression analysis was performed to detect the independent risk factors for failure of the PACU pathway.

Results: Out of 11895 patients undergoing cardiac surgery, 5367 patients (45.2\%) were postoperatively admitted to the PACU. The protocol was successful in 4510 patients (84.0\%). Using the multivariate logistic regression analysis, older age and left ventricular dysfunction were found as independent risk factors for failure of the PACU protocol [Odds ratio of 0.98 /year (0.97-0.98) and 0.31 (0.14-0.70) respectively]. Conclusions: Our fast-track management, called the PACU protocol, is efficient and safe for the postoperative management of selected patients undergoing cardiac surgery. Age and left ventricular dysfunction are significant preoperative predictors of failure of this protocol.

Key words: Anesthesia, fast-track; Cardiac Surgery; Outcome 


\section{Introduction}

The advantages of early extubation after cardiac surgery have been well-established[1]. Many investigators ${ }^{[2-5]}$ tried to find a clinical fast-track pathway for an efficient and safe approach to the postoperative management of cardiac surgery patient. The main aim of most studies was to achieve a rapid uncomplicated recovery with minimal load on the intensive care unit (ICU).[3] Different end-points have been used to define the success of these different pathways. Most investigators focused on ventilation time, length of ICU and hospital stay, and post- operative complications as the main end points to evaluate the outcome of fast-track management. $[6,7]$

In 2001, we started the fast-track protocol in our institution for selected patients undergoing cardiac surgery. These patients were managed postoperatively in a PostAnesthesia Care Unit (PACU). The aim of this protocol was to transfer the patients postoperatively to the ordinary ward on the same day of the operation. Since 2004, we have prospectively collected the data of these patients in our computerized database. In this study, these data were analyzed to evaluate the outcome of these patients and determine the efficacy of the PACU protocol.

\section{MATERIALS AND METHODS}

This study was performed in a single center (Catharina Hospital, Eindhoven, and the Netherlands) from January 2004 till December 2010. The local medical ethics committee approved the study and waived the need for an informed consent. All consecutive patients who met the inclusion criteria and entered the PACU protocol were included in this study. Clinical data, including demographics, risk factors, and complications, were prospectively collected in our computerized database.

\section{Inclusion criteria for the PACU protocol:}

1. Patients scheduled for isolated coronary artery bypass grafting (CABG), Off-pump coronary artery bypass (OPCAB), isolated aortic valve replacement (AVR) or combined AVR with one coronary bypass graft.

2. Non-complex isolated cardiac surgical procedures (closure of ASD or removal of an atrial myxoma) 


\section{Exclusion criteria for the PACU protocol:}

1. Physical status Class of $>3$ [according to the American Society of Anesthesiologists (ASA) classification]

2. Patients undergoing re-operation.

3. Chronic obstructive pulmonary disease (COPD) Gold CLASS $\geq 2$.

4. Left ventricular dysfunction.

5. Serum Creatinine of $\geq 150 \mu \mathrm{mol} / \mathrm{L}$.

6. Body mass index of $\geq 35 \mathrm{Kg} / \mathrm{m}^{2}$.

7. Emergency operations.

8. Surgical complications necessitating prolonged cardiopulmonary bypass time (CPB) (>150 minutes).

\section{Anesthetic technique}

All preoperative medications were continued until the morning of operation. Premedication consisted of oral temazepam $20 \mathrm{mg} /$ lorazepam $2 \mathrm{mg}$ (1 mg for patients $>70$ years old) before the night and lorazepam $2 \mathrm{mg}$ ( $1 \mathrm{mg}$ for patients >70 years old) and paracetamol $1000 \mathrm{mg}$ in the morning 1 hour before surgery.

Anesthesia was induced with fentanyl $6 \mu \mathrm{g} . \mathrm{kg}^{-1}$ etomidate $0.3 \mathrm{mg} \cdot \mathrm{kg}^{-1}$ and midazolam $5 \mathrm{mg}$. Before intubation, rocuronium $0.4 \mathrm{mg} \cdot \mathrm{kg}^{-1}$ was administered. Ventilation was started and sevoflurane was often added after intubation until continuous intravenous medications were administered via the central venous catheter. Maintained anesthesia was achieved using propofol $0.06 \mathrm{mg} \cdot \mathrm{kg}^{-1} \cdot \mathrm{min}^{-1}$ and alfentanil $1 \mu \mathrm{\mu g} \cdot \mathrm{kg}^{-1}$. min. A Bispectral index monitor ${ }^{\circledR}$ (Philips Medical System, Best, The Netherlands) was used to guard the depth of anesthesia.

Postoperatively, alfentanil was stopped 15 minutes after arrival on the PACU. In addition, we gave $1 \mathrm{~g}$ Tranexamic acid and $2 \mathrm{~g}$ cefotaxim (IV) which was continued for 24 hours postoperatively. The postoperative pain management plan consisted of paracetamol and non-steroidal anti-inflammatory drugs, such as diclofenac, intravenously. No morphinomimetics were administrated in the postoperative period.

\section{Operative techniques}

Normothermic nonpulsatile flow was used during cardiopulmonary bypass (CPB). According to the surgeon's preference, cold antegrade crystalloid cardioplegia (St Thomas solution) or warm intermittent antegrade blood cardioplegia was used to induce and maintain cardioplegic arrest. All patients undergoing CABG with use of cardiopulmonary bypass (CPB) received a low dose of aprotinin (2 million kallikreininactivating units, or KIU) administered in the priming solution for CPB. Since November 2007, aprotinin was no more administered perioperatively. Patients undergoing off-pump surgery did not receive aprotinin. The patient was weaned from the CPB only when the nasal temperature was $\geq 37.0^{\circ} \mathrm{C}$ and the rectal temperature was $\geq 35.0^{\circ} \mathrm{C}$. 
In order to reach these levels of temperature, the patient was actively warmed using the CPB or with a bear hugger (active external warming) in case of OPCAB.

\section{The PACU protocol}

The aim of the PACU protocol was to transfer the patient postoperatively to the ward on the same day of the operation. The first scheduled patients of the day were admitted to the PACU directly after the operation. Patients were extubated on the PACU after normalization of the body temperature (rectal temperature $>36.5^{\circ} \mathrm{C}$ ), and adequate stabilization of their hemodynamic and respiratory conditions. Strictly, measurement of the hemodynamic parameters as blood pressure, heart rate, diuresis and peripheral temperature was performed during the whole postoperative day. If any of these parameters did not meet the determined 'protocol values' for diuresis, hemodynamics, respiratory condition and blood loss, the patient was transferred to the ICU. If these conditions remained stable, the patients were transferred to the ordinary ward. The dedicated PACU beds were closed at the end of the day at 20.00 hrs. On the ward, patients received telemetric surveillance of heart rhythm, blood pressure and saturation until the following day. Blood loss via the chest tubes was carefully checked during the first 24 hours. If any disturbance of a physiological parameter was recorded on the ward, an ICU physician reevaluated the patient and, if necessary, the patient was transferred to the ICU.

\section{Transfer to the ward}

Patients were transferred to the ordinary ward on the same day of the operation when they fulfill the following conditions:

1. Stable hemodynamic parameters without pharmacological or mechanical cardiac supports. Systolic blood pressure of $>100 \mathrm{mmHg}$, dialstolic blood pressure lower than $90 \mathrm{mmHg}$.

2. Awake and alert patients. Patients do answer questions and follow orders.

3. A stable sinus rhythm on the electrocardiogram (ECG) without signs of ischemia. Heart rate of $<100 /$ minute. No atrial fibrillation.

4. Normal respiratory function with $\mathrm{O}_{2}$ saturation of $>90 \%$ with maximum $5 \mathrm{~L}$ supplementary oxygen through a nasal catheter, and arterial $\mathrm{pCO}_{2}$ level of $<50 \mathrm{mmHg}$ on arterial blood gas analysis.

5. Blood loss of $<50 \mathrm{ml} / \mathrm{h}$ via the chest tubes.

6. Urine output of $>0.5 \mathrm{ml} . \mathrm{kg}^{-1} / \mathrm{h}^{-1}$.

7. Temperature difference between rectal and peripheral temperatures (delta $\mathrm{T}$ ) of $<5{ }^{\circ} \mathrm{C}$. (unless the $\mathrm{O}_{2}$ saturation of the venous blood sample is $>70 \%$ ). 


\section{Study endpoints}

The PACU short track pathway was considered successful when the patient was transferred to the ward the same day of the operation, no admission to the ICU, no take-back to the operation room for exploration and no operative mortality or morbidity.

\section{Statistical analyses}

Univariate logistic regression analyses were performed to investigate the impact of biomedical variables on fulfilling the PACU protocol. If significant at $p<0.05$, the variables were included into the multivariable logistic regression analyses. A p-value $<0.05$ was used for all tests to indicate statistical significance. Odds ratios (OR) with a confidence interval $(\mathrm{Cl})$ of $95 \%$ with p-values are reported. All statistical analyses were performed using SPSS version 15.0 (SPSS Inc, Chicago, IL).

\section{RESULTS}

During the study period (January 2004-December 2010), 11895 patients underwent cardiac surgical procedures in our institution. Out of this number, 5367 patients (45.2\%) fulfilled the criteria of the PACU protocol and were included in this study. Demographic data are shown in table 1.

TABLE 1. DEMOgRAPHIC DATA AND CO-MORBIDITIES

\begin{tabular}{|l|c|}
\hline Variable & Incidence \\
\hline Male gender & $4151 \quad(77.3 \%)$ \\
Age, $y$, mean (range) & $64.6 \pm 9.6(19-87)$ \\
Diabetes, $n$ & $1059 \quad(19.7 \%)$ \\
COPD, $n$ & $482 \quad(9 \%)$ \\
CVA, $n$ & $191 \quad(3.6 \%)$ \\
Peripheral vascular disease, $n$ & $653(12.1 \%)$ \\
Hypertension, $n$ & $2741 \quad(51.1 \%)$ \\
Renal dysfunction, $n$ & $110 \quad(2 \%)$ \\
BMl>35 kg.m-2 & $171 \quad(3.2 \%)$ \\
EF<35\%, $n$ & $27 \quad(0.5 \%)$ \\
Previous myocardial infarction, $n$ & $1869 \quad(34.8 \%)$ \\
Previous PCl, $n$ & $1036(19.3 \%)$ \\
Logistic EuroSCORE, mean & $2.9 \pm 3.0$ \\
Additive EurosCORE, mean & $3.0 \pm 2.2$ \\
\hline
\end{tabular}

Data are given as a mean \pm SD or as numbers (\%).

$\mathrm{BMI}=$ body mass index; $\mathrm{COPD}=$ chronic obstructive pulmonary disease;

$\mathrm{CVA}=$ previous cerebro-vascular accident; $\mathrm{EF}=$ left ventricular ejection fraction;

$\mathrm{PCl}=$ percutanous coronary intervention 
The majority of the patients were males (77.3\%). The most important co-morbidities were: diabetes (19.7\%), chronic obstructive pulmonary disease (COPD) (9\%), previous cerebro-vascular accident (CVA) (3.6\%), peripheral vascular disease (PVD) (12.2\%), hypertension (51.1\%), renal dysfunction (2\%), and body mass index (BMI) $>35 \mathrm{~kg} \cdot \mathrm{m}^{-2}$ (3.2\%). Previous myocardial infarction was present in 34.8\% of the patients and $19.3 \%$ of the patients had previous percutaneous coronary intervention $(\mathrm{PCI})$.

Operative data are shown in table 2. Of the CABG patients, 713 (13.3\%) were operated with the off-pump technique (OPCAB). The mean number of distal anastomoses was $3.5 \pm 1$. None of the PACU patients has got bilateral internal thoracic artery revascularization. Our strategy is to use the radial artery in case of complete arterial revascularization.

TABLE 2. OpERATIVE DATA

\begin{tabular}{|l|r|}
\hline CABG, $n$ & $3990(74.3 \%)$ \\
OPCAB, $n$ & $713(13.3 \%)$ \\
AVR, $n$ & $573(10.7 \%)$ \\
AVR+CABG, $n$ & $47(0.9 \%)$ \\
Use of LITA & $3937(83.7 \%)$ \\
Number of distal anastomoses & $3.5 \pm 1$ \\
Left ventriclular aneurysmectomy, $n$ & 4 \\
Concomittant PVISO & $61 \quad(1.1 \%)$ \\
AVR + MORROW procedure, $n$ & 2 \\
Pericadial resection, $n$ & 1 \\
Resection of myxoma, $n$ & $11(0.2 \%)$ \\
Closure of ASD & $28 \quad(0.5 \%)$ \\
CPB time, min & $60.2 \pm 39.0$ \\
\hline
\end{tabular}

Data are number (\%) or mean \pm SD

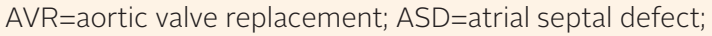

$\mathrm{CABG}=$ coronary artery bypass grafting; $\mathrm{CPB}=$ cardiopulmonary bypass;

LITA=left internal thoracic artery; OPCAB= off-pump coronary artery bypass;

$\mathrm{PVISO}=$ pulmonary vein isolation 
Operative mortality included 24 patients (0.4\%) (Table 3). The mean duration of stay in the PACU was $6.8 \pm 1.7$ hours. The number of patients who were transferred to the ward on the same day of the operation was 4569 patients (85.1\%). Twenty-nine patients (0.5\%) were admitted to the ICU within 12 hours, 3 patients (0.1\%) within one day, 26 patients (0.5\%) within one week, and five patients (0.1\%) after the first postoperative week. The number of patients who were transferred from the PACU to the ICU was 785 patients (14.6\%). Table 4 shows the different causes of transferring the patient to the ICU. The PACU pathway was successful in 4510 patients (84.0\%).

TABle 3. Postoperative data

\begin{tabular}{|l|c|}
\hline Variable & Incidence \\
\hline Transfer to the ward on the same day, $\mathrm{n}$ & $4569(85.1 \%)$ \\
Re-exploration, $\mathrm{n}$ & $199(3.7 \%)$ \\
Perioperative myocardial infarction, $\mathrm{n}$ & $100(1.9 \%)$ \\
Postoperative new-onset AF & $1093(20.4 \%)$ \\
Operative mortality, $\mathrm{n}$ & $24 \quad(0.4 \%)$ \\
Mean stay in PACU, hr & $6.8 \pm 1.7$ \\
Admission to ICU, $\mathrm{n}$ & \\
within 12 hours postoperatively & $29(0.5 \%)$ \\
within the first postoperatively day & $3(0.1 \%)$ \\
within on week postoperatively & $26(0.5 \%)$ \\
after the first postoperatively week & $5(0.1 \%)$ \\
Success of the PACU protocol, $\mathrm{n}$ & $4510 \quad(84.0 \%)$ \\
\hline
\end{tabular}

Data are numbers (\%) or mean \pm SD (range).

$\mathrm{AF}=$ atrial fibrillation; $\mathrm{PACU}=$ post-anesthesia care unit; $\mathrm{ICU}=$ intensive care unit 
TABLE 4. CAUSES For TRANSFER FROM PACU to ICU ( $N=785)$

\begin{tabular}{l|rl} 
Cause & \multicolumn{3}{|c}{ Number (\%) } \\
\hline Blood loss >50ml/hr, n & 219 & $(4.1 \%)$ \\
Myocardial Ischemia, $n$ & 184 & $(3.4 \%)$ \\
Resperiatory insufficiency, $n$ & 67 & $(1.2 \%)$ \\
Air leakage of the chest tune & 6 & $(0.1 \%)$ \\
Hemodynamically unstable, $n$ & 76 & $(1.4 \%)$ \\
Not awake enough, $n$ & 119 & $(2.2 \%)$ \\
Postoperative CVA, n & 4 & $(0.1 \%)$ \\
Other operation than planned, $n$ & 4 & $(0.1 \%)$ \\
Dysrhythmia, n & 19 & $(0.4 \%)$ \\
No available bed on the ward, $n$ & 6 & $(0.1 \%)$ \\
Other/unknown, $n$ & 81 & $(1.5 \%)$
\end{tabular}

Data are presented as numbers (\%)

$\mathrm{CVA}=$ cerebrovascular accident; $\mathrm{EF}=$ left ventricular ejection fraction

The mean value of length of postoperative hospital stay was $6.7 \pm 5.5$ days. Many patients were discharged to their own hospital on the $3 r d$. postoperative day for further postoperative recovery. Information is lacking about the length of stay of those patients in their hospitals.

The most important causes of hospital mortality $(n=24)$ were: low cardiac output $(n=10)$, surgical bleeding $(n=1)$ sepsis $(n=4)$, multi-organ failure $(n=1)$, neurological disorders ( $n=3)$ and respiratory insufficiency $(n=1)$. Four patients died after discharge from the Hospital. The cause of death was not retrieved in these four patients.

Table 5 shows the results of the logistic regression analysis for the prediction of failure of the PACU protocol. Univariate logistic regression analysis revealed older age (OR=0.97 / year), hypertension ( $\mathrm{OR}=0.83)$, renal dysfunction $(\mathrm{OR}=0.6)$ and left ventricular ejection fraction (EF) lower than $35 \%(\mathrm{OR}=0.32)$ as predictors of failure of the fast-track pathway after cardiac surgery. Both the logistic and the additive EuroSCORE are also univariate predictors of the success of the PACU protocol. 
TABLE 5. RESULTS OF LOGISTIC REGRESSION ANALYSES FOR OUTCOME OF THE PACU PROTOCOL

\begin{tabular}{|c|c|c|c|c|}
\hline \multirow{2}{*}{ Variable } & OR $(95 \% \mathrm{Cl})$ & $p$-value & OR $(95 \% \mathrm{Cl})$ & $p$-value \\
\hline & \multicolumn{2}{|c|}{ Univariate analysis } & \multicolumn{2}{|c|}{ Multivariate analysis } \\
\hline Male & $1.18(0.99-1.40)$ & .052 & & \\
\hline Age $^{*}$ & $0.97(0.97-0.98) \dagger$ & $\dagger<.0001$ & $0.98(0.97-0.98)$ & $\dagger<.0001$ \\
\hline Diabetes & $0.93(0.77-1.11)$ & .460 & & \\
\hline COPD & $0.86(0.67-1.10)$ & .239 & & \\
\hline Peripheral vascular disease & $0.91(0.73-1.14)$ & .443 & & \\
\hline Hypertention & $0.83(0.72-0.96)$ & .016 & & \\
\hline Renal dysfunction & $0.60(0.38-0.94)$ & .028 & $0.86(0.74-1.00)$ & .058 \\
\hline $\mathrm{BMI}>35 \mathrm{Kg} / \mathrm{m}^{2}$ & $0.89(0.59-1.32)$ & .568 & $0.69(0.44-1.08)$ & .111 \\
\hline$E F<35 \%$ & $0.32(0.14-0.70)$ & .004 & & \\
\hline AVR & $1.08(0.84-1.37)$ & .532 & $0.31(0.14-0.70)$ & .005 \\
\hline$A V R+C A B G^{* *}$ & $0.30(0.16-0.54)$ & $<.0001$ & & \\
\hline Other procedures & $0.73(0.35-1.52)$ & .470 & & \\
\hline Logistic EuroSCORE* & $0.94(0.92-0.97)$ & $<.0001$ & & \\
\hline Additive EuroSCORE* & $0.89(0.86-0.92)$ & $<.0001$ & & \\
\hline
\end{tabular}

* entered as a continuous variable

${ }^{* *}$ Compared to CABG

t $\mathrm{OR}$ is per year.

$A V R=$ aortic valve replacement; $\mathrm{BMI}=$ body mass index;

$\mathrm{CABG}=$ coronary artery bypass grafting; $\mathrm{COPD}=$ chronic obstructive pulmonary disease;

$\mathrm{EF}=$ ejection fraction; $\mathrm{PACU}=$ post anesthesia care unit;

$\mathrm{PCl}=$ percutaneous coronary intervention

Multivariate logistic regression analysis revealed only older age (as a continuous variable) $(\mathrm{OR}=0.98)$ and left ventricular ejection fraction $(E F)$ lower than $35 \%$ $(\mathrm{OR}=0.31)$ as independent predictors of failure of the PACU protocol. 
Figure 1. PREDicted PROBABILITY OF THE SUCCESS OF THE PACU PROTOCOL DEPENDING ON AGE

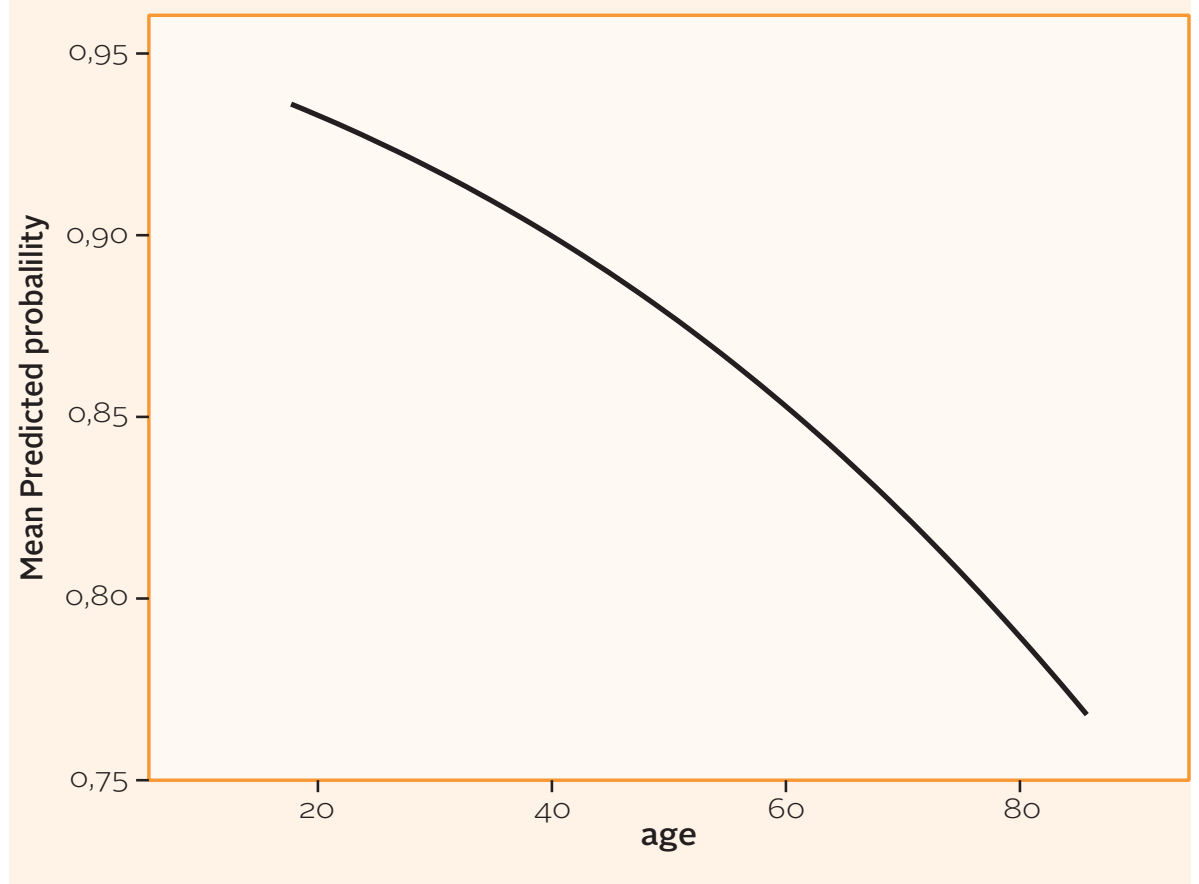

Fig. 1 shows the predicted probability of the outcome of the PACU pathway according to age as a continuous variable... Older age is correlated with the higher chance of failure of the PACU pathway.

\section{DISCUSSION}

In this study, we confirmed the safety and efficiency of the short-track postoperative management in selected patients undergoing cardiac surgery. Advanced age and left ventricular dysfunction (i.e. EF <35\%) were found to be significant predictors of failure of this fast-track pathway and transfer to the ICU. During the study period, 5367 patients were managed according to the new PACU pathway. This number represents almost the half (45.2\%) of the total number of patients who underwent cardiac surgical procedures in our institution.

In the last two decades, many centers have adopted the fast-track postoperative management in order to gain beneficial effect on the costs of cardiac surgical procedures $^{[2,3]}$. Such a protocol is an efficient method to combat the problem of decreasing numbers of ICU beds and working nurses and to save costs as a result of shortened length-of-stay in expensive postoperative units. [4] The benefits of 
early extubation include improved cardiac function and patient comfort, reduction in respiratory complications, as well as ease in management. [8] On the other hand, the number of patients with higher risk profiles is increasing and includes older and more obese patients[5,6]. This makes the need for a cost-effective postoperative practice after cardiac surgery an important demand.

In our hospital, we started the PACU pathway because the cardiac surgery program was hampered by the lack of sufficient ICU beds. For this purpose, we have operated on these selected patients using general anesthesia without regional anesthetic techniques. In this regards, different combinations of anesthetic techniques were described ${ }^{[7,9]}$ with the aim to shorten the postoperative course of cardiac surgery patients without affecting safety. Hemmerling et al.[10] and Chaney[11] reported an epidural technique in order to facilitate early extubation and length of ICU stay. Numerous combinations of drugs and techniques have been described in order to shorten the process of fast-track anesthesia. [9-13] However, attention should be paid to the possibility of patient awareness while using short acting drugs. In our patients, with the use of sevoflurane and midazolam at the beginning of the procedure, no operative patient awareness was detected.

Different independent risk factors have been reported to predict failure of a fast-track process after cardiac surgery[14,15]. Tuman et al.[16] discussed a model for stratifying the risk of serious morbidity in 3156 patients after adult cardiac surgery. Among all the preoperative factors, they identified emergency operation, type of procedure, age, renal dysfunction, CVA, reoperation, female gender, and left ventricular dysfunction as significant predictors of morbidity and prolonged ICU stay. Ettema et al. ${ }^{[17]}$ systematically reviewed 20 models for the prediction of prolonged ICU stay after adult cardiac surgery and concluded the Parsonnet and EuroSCORE to be superior risk models in this regards.

Some patients with left ventricular dysfunction $(n=29(0.5 \%))$ were managed according to the PACU protocol because preoperative evaluation of the EF was subjectively performed using left ventriculography. The result of the multivariate analysis confirms that an EF of $<35 \%$ is a predictor of failure of the PACU protocol and should be rigorously respected as a contraindication for this protocol. On the other hand, 24 patients ( $0.4 \%$ ) with an EF of $<35 \%$ have completed the PACU pathway successfully. The cut-off point of $35 \%$ was arbitrary and is possibly too high to discard patients from the PACU management. In addition, the postoperative course of these patients could not be merely predicted by the preoperative value of the EF but rather by other preoperative findings like the amount of viable myocardium and LV volume ${ }^{[18]}$.

In the current study, we showed that general anesthesia without a regional technique is sufficient for efficient adult cardiac surgery. There are important contributory factors to help the success of the fast-track cardiac surgery. Precise preoperative screening and patient selection is critical. In addition, careful monitoring within the first 24 hours 
postoperatively and the availability of experienced and highly trained nurses on the ward are essential to detect changes in patient's condition on time. At the initial start of our PACU protocol, we tried to create optimal safety and provided sufficient and direct communication among all participating staff. Communication between the dedicated nursing staff on the ward and the responsible physicians is mandatory for the success of this protocol.

Many investigators have focused on the time to extubation as an important goal of the fast-track pathways ${ }^{[19]}$. This was not the case in our PACU protocol. Time to extubation itself was not critical in determining the success of the of fast-track process. Rewarming the patient and postoperative stabilization of the hemodynamic parameters is essential before extubation[20]. As we mentioned above, the success of the PACU protocol was defined as the transfer to the ordinary ward on the same day of the operation, no admission to the ICU, no take-back to the operation room and no mortality. Many authors[21, 22] have advised early mobilization and restoration of normal physiological function after cardiac surgery. We believe that immediate restoration of normal body temperature in addition to pain-free and stress-free awakening of the patient is of utmost importance, especially in patients undergoing off-pump (OPCAB) surgery. In order to achieve these criteria, extubation 2 to 3 hours after arrival on the PACU was expected. On the PACU, postoperative administration of morphine derivatives was abandoned.

In this study, advanced age was identified as significant factor to predict failure of the PACU protocol. In contrast, an earlier study of Paone et al.[5] found no need to modify the clinical pathways according to age. However, we believe that older patients need more time to clear their body systems of the anesthetic drugs. This can prolong the awakening times and delay the discharge of the patient from the PACU. In this case, the patient is subsequently transferred to the high care division of the ICU to stay overnight. An important limitation of our study is that we used age as a continuous variable, without a definite cut-off point, to determine its effect on the postoperative course of PACU patients. In the study of Paone et al.[5], patients older than 70 years showed longer ICU and hospital stay than did younger patients. On the other hand, Hannan et al.[23] showed a higher incidence of readmission after isolated CABG in patients $\geq 80$ years old than other patients. Beside age, other factors should be taken into consideration including vitality, cognitive function and renal function before accepting older patients for the PACU pathway[24].

Although lacking statistical significance, our data suggest that bleeding complications, signs of myocardial ischemia, respiratory insufficiency and being inadequately awake were the most frequent causes for failure of the PACU protocol. Toraman et al.,[25] found respiratory distress to be the main reason for ICU readmission after CABG. In their multivariate analysis, age above 65 years, peripheral arterial disease and postoperative drainage of more than $500 \mathrm{ml}$ blood were independent risk factors 
for failure of the fast-track management of CABG patients. For valve surgery, only preoperative congestive heart failure was an independent risk factor for fast-track surgery. Kogan et al. ${ }^{[14]}$ found stroke, renal failure and combined procedures to be independently associated with failed early extubation and delayed ICU and hospital discharge. In their analysis, infection and atrial fibrillation were independent risk factors in predicting possible late discharge.

\section{Limitations}

This is a retrospective observational single center study. Therefore, we must be cautious in interpreting our results. Our findings were the result of the local hospital protocol agreed upon by a team of anesthesiologists, ICU physicians, cardiac surgeons and nursing staff. Whether the same results can be applied to other settings remains to be investigated.

\section{CONCLUSIONS}

This study demonstrates that our fast-track management, called the PACU protocol, is efficient and safe for the postoperative management of selected patients undergoing cardiac surgery. Age and left ventricular dysfunction were the preoperative predictors of failure of the protocol.

Conflict of interest: none declared 
1. Cheng DC, Karski J, Peniston C et al. Early tracheal extubation after coronary artery bypass graft surgery reduces costs and improves resource use: A prospective, randomized, controlled trial. Anesthesiology 1996;85:1300-10

2. Engelman RM, Rousou JA, Flack JE 3rd et al. Fast-track recovery of the coronary bypass patient. Ann Thorac Surg 1994; 58:1742-6

3. Cheng DC, Karski J, Peniston C et al. Morbidity Outcome in early versus Conventional tracheal Extubation after Coronary Artery Bypass grafting: A prospective randomized Controlled trial. J Thorac Cardiovasc Surg 1996;112:755-64

4. Myles PS, Daly DJ, Djaiani G, Lee A, Cheng DC. A systemic review of the safety and effectiveness of fast-track cardiac anesthesia. Anesthesiology 2003;99:982-7

5. Paone G, Higgins RS, Havstad SL, Silverman NA. Does age limit the effectiveness of clinical pathways after coronary artery bypass graft surgery? Circulation 1998;98:41-5

6. Parlow JL, Ahn R, Milne B. Obesity is a risk factor for failure of fast-track extubation following coronary artery bypass surgery. Can J Anaesth 2006;53:288-94

7. Ahonen J, Olkkola KT, Hynynen M et al. Comparison of alfentanil, fentanyl and sufentanil for total intravenous anaesthesia with propofol in patients undergoing coronary artery bypass surgery. Br J Anaesth. 2000;85:533-40

8. Higgins TL. Pro: early endotracheal extubation is preferable to late extubation in patients following coronary artery surgery. J Cardiothorac Vasc Anesth 1992; 6:488-93

9. Howie MB, Cheng D, Newman MF et al. A Randomized Double-Blinded Multicenter Comparison of Remifentanil versus Fentanyl When combined with Isoflurane/Propofol for Early Extubation in Coronary Artery Bypass Graft Surgery. Anesth Analg 2001;92:1084-93

10. Hemmerling TM, Djaiani G, Babb P, Williams JP. The use of epidural analgesia in cardiac surgery should be encouraged. Anesth Analg 2006;103:1592-3

11. Chaney MA. Intrathecal and epidural anesthesia and analgesia for cardiac surgery. Anesth Analg 2006;102:45-64

12. De Hert SG, ten Broecke PW, Mertens E et al. Sevoflurane but not propofol preserves myocardial function in coronary surgery patients. Anesthesiology 2002;97:42-9

13. Roekaerts PM, Huygen FJ, de Lange S. Infusion of propofol versus midazolam for sedation in the intensive care unit following coronary artery surgery. J Cardiothorac Vasc Anesth 1993;7:142-7

14. Kogan A, Ghosh P, Preisman S et al. Risk factors for failed "fast-tracking" after cardiac surgery in patients older than 70 years. J Cardiothorac Vasc Anesth 2008;22:530-5

15. Constantinides VA, Tekkis PP, Fazil A et al. Fast-track failure after cardiac surgery: development of a prediction model. Crit Care Med 2006; 34:2875-82 
16. Tuman KJ, McCarthy RJ, March RJ, Najafi H, Ivankovich AD. Morbidity and duration of ICU stay after cardiac surgery. A model for preoperative risk assessment. Chest 1992;102:36-44

17. Ettema RG, Peelen LM, Schuurmans MJ, Nierich AP, Kalkman CJ, Moons KG. Prediction models for prolonged intensive care unit stay after cardiac surgery: systematic review and validation study. Circulation 2010;122;682-9

18. Soliman Hamad MA, Tan ME, van Straten AH, van Zundert AA, Schönberger JP. Long-term results of coronary artery bypass grafting in patients with left ventricular dysfunction. Ann Thorac Surg 2008;85:488-93

19. Quasha AL, Loeber N, Feeley TW, Ullyot DJ, Roizen MF. Postoperative Respiratory Care: A Controlled trial of Early and late extubation following Coronary Artery Bypass grafting. Anesthesiology 1980;52:135-41

20. Siliciano D. Con: early extubation is not preferable to late extubation in patients following coronary artery surgery. J Cardiothorac Vasc Anesth 1992;6:494-8

21. Oxelbark S, Bengtsson L, Eggersen M, Kopp J, Pedersen J, Sanchez R. Fast-track as a routine for open heart surgery. Eur J Cardiothorac Surg 2001;19:460-3

22. Ender J, Borger MA, Scholz M et al. Cardiac surgery fast-track treatment in a post anesthetic care unit: six-month results of the Leipzig fast-track concept. Anesthesiology 2008;109:61-6

23. Hannan EL, Racz MJ, Walford G et al. Predictors of readmission for complications of coronary artery bypass graft surgery. JAMA 2003;290:773-80

24. van Straten AH, Tan EM, Hamad MA, Martens EJ, van Zundert AA. Evaluation of the EuroSCORE risk scoring model for patients undergoing coronary artery bypass graft surgery: a word of caution. Neth Heart J 2010;18:355-9

25. Toraman F, Senay S, Gullu U, Karabulut H, Alhan C. Readmission to the intensive care unit after fast-track cardiac surgery: analysis of risk factors and outcome according to type of operation. Heart Surg Forum 2010;13:E212-7 




\section{Reducing the immediate availability of red blood cells in cardiac surgery, \\ a single-centre experience}

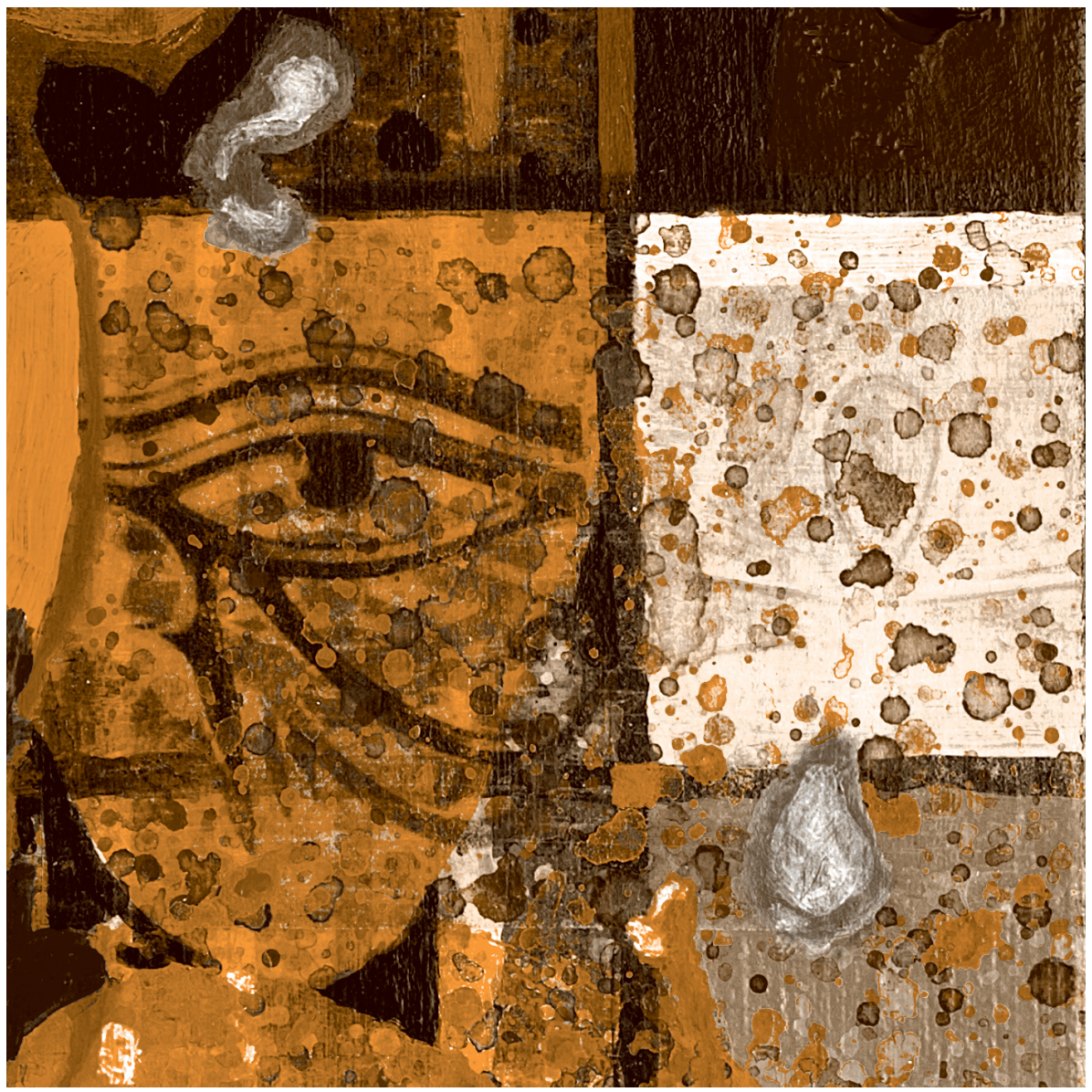





\section{REDUCING THE IMMEDIATE}

\section{AVAILABILITY OF RED BLOOD CELLS}

\section{IN CARDIAC SURGERY,}

\section{A SINGLE-CENTRE EXPERIENCE}

Marco C. Haanschoten, MD[1, 2]; MD, Albert H.M. van Straten, PhD[3];

Frank Verstappen[3]; Daan van de Kerkhof, PhD[4];

André A.J. van Zundert MD, PhD, FRCA [1,5]; and

Mohamed A. Soliman Hamad MD, PhD[3]
1. Department of Anesthesiology and
2. Intensive care unit, Catharina Hospital, Eindhoven, The Netherlands.
3. Department of Cardio-Thoracic Surgery, Catharina Hospital, Eindhoven, The Netherlands
4. Clinical laboratory, Catharina Hospital, Eindhoven, The Netherlands.
5. Department of Anesthesiology, University Hospital Ghent, Ghent, Belgium and University Hospital Maastricht 


\section{ABSTRACT}

Background: In our institution, we have redefined our criteria for direct availability of red blood cells RBC units in the operation room. In this study, we sought to evaluate the safety of applying this new logistical policy of blood transfusion in the first preliminary group of patients.

Methods: Since March 2010, we have started a new policy concerning the elective availability of RBC units in the operation room. This policy was called: No Elective Red Cells (NERC) program. The program was applied for patients undergoing primary isolated coronary artery bypass grafting (CABG) or single valve surgery. No elective RBC units were preoperatively ordered for these patients. In case of urgent need, blood was delivered to the operating room within 20 minutes. The present study includes the first 500 patients who were managed according to this policy. Logistic regression analyses were performed to investigate the impact of biomedical variables on fulfilling this NERC program.

Results: The majority of patients ( $n=409,81 \%$ ) did not receive any RBCs during the hospital stay. In patients who did receive RBCs ( $n=91,19 \%), 11$ patients (2.2\%) received RBC after 24 hours postoperatively. Female gender, left ventricular ejection fraction (LVEF) and EuroSCORE were significant predictors for the need of blood transfusion (OR=3.12; 2.79; 1.17 respectively).

Conclusion: In a selected group of patients, it is safe to perform cardiac surgery without the immediate availability of RBCs in the operating room. Transfusion was avoided in $81 \%$ of these patients. Female gender, LVEF and EuroSCORE were associated with blood transfusion.

Key words: Cardiac Surgery, Red Blood Cells, Transfusion. 


\section{Introduction}

Perioperative transfusion of red blood cells (RBCs) has been associated with increased mortality, morbidity, and costs and decreased long-term survival after cardiac surgery ${ }^{[1,2]}$. The severity of the adverse effects of perioperative RBC transfusion is dose-dependent. Unnecessary transfusion might cause postoperative complications and subsequent hospitalization $\operatorname{costs}^{[1,3]}$. In an earlier report $[4]$, we have identified the independent, patient-related risk factors of RBC transfusion after coronary artery bypass grafting ( $C A B G$ ). Identification of these risk factors has led us to follow a new policy concerning the direct availability of packed RBCs in the operating theatre. It was a standard practice in our hospital to have two units of RBCs directly available in the operating theatre for every patient who is planned for an elective CABG. If these two units are not used, they are returned back to the laboratory to be used for another patient. The quality of these RBCs is sometimes decreased and cannot be used anymore. Since March 2010, we have followed a policy that is called: no elective Red Cells (NERC) protocol. With this new protocol, in a selected group of patients, no units of RBCs are directly available in the operating theatre. According to this protocol, RBCs that are available in the blood bank are delivered in the OR within 20 minutes after request.

In the present study, we have analyzed our results of the first consecutive 500 patients who have been managed according to the NERC protocol.

\section{MATERIALS AND METHODS}

\section{The NERC protocol}

In our institution, we have started a new strategy concerning direct availability of RBC units in the operating room for a selected group of patients undergoing cardiac surgery. In this group of patients, only ABO typing and screening for irregular antibodies without cross matching were performed. Units of RBCs were kept in the hospital's blood bank. All patients were examined in the preoperative screening outpatient clinic to select suitable candidates for the NERC program. For patients included in the protocol, no RBCs were ordered before the operation. Patients included in the NERC program were screened for blood type and irregular antibodies the day before surgery. In case of urgent need for transfusion of RBC during or immediately after the operation, the local blood bank prepared the RBCs, including electronic cross matching, and delivered them within 20 minutes. Uncross-matched blood has been never given to any patient of this population. 
We always perform a double ABO screening including the Rh typing. In addition, we performed one screening for every patient on irregular antibodies. These tests are valid for 48 hours. Afterwards, a double ABO and antibody screenings should be repeated.

\section{Patients}

The study included the first consecutive 500 patients who were managed according to the NERC protocol starting in March 2010. Approval was obtained from the institution's research review board that waived the need for informed consent. Data of demographics, operative techniques, blood transfusions and adverse events were prospectively collected in the computerized database of our department.

Patients were managed according to the NERC protocol when they fulfilled the following criteria:

- Isolated primary coronary artery bypass grafting (CABG), isolated aortic valve replacement (AVR) or isolated mitral valve surgery.

- Preoperative haemoglobin $(\mathrm{Hb})$ level of $>7.0 \mathrm{mmol} / \mathrm{L}(11.3 \mathrm{~g} / \mathrm{dL})$.

- Body surface area (BSA) of $>1.7 \mathrm{~m}^{2}$.

- Negative test for irregular antibodies.

Patients were excluded from the NERC protocol in case of the following criteria:

- Combined CABG and/or valve surgery.

- Prior cardiac surgery.

- Positive test for irregular antibodies.

\section{Operative technique}

All patients received short-acting anaesthetic drugs to facilitate early extubation and rapid recovery according to our daily practice. Normothermic extracorporeal circulation (ECC) was performed using non-pulsatile flow. Cold crystalloid cardioplegia (St Thomas' solution) or warm blood cardioplegia was used to induce and maintain cardioplegic cardiac arrest, according to the surgeon's preference. Cell saver was used to collect all shed and/or residual blood, which was retransfused immediately after the operation.

\section{Indications of RBC transfusion}

In our hospital, transfusion of one or more RBC units is indicated in the postoperative period in case of hemoglobin level of $<5 \mathrm{mmol} / \mathrm{L}(8 \mathrm{~g} / \mathrm{dL})$ or hematocrit value of $<0.25$. A hemoglobin level of $<6 \mathrm{mmol} / \mathrm{L}(9.5 \mathrm{~g} / \mathrm{dL})$ is adopted in case of hemodynamically unstable patients or patients with postoperative ischemia or excessive bleeding. If the patient did not fulfil any of these criteria, no blood transfusion was given. 


\section{Statistics}

Continuous variables are expressed as mean \pm SD and categorical data are expressed as numbers (percentage). Univariate logistic regression analyses were performed to investigate the impact of biomedical variables on fulfilling the NERC protocol. A P-value $<0.05$ was used for all tests to indicate statistical significance. Odds ratios (OR) with a confidence interval $(\mathrm{Cl})$ of $95 \%$ with p-values are reported. All statistical analyses were performed using SPPS version 17.0 (SPSS Inc, Chicago, IL).

\section{RESULTS}

Starting in March 2010, 500 consecutive patients underwent cardiac surgery in our hospital and fulfilled the criteria for the NERC protocol. Demographic data and comorbidities are shown in table 1.

\section{TABLE 1. DeMOgRAPHIC DATA AND CO-MORBIDITIES}

\begin{tabular}{|l|c|}
\hline Variable & Incidence \\
\hline Male gender & $411(82.2 \%)$ \\
Age & $63.8 \pm 9.7(29-87)$ \\
Diabetes & $93(19 \%)$ \\
Hypertension & $264(52.8 \%)$ \\
Serum Hemoglobin $(\mathrm{mmol} / \mathrm{L})$ & $8.7 \pm 0.7(7.0-10.7)$ \\
Serum Creatinine $(\mu \mathrm{mol} / \mathrm{L})$ & $94.6 \pm 27.8(54-390)$ \\
Serum Creatinine $>200 \mu \mathrm{mol} / \mathrm{L}$ & $6(1.21 \%)$ \\
COPD & $45(9 \%)$ \\
PVD & $68(13.6 \%)$ \\
AF & $22(4.4 \%)$ \\
Previous myocardial infarction & $182(37.6 \%)$ \\
LVEF<35\% & $19(3.8 \%)$ \\
Logistic EuroSCORE & $3.2 \pm 3.3(1-35)$ \\
Additive EuroSCORE & $3.1 \pm 2.3(0-11)$ \\
\hline
\end{tabular}

$\mathrm{AF}=$ atrial fibrillation; $\mathrm{COPD}=$ chronic obstructive pulmonary disease;

$L V E F=l e f t$ ventricular ejection fraction; $P V D=$ peripheral vascular disease

Data are presented as numbers (\%) or mean \pm SD.

The majority of patients were male (82\%). The following co-morbidities were present: diabetes (19\%), hypertension (52.8\%), severe renal function impairment (1.2\%), chronic obstructive pulmonary disease (COPD) (9\%), peripheral vascular disease (PVD) (13.6\%), history of preoperative atrial fibrillation (4.4\%) and preoperative myocardial infarction (37.6\%). The mean logistic EuroSCORE was $3.2 \pm 3.3$ and the mean additive EurosCORE was $3.1 \pm 2.3$. 
Table 2 shows the type of the performed operations. The majority of patients underwent coronary artery bypass grafting (CABG) including on pump (74\%) and off pump (OPCAB) (12\%) surgery. An overview of the number of transfusions of blood products in the first 24 hours is given in table 3 .

The number of patients who did not receive any RBCs during hospital stay was 409 patients (81\%). Sixty-one patients (12.2\%) received $1-2$ units of blood and 14 patients (2.8\%) received 3-5 units of blood within the first 24 hours after surgery. In all these patients, blood was available within 20 minutes as planned. Only 11 patients (2.2\%) received $\mathrm{RBC}$ on the ward after 24 hours of surgery.

Mean serum haemoglobin was $6.4 \pm 0.8 \mathrm{mmol} / \mathrm{l}(10.3 \pm 1.3 \mathrm{~g} / \mathrm{dL})$ on the first postoperative day, and $6.8 \pm 0.8 \mathrm{mmol} / \mathrm{l}(11 \pm 1.3 \mathrm{~g} / \mathrm{dL})$ on the third postoperative day.

TABLE 2. TYPE OF SURGICAL PROCEDURE

\begin{tabular}{|l|c|l|}
\hline Operation & Number (\%) & Mean duration of ECC \\
\hline CABG & $373(74.5 \%)$ & $67 \pm 26$ \\
OPCAB & $60(12 \%)$ & N/A \\
AVR & $50(10 \%)$ & $77 \pm 20$ \\
MVR/MV repair & $17(3.4 \%)$ & $85 \pm 35$ \\
\hline
\end{tabular}

$A V R=$ aortic valve replacement; $C A B G=$ coronary artery bypass grafting,

$E C C=$ extracorporeal circulation; $M V=$ mitral valve; $M V R=$ mitral valve replacement;

$\mathrm{OPCAB}=$ off pump coronary artery bypass grafting

Data are numbers (\%) or mean \pm SD.

Table 3 shows the number of transfused blood products, the level of serum haemoglobin, and transfusion of RBCs as well as Fresh Frozen Plasma (FFP) units. The serum haemoglobin levels in first and third postoperative days are also shown.

TABLE 3. TRANSFUSIONS OF BLOOD PRODUCTS AND POSTOPERATIVE SERUM

\begin{tabular}{|l|r|}
\hline Number of patients RBC transfusions within $\mathbf{2 4}$ hrs & \\
\hline 1-2 units & $61(12.2 \%)$ \\
3-5 units & $14(2.8 \%)$ \\
$>5$ units & $5(1 \%)$ \\
Number of patients with RBC transfusion after 24 hrs & $11(2.2 \%)$ \\
Number of patients with no RBC transfusion during hospital stay & $409(81 \%)$ \\
Number of patients with transfusion of Fresh Frozen Plasma & $46(9.2 \%)$ \\
Number of patients with tranfusion of platelets & $23(4.6 \%)$ \\
Serum Hemoglobin on the 1st. postoperative day (mmol/L) & $6.4 \pm 0.8$ \\
Serum Hemoglobin on the 3rd. postoperative day (mmol/L) & $6.8 \pm 0.8$ \\
\hline
\end{tabular}

Data are presented as numbers (\%) or mean \pm SD 
Postoperative complications (table 4) included re-exploration for bleeding (4.6\%), myocardial infarction (3.2\%), cerebro-vascular accident (CVA) (0.4\%) and deep sternal wound infection (0.6\%).

\section{TABle 4. Postoperative complications}

\begin{tabular}{|l|r|}
\hline Complication & Incidence \\
\hline Re-exploration for bleeding & $24(4.6 \%)$ \\
Myocardial infarction & $16(3.2 \%)$ \\
CVA & $2(0.4 \%)$ \\
Deep sternal wound infection & $3(0.6 \%)$ \\
Operative mortality & $1(0.2 \%)$ \\
\hline
\end{tabular}

CVA = cerebro-vascular accident

Results of the univariate logistic regression analysis for the need for blood transfusion are shown in table 5. Female gender $(\mathrm{OR}=3.12)$ and $L V E F<35 \%(\mathrm{OR}=2.79)$ predicted a higher risk of blood transfusion. A higher logistic $(\mathrm{OR}=1.06)$ and a higher additive EuroSCORE $(O R=1.17)$ are significant predictors for the need of RBC transfusion.

TABLE 5. UNIVARIATE LOGISTIC REGRESSION ANALYSIS FOR PREDICTORS OF PERIOPERATIVE RBC TRANSFUSION

\begin{tabular}{|l|c|c|}
\hline Variable & OR $(95 \% \mathrm{CI})$ & p-value \\
\hline Age* & $1.02(0.99-1.04)$ & .060 \\
Female sex & $3.12(1.86-5.23)$ & $<.0001$ \\
Diabetes & $0.89(0.49-1.61)$ & .703 \\
Hypertension & $1.44(0.91-2.30)$ & .117 \\
COPD & $1.51(0.73-3.12)$ & .258 \\
PVD & $0.74(0.36-1.52)$ & .423 \\
LVEF<35\% & $2.79(1.06-7.31)$ & .036 \\
Preop. serum Creatinine* & $1.00(0.99-1.00)$ & .923 \\
Logistic EuroSCORE* & $1.06(1.00-1.12)$ & .043 \\
Additive EuroSCORE* & $1.17(1.06-1.29)$ & .001 \\
\hline
\end{tabular}

$\mathrm{OR}=$ Odds ratio, $\mathrm{Cl}=$ confidence interval, $\mathrm{COPD}=$ chronic obstructive pulmonary disease; $\mathrm{PVD}=$ peripheral vascular disease; LVEF = left ventricular ejection fraction

* used as a continuous variable 


\section{DISCUSSION}

This study demonstrated that, in a selected group of patients, it is safe to perform cardiac surgery without the immediate availability of RBCs in the operating room. This resulted in a considerable reduction in cross-matching and transportation with possible damage of non-used RBC. We used data from an earlier report of our group ${ }^{[4]}$ to identify patients with a relatively low risk for receiving perioperative RBC transfusions.

Transfusion of RBCs is not only associated with an increase in morbidity and mortality, but also with a longer ICU stay and total hospital stay ${ }^{[1]}$. Moreover, the effect of duration of storage of RBC on morbidity has been addressed [5-10]. In an earlier retrospective analysis of 10.626 patients undergoing cardiac surgery in our institution [2], we found a significant correlation between the number of RBC units received by the patients and the incidence of early mortality. McKenny et al.[9] also found the number of transfused RBC units to be associated with adverse outcome and longer hospital stay after cardiac surgery. Koch et al. ${ }^{[11]}$ found significantly reduced survival among transfused patients compared to non-transfused patients. Both early ( 6 months) and late hazard phases (up to 10 years) showed that transfusion of red cells is associated with a decreased survival in isolated CABG patients. According to these authors, attention should be directed toward blood conservation methods and a more judicious use of the RBCs ${ }^{[11]}$. One of the primary rationales of the NERC protocol is to help maintenance of adequate preservation of the RBCs. Non-used units of blood must be returned back to the blood bank for further use. However, the quality of these RBC units is likely to be adversely influenced by the improper reservation in the operation room as well as during transport [12]. The value of transfusion of these RBC units is physiologically less effective and can even increase the incidence of postoperative complications[13-15]. The effect of storage time of RBCs on the outcome after cardiac surgery has gained an increasing interest in recent literature. In an earlier study, storage time of the RBCs was not found to be a significant predictor of early or late mortality after CABG in our centre[5]. The end point of that study was all-cause mortality without analysing the effect of storage time of RBCs on morbidity.

On the other hand, Sanders et al. ${ }^{[10]}$ found that patients receiving older blood have an increased incidence of prolonged hospital stay and renal complication compared to those receiving new blood[10]. Koch et al. ${ }^{[6]}$ also found a correlation between transfusion of old blood and mortality and both renal and pulmonary complications after cardiac surgery. The controversy between different reports might be explained by the various patient populations studied, differences in study design or analysis, or different methods of blood storage.[5]

The criteria of selected patients who are candidates of this NERC protocol are of utmost important. We have applied these criteria after studying the risk factors of perioperative transfusion in our centre[4]. These criteria can vary in different centres 
and according to the availability of RBC units. If the blood is not electively ordered, it must be possible to deliver it on time if urgently needed.

Several blood conservation strategies ${ }^{[16-18]}$ have been proposed in order to improve outcome after cardiac surgery, reduce the need for donor blood and hence lowering the overall costs of transfusion. A wide variation in clinical practice and the application of guidelines have been reported in as many as 1.402 surveys in 1.061 institutions in the United States and Canada[19] Most of these studies examined liberal versus restrictive transfusion practices in cardiac surgery. However, there is no prospective randomized trial comparing the outcomes of a program that practises blood conservation versus the common practice of blood use in cardiac surgery[20]. Our NERC protocol is prospectively designed and the data of patients are prospectively collected as well. Only $19 \%$ of the patients needed blood transfusion during the whole hospital stay. In all these patients, the needed blood was immediately available on site in the hospital. In the present study, the incidence of postoperative complications is comparable with the general incidence of complications in our institution as demonstrated in previous studies of similar patients in our department ${ }^{[2]}$. Univariate predictors of postoperative need for blood transfusion were found to be gender (Female sex), LVEF $<35 \%$, logistic and additive EuroSCORE. The use of cell saver for shed blood or residual blood is a routine in our daily cardiac surgical practice. Current evidence suggests that the use of a cell saver reduces exposure to allergenic blood products or red blood cell transfusion for patients undergoing cardiac surgery[21].

\section{Limitations}

The results of this observational single center study must be interpreted with caution. Our findings were the result of the local protocol agreed upon by a team of anesthesiologists, ICU physicians, cardiac surgeons and blood bank. Whether the same results can be applied to other institutions remains to be investigated. The lack of a control group is also a shortcoming. However, matching this group with another group that was operated earlier was not convenient.

\section{CONCLUSIONS}

In a selected group of patients, it is safe to perform cardiac surgery without the immediate availability of RBCs in the operating room. Preoperative univariate predictors of the need for postoperative RBC transfusion were female gender, left ventricular function (LVEF) $<35 \%$ and the EuroSCORE.

Conflict of interests: None declared 
1. Murphy GJ, Reeves BC, Rogers CA, Rizvi SI, Culliford L, Angelini GD. Increased mortality, postoperative morbidity, and cost after red blood cell transfusion in patients having cardiac surgery. Circulation 2007;116:2544-52

2. van Straten AH, Bekker MW, Soliman Hamad MA, et al. Transfusion of red blood cells: the impact on short-term and long-term survival after coronary artery bypass grafting, a ten-year follow-up. Interact Cardiovasc Thorac Surg 2010;10:37-42

3. Koch CG, Li L, Duncan Al, et al. Morbidity and mortality risk associated with red blood cell and blood-component transfusion in isolated coronary artery bypass grafting. Crit Care Med 2006;34:1608-16

4. van Straten AH, Kats S, Bekker MW et al. Risk factors for red blood cell transfusion after coronary artery bypass graft surgery. J Cardiothorac Vasc Anesth 2010;24:413-7

5. van Straten AH, Soliman Hamad MA, van Zundert AA et al. Effect of duration of red blood cell storage on early and late mortality after coronary artery bypass grafting. J Thorac Cardiovasc Surg 2011; 141:231-7

6. Koch CG, Li L, Sessler DI et al. Duration of red-cell storage and complications after cardiac surgery. N Engl J Med 2008;358:1229-39

7. Basran S, Frumento RJ, Cohen A et al. The association between duration of storage of transfused red blood cells and morbidity and mortality after re-operative cardiac surgery. Anesth Analg 2006;103:15-20

8. Van de Watering L, Lorinser J, Versteegh M, Westendord R, Brand A. Effects of storage time of red blood cell transfusions on the prognosis of coronary artery bypass graft patients. Transfusion 2006;46:1712-8

9, McKenny M, Ryan T, Tate H, Graham B, Young VK, Dowd N. Age of transfused blood is not associated with increased postoperative adverse outcome after cardiac surgery. Br J Anaesth 2011;106:643-9

10. Sanders J, Patel S, Cooper J et al. Red blood cell storage is associated with length of stay and renal complications after cardiac surgery. Transfusion 2011; 51:2286-94

11. Koch CG, Li L, Duncan Al et al. Transfusion in coronary artery bypass grafting is associated with reduced long-term survival. Ann Thorac Surg 2006;81:1650-7

12. Zimrin AB, Hess JR. Current issues relating to the transfusion of stored red blood cells. Vox Sang. 2009;96:93-103

13. Dzik W. Fresh blood for everyone? Balancing availability and quality of stored RBCs. Transfus Med 2008;18:260-5

14. Hod EA, Brittenham GM, Billote GB et al. Transfusion of human volunteers with older, stored red blood cells produces extravascular hemolysis and circulating non-transferrin-bound iron. Blood 2011;118:6675-82 
15. Tinmouth A, Fergusson D, Yee IC et al. Clinical consequences of red cell storage in the critically ill. Transfusion 2006;46:2014-27

16. Beckmann SR, Carlile D, Bissinger RC, Burrell M, Winkler T, Shely WW. Improved coagulation and blood conservation in the golden hours after cardiopulmonary bypass. J Extra Corpor Technol 2007;39:103-8

17. Takagi H, Manabe H, Kawai N, Goto SN, Umemoto T. Aprotinin increases mortality as compared with tranexamic acid in cardiac surgery: a meta-analysis of randomized head-tohead trials. Interact Cardiovasc Thorac Surg 2009;9:98-101

18. Raghunathan K, Connelly NR, Kanter GJ. $\varepsilon$-Aminocaproic acid and clinical value in cardiac anesthesia. J Cardiothorac Vasc Anesth 2011;25:16-9

19. Likosky DS, FitzGerald DC, Groom RC et al. The effect of the perioperative blood transfusion and blood conservation in cardiac surgery Clinical Practice Guidelines of the Society of Thoracic Surgeons and the Society of Cardiovascular Anesthesiologists upon clinical practices. Anesth Analg 2010;111:316-23

20. Moskowitz DM, McCullough JN, Shander A et al. The impact of blood conservation on outcomes in cardiac surgery: is it safe and effective? Ann Thorac Surg 2010;90:451-8

21. Wang G, Bainbridge D, Martin J, Cheng D. The efficacy of an intraoperative cell saver during cardiac surgery: a meta-analysis of randomized trials. Anesth Analg 2009;109:320-30 



\section{Reply}

Red blood transfusion in patients undergoing cardiac surgery

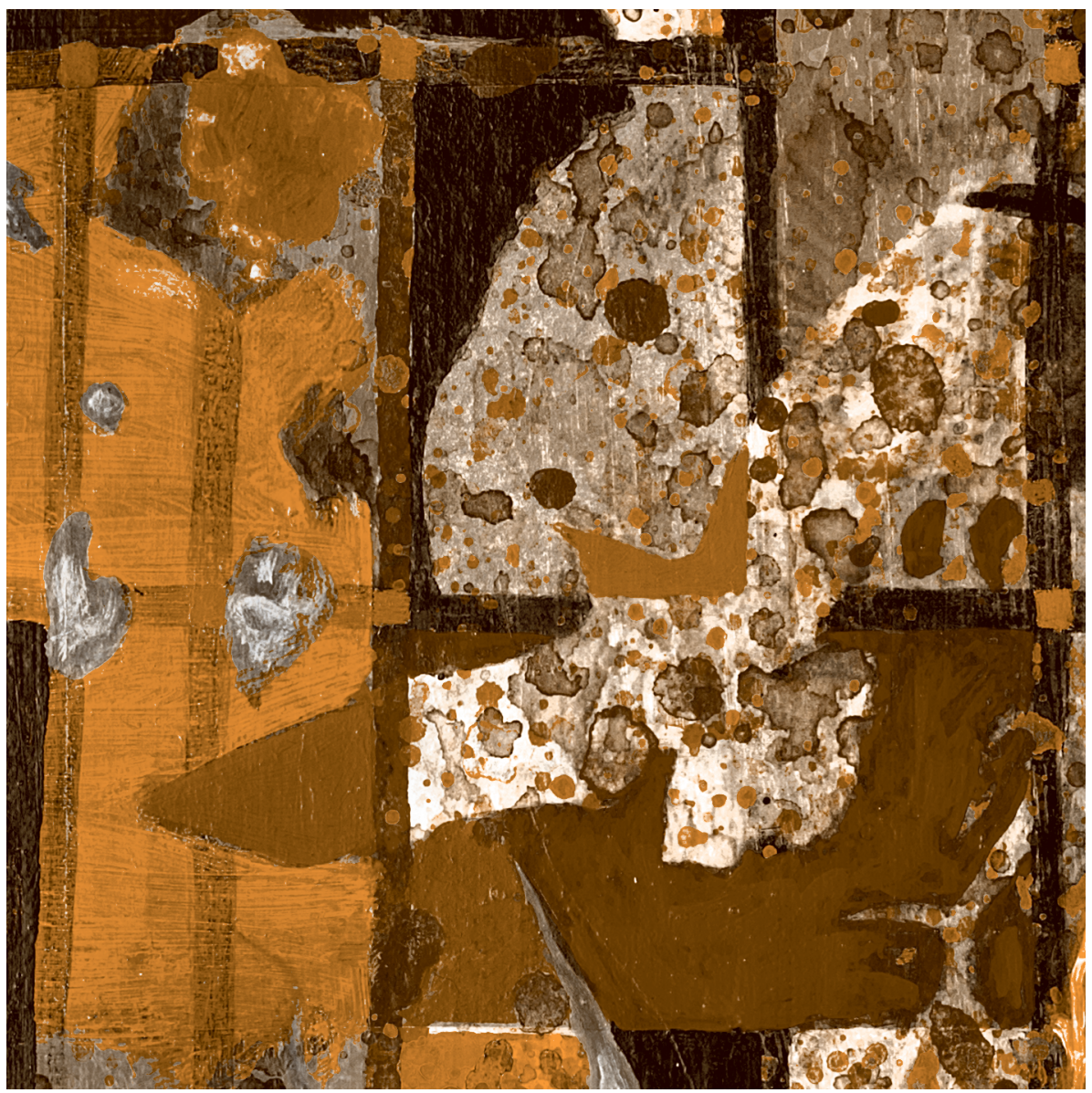





\section{RED BLOOD TRANSFUSION IN PATIENTS UNDERGOING CARDIAC SURGERY} REPLY

M.C. Haanschoten[1], A.H.M. van Straten[2] and M.A. Soliman Hamad[2]

1. Department of Anesthesiology, Department of Intensive Care Unit, Catharina Hospital, Eindhoven, The Netherlands

2. Department of Cardiothoracic Surgery, Catharina Hospital, Michelangelolaan 2, PO Box 1350, 5602 ZA Eindhoven, The Netherlands

\section{To the editor,}

We would like to thank Dr. Noyez for his comments ${ }^{[1]}$ on our study[2]. In our study, we investigated the safety and logistic convenience of the No Elective Red Cells (NERC) program. We presented the results of the first 500 patients who were managed according to this strategy. According to these results, it was safe to perform cardiac surgery without the immediate availability of blood in the operating room. Transfusion was avoided in $81 \%$ of the patients. Predictors for perioperative blood transfusion were female, left ventricular function and EuroSCORE.

An important question that was raised in Dr. Noyez's comment ${ }^{[1]}$ is about the percentage of red cell units returned to the blood bank and the percentage of units that could no longer be used because of reduced quality. This was not one of our endpoints when designing the study. We did not have a control group, which is one of the limitations of this study. However, the question could be answered in a new study design apart from the NERC program. It is possible to review the database of the blood bank in a certain period in order to find an answer to this relevant question.

One of the advantages of this new strategy is the possibility to decrease the number of units of blood in the stock of the hospital blood bank. As a result, the number of units of blood supplied by the central Dutch blood bank to our blood bank has decreased. This leads to less general requests for blood donation and consequently to a decrease in the costs. 
In our study[2], we have shown that blood was available within 20 min of ordering it for all patients who needed blood transfusion intraoperatively. Without this logistic convenience, this program would not have been considered successful.

In our series of 500 patients, we did not encounter any catastrophic bleeding problems that necessitated emergency blood transfusion. We agree with the author that these problems can occur even in the simplest procedure. In case of an emergency, blood units can be delivered within 10 min of ordering. This is facilitated by preoperative typing and screening of all patients.

\section{Open Access}

This article is distributed under the terms of the Creative Commons Attribution License which permits any use, distribution, and reproduction in any medium, provided the original author(s) and the source are credited.

\section{REFERENCES}

1. Noyez $L$. Red blood transfusion in patients undergoing cardiac surgery. Neth Heart 2015;23:26-7

2. Haanschoten MC, van Straten AH, Verstappen F, van de Kerkhof D, van Zundert AA, Soliman Hammad A. Reducing the immediate availability of red blood cells in cardiac surgery, a single-centre experience. Neth Heart J 2015;23:28-32 



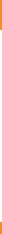


Part 2 - IMPACT OF COMPLICATIONS 



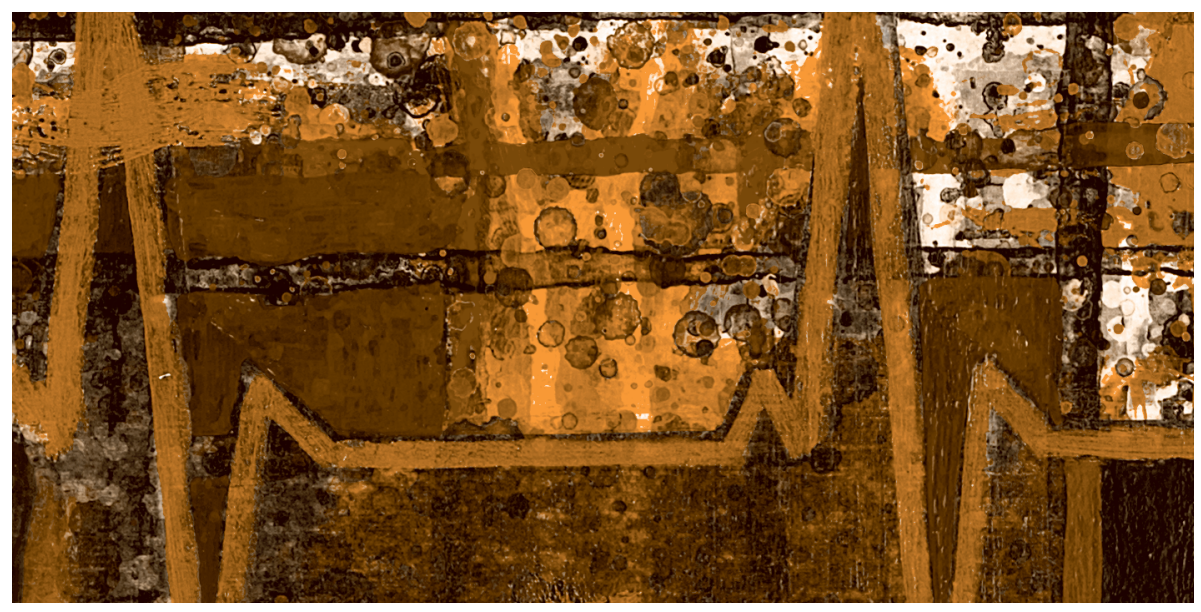

The impact of postoperative renal replacement therapy on Long-term outcome after cardiac surgery increases with age

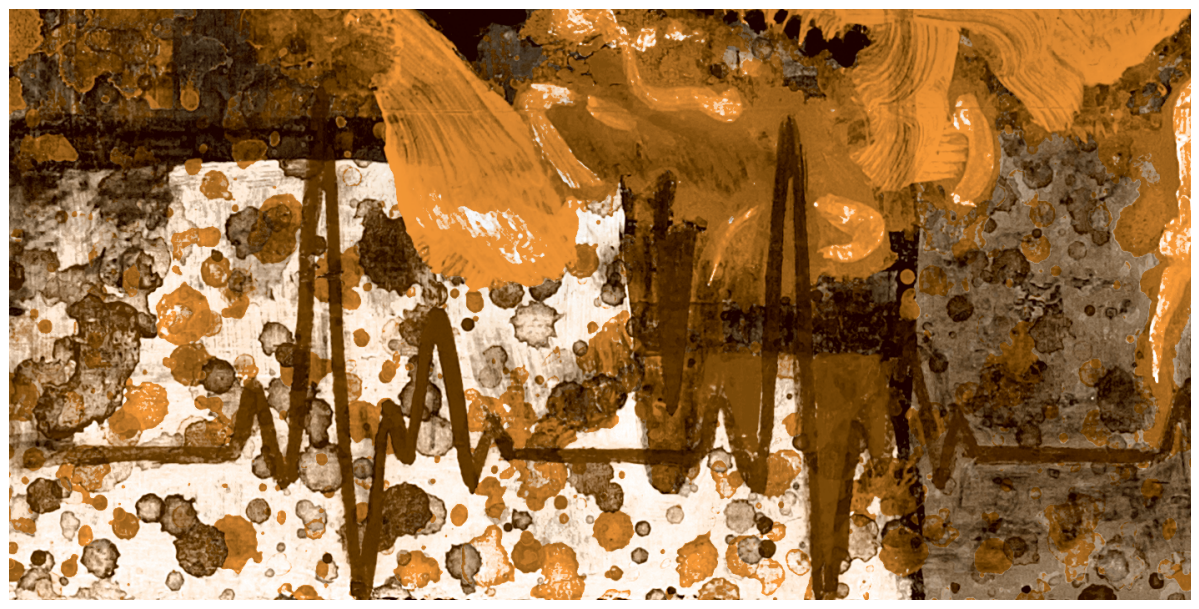





\section{THE IMPACT OF POSTOPERATIVE RENAL REPLACEMENT THERAPY ON LONG-TERM OUTCOME AFTER CARDIAC SURGERY INCREASES WITH AGE}

Marco C. Haanschoten, MD[1, 2]; Albert H.M. van Straten, MD, PhD[3]; Arthur Bouwman, MD, PhD ${ }^{[1,2]}$; Alexander J.G.H. Bindels, MD, PhD[2, 4]; André A.J. van Zundert, MD, PhD, FRCA, EDRA [1, 5]; and Mohamed A. Soliman Hamad, MD PhD[3]

Short title: Renal dialysis and mortality after cardiac surgery

1. Department of Anesthesiology and

2. Intensive Care Unit, Catharina Hospital, Eindhoven, The Netherlands.

3. Department of Cardio-Thoracic Surgery, Catharina Hospital, Eindhoven, The Netherlands

4. Department of internal medicine, Catharina Hospital, Eindhoven, The Netherlands

5. Department of Anesthesiology, University Hospital Ghent, Ghent, Belgium 


\section{ABSTRACT}

Backward and aim of the study: In the present study, we investigated the survival of patients who received postoperative renal replacement therapy (RRT) after cardiac surgery. We specifically focused on factors predicting long-term outcome in elderly patients.

Methods: Data of all patients that received unintentional renal replacement therapy following cardiac surgery between 2004 and 2010 were analyzed. Logistic- and Cox regression analyses were performed to detect the predictors of early and late mortality respectively.

Results: During the study period, 11899 patients underwent cardiac surgery in our centre. Postoperative RRT was performed in 138 patients (1.2\%). In this group of patients, thirty-day mortality included 72 patients (52\%) and the total overall mortality included 107 patients (77.5\%). Regression analyses revealed that age predicted 30-day mortality (odds ratio $=1.08$ [1.03-1.12]) as well as late mortality (odds ratio $=1.05$ [1.02-1.07]).

Conclusions: Patients requiring RRT after cardiac surgery have a poor prognosis with a high mortality. Older age predicted both 30-day and late mortality in these patients.

Key words: Anesthesia, Dialysis; Cardiac Surgery; Survival 


\section{Introduction}

Acute kidney injury (AKI) following cardiac surgery is associated with poor early and late survival[1]. Acknowledged risk factors for post-cardiac surgery AKI include age, impaired left ventricular (LV) function, preoperative renal impairment, diabetes, emergency procedures, prolonged cardiopulmonary bypass (CPB) time, peripheral vascular disease (PVD), previous cardiac surgery, low preoperative hemoglobin, increased C-reactive protein, perioperative myocardial infarction and the number of blood transfusions. ${ }^{[2-4]}$

Recent evidence suggests that up to $25 \%$ of patients admitted to intensive care units develop AKI with considerably reduced survival[5]. In 1\% of the patients undergoing cardiac surgery, the renal insult is such that renal replacement therapy (RRT) is indicated. [6] Several risk models use the established factors to estimate the risk for postoperative acute renal failure requiring RRT. However, how risk factors interact and whether these factors predict the outcome once acute kidney injury has developed, remains to be established.

In the present study using our single center database, we aimed to 1) investigate the incidence of renal replacement therapy after cardiac surgery, and 2) identify the predictors of both 30-day and late mortality in patients undergoing renal replacement therapy after cardiac surgery and specifically focused on outcome in elderly patients. Apart from age, other preoperative possible predictors such as gender, diabetes, impaired LV function, PVD and emergency indication were also investigated.

\section{MATERIAL AND METHODS}

\section{Patients}

The institutional Review Board of the Catharina Hospital approved the study and waived the need for an informed consent. Patients that required postoperative renal replacement therapy after cardiac surgery were selected from the database of the department of cardiothoracic surgery and included in this retrospective analysis. This database contains the prospectively collected clinical data of 11899 patients including demographic data, risk factors and complications of all cardiac operations performed at the Catharina Hospital (Eindhoven, Netherlands) between January 2004 and December 2010. All patients who underwent RRT postoperatively were included in the analysis ( $n=138)$; no patients were excluded.

Acute Kidney Injury was determined according to the RIFLE- and AKIN criteria[7, 8], and renal replacement therapy was initiated according to current guidelines[9]. 
These guidelines were always adopted by all intensive care physicians:

- Urine output was less than $0.5 \mathrm{ml} / \mathrm{kg} / \mathrm{hr}$ during first two days after surgery,

- Serum creatinine increased by $100 \mathrm{mmol} /$ day with or without deterioration of hemodynamic stability for which inotropic support was needed,

- Potassium level was more than $6.0 \mathrm{mmol} / \mathrm{L}$.

Renal replacement therapy consisted of continuous veno-venous hemofiltration (CVVH) only. In our hospital, the standard method of RRT in all intensive care patients is the CVVH. The rational of our intensivists is to avoid abrupt fluid and electrolyte shift in these patients who are usually hemodynamically unstable. When the patient is stable enough to be transferred, either to the ward, referring hospital or home, RRT is continued with a regular dialysis program.

\section{Follow-Up}

Follow-up data concerning late mortality were gathered using databases from medical insurance companies. Early mortality was defined as any-cause mortality within 30 days postoperatively (30-day mortality), whereas late mortality was defined as any-cause mortality that occurred after 30 days during the total follow-up period. Renal function of survivors was obtained by contacting the referring cardiologists.

\section{Statistical Analyses}

Discrete variables are presented as numbers and percentages. Continuous variables are presented as mean \pm standard deviations. Univariate logistic regression analyses were performed to investigate the effect of biomedical variables on 30-day mortality. Bivariate correlation was used to test the correlation between the duration of CVVH and mortality. The predicted probability of early mortality according to age was calculated using binary logistic regression analysis. Long-term survival was described using the Kaplan-Meier method. Cox proportional hazard regression analyses were performed for the predictors of late mortality.

Patients were classified into four groups according to age: $\leq 65$ years old; 66-70 years old; 71-75 years old; and > 75 years old. This classification follows the European System for Cardiac Operative Risk Evaluation (EuroSCORE) ${ }^{[10]}$. Comparisons of long-term survival between these groups were done using log-rank statistics. Odds ratios (HR) with 95\% confidence intervals ( $\mathrm{Cl}$ ) are reported. A p-value of less than.05 was considered to be statistically significant. All statistical analyses were performed using SPSS software (Statistical Product and Services Solutions, version 15.0, SPSS Inc, Chicago, IL, USA). 


\section{RESULTS}

During the period of the study (January 2004 through December 2010), 11899 adult cardiac operations were performed in our centre. Postoperative AKI, for which RRT was started, developed in 138 patients (1.2\%) who were included in this study. The mean duration of follow-up was $438 \pm 770$ days (1.2 \pm 2.1 years), with a median of 29 days. Demographic data, risk factors and perioperative data of the study population $(n=138)$ are shown in table 1.

TABLE 1. DEMOGRAPHIC DATA, RISK FACTORS AND PERIOPERATIVE DATA

\begin{tabular}{|l|c|}
\hline Preoperative data & \\
Male gender & $84(60.9 \%)$ \\
Age, year & $68.9 \pm 10.9$ \\
Diabetes, $n$ & $35(25.4 \%)$ \\
Hypertension, $n$ & $67(48.6 \%)$ \\
COPD, $n$ & $22(15.9 \%)$ \\
PVD, $n$ & $29(21 \%)$ \\
CVA, $n$ & $13(9.4 \%)$ \\
EF<35\%, $n$ & $15(10.9 \%)$ \\
Pior cardiac surgery, $n$ & $36(26.1 \%)$ \\
Endocarditis, $n$ & $10(7.2 \%)$ \\
Preoperative creatinine, $\mathrm{mg} / \mathrm{dL}$ & $1.44 \pm 1.18$ \\
Preoperative CrCl $<60 \mathrm{~mL} / \mathrm{min}$ (MDRD), $\mathrm{n}$ & $26(18 \%)$ \\
Additive EuroSCORE & $8.8 \pm 3.8$ \\
Logistic EuroSCORE & $19 \pm 19$ \\
& \\
Perioperative data & \\
\hline Re-exploration, $\mathrm{n}$ & $56(40.6 \%)$ \\
Perioperative MI, $\mathrm{n}$ & $22(15.9 \%)$ \\
AoX, min & $85 \pm 53$ \\
ECC duration, min & $146 \pm 84$ \\
\hline
\end{tabular}

Data are numbers (\%) or mean \pm SD

AoX $=$ aortic cross-clamping time, $C O P D=$ chronic obstructive pulmonary disease,

$\mathrm{CrCl}=$ creatinine clearance, $\mathrm{CVA}=$ cerebro-vascular accident,

$\mathrm{ECC}=$ extra-corporeal circulation, $\mathrm{EF}=$ left ventricular ejection fraction,

Periop $\mathrm{MI}=$ perioperative myocardial infarction, $\mathrm{PVD}$ = peripheral vascular disease

The majority of the patients were males. Only 26 patients (18\%) had preoperative renal dysfunction. Preoperative mean additive EuroSCORE (European System for Cardiac Operative Risk Evaluation $)^{[10]}$ was $8.8 \pm 3.8$ and the mean logistic EuroSCORE 
was 19 \pm 19 , indicating a high-risk profile. In 56 patients (40.6\%), re-exploration was performed because of the following reasons:

- Postoperative bleeding with or without cardiac tamponade: 28 patients (20.3\%)

- Postoperative sternal dehiscence or mediastinitis: 17 patients (12.3\%)

- Postoperative valve dysfunction: nine patients (6.5\%)

- Postoperative myocardial ischemia: two patients (1.5\%). In one patient, there was a postoperative evidence of anterior-lateral ischemia after a CABG operation. Re-exploration was performed and an extra venous graft from the aorta to the left anterior descending ( $L A D)$ coronary artery was performed. The ischemia was relieved. In another patient, lateral wall ischemia was diagnosed postoperatively after a CABG procedure. Postoperative coronary angiography showed that the venous graft of the diagonal branch was occluded. The patient was re-explored and a new venous graft to the diagonal branch was performed.

Table 2 shows types of cardiac surgical procedures performed. The majority of the patients (57.3\%) underwent combined procedures.

TABLE 2. TYPE OF CARDIAC SURGICAL PROCEDURE

\begin{tabular}{|c|c|}
\hline Procedure & No. (\%) \\
\hline CABG & $37(26.8 \%)$ \\
\hline$M V R+C A B G$ & $21(15.2 \%)$ \\
\hline MVR & $14 \quad(10.1 \%)$ \\
\hline AVR & $8(5.8 \%)$ \\
\hline AVR + aortic root surgery & $8(5.8 \%)$ \\
\hline$A V R+C A B G$ & $7(5.1 \%)$ \\
\hline MVR + TVP & $5(3.6 \%)$ \\
\hline$A V R+$ root surgery + CABG & $4(2.9 \%)$ \\
\hline$A V R+M V R$ & $4(2.9 \%)$ \\
\hline Others & $23(16.7 \%)$ \\
\hline $\mathrm{AVR}^{*}$ & $46(33.3 \%)$ \\
\hline $\mathrm{MVR}^{*}$ & $58(42 \%)$ \\
\hline $\mathrm{CABG}^{*}$ & $87(63 \%)$ \\
\hline Aortic root surgery* & $18(13 \%)$ \\
\hline Other* & $45(32.6 \%)$ \\
\hline
\end{tabular}

$\mathrm{CABG}=$ coronary artery bypass grafting, $\mathrm{MVR}=$ mitral valve replacement/repair, AVR = aortic valve replacement, TVP = tricuspid valve repair,

${ }^{*}=$ In combination with other procedures 


\section{0-day mortality}

More than half of the patients who had postoperative RRT due to AKI; $n=72$ out of 138 (52\%) died within 30 days after the operation. The mean duration of RRT was $8.5 \pm 8.8$ days. The median duration of RRT was 5 days (range 1-58 days). Four surviving patients were excluded from this calculation and they were still on dialysis at the time of follow up. In 65 deceased patients (47, 1\%), the date of death was considered as the date of ending RRT. Using bivariate correlation test, there was no significant correlation between the length of RRT and overall mortality ( $p=0.391)$

Table 3 shows the results of the logistic regression analyses for predictors of 30-day mortality. Only age was identified a significant predictor of 30-day mortality.

TABLE 3. LOGISTIC REGRESSION ANALYSES FOR 3O-DAY MORTALITY

\begin{tabular}{|l|c|c|}
\hline & OR (95\%Cl) & p-value \\
\hline Male gender & $0.80(0.40-1.58)$ & .524 \\
Diabetes & $1.08(1.03-1.12)$ & $<.0001$ \\
Hypertension & $1.52(0.70-3.33)$ & .285 \\
COPD & $1.26(0.64-2.47)$ & .486 \\
PVD & $0.90(0.36-2.24)$ & .824 \\
CVA & $0.82(0.36-1.86)$ & .637 \\
EF<35\% & $0.76(0.24-2.40)$ & .649 \\
Previous cardiac surgery & $0.97(0.33-2.86)$ & .962 \\
Endocarditis & $0.76(0.38-1.51)$ & .442 \\
Preoperative creatinine* & $0.90(0.25-3.29)$ & .886 \\
Re-exploration & $1.00(0.99-1.00)$ & .880 \\
Periop MI & $0.76(0.38-1.51)$ & .442 \\
AoX time* & $0.89(0.35-2.22)$ & .808 \\
Duration of ECC* & $1.00(0.99-1.00)$ & .542 \\
Associated CABG & $1.00(0.99-1.00)$ & .198 \\
\hline
\end{tabular}

AoX $=$ aortic cross clamp, $C A B G=$ coronary artery bypass grafting

COPD = chronic obstructive pulmonary disease,

CVA = cerebro vascular accident, ECC = extra-corporeal circulation,

$\mathrm{EF}=$ left ventricular ejection fraction, periop $\mathrm{Ml}=$ perioperative myocardial infarction,

PVD = peripheral vascular disease.

* $=$ entered as a continuous variable. 


\section{Overall mortality}

The total overall mortality included 107 patients out of 138 who form the study population (77.5\%). Cox regression analyses for late mortality revealed again only age to be a predictor of overall mortality as shown in table 4 . When coronary artery bypass grafting was performed whether isolated or in combination with any other cardiac surgical procedure, the risk for 30-day mortality was increased (OR of 2.62 [1.28-5.35]; P-value $=.008)$

TABLE 4. COX REGRESSION ANALYSES FOR LATE MORTALITY

\begin{tabular}{|l|c|c|}
\hline & OR (95\%Cl) & p-value \\
\hline Male gender & $0.82(0.55-1.20)$ & .320 \\
Diabetes & $1.05(1.02-1.07)$ & $<.0001$ \\
Hypertension & $1.36(0.89-2.10)$ & .153 \\
COPD & $1.05(0.72-1.54)$ & .776 \\
PVD & $0.99(0.59-1.64)$ & .977 \\
CVA & $0.99(0.62-1.57)$ & .970 \\
EF<35\% & $1.15(0.61-2.15)$ & .653 \\
Prior cardiac surgery & $1.48(0.84-2.62)$ & .170 \\
Endocarditis & $0.92(0.60-1.42)$ & .738 \\
Preop creatinine* & $0.85(0.40-2.66)$ & .756 \\
Re-exploration & $0.99(0.98-1.00)$ & .291 \\
Periop Ml & $0.92(0.64-1.40)$ & .803 \\
AoX time* & $1.05(0.62-1.77)$ & .844 \\
ECC duration* & $1.00(0.99-1.00)$ & .503 \\
\hline
\end{tabular}

AoX $=$ aortic cross clamp, $C O P D=$ chronic obstructive pulmonary disease,

CVA = cerebro vascular accident, ECC = extra-corporeal circulation,

$\mathrm{EF}=$ left ventricular ejection fraction, periop $\mathrm{MI}=$ perioperative myocardial infarction,

PVD = peripheral vascular disease.

* $=$ entered as a continuous variable.

Figure 1 shows the predicted probability of 30-day mortality according to age in this group. The older the age, the higher the possibility of 30-day mortality. 
FIGURE 1. PREDICTED PROBABILITY OF 3O-DAY MORTALITY ACCORDING TO AGE

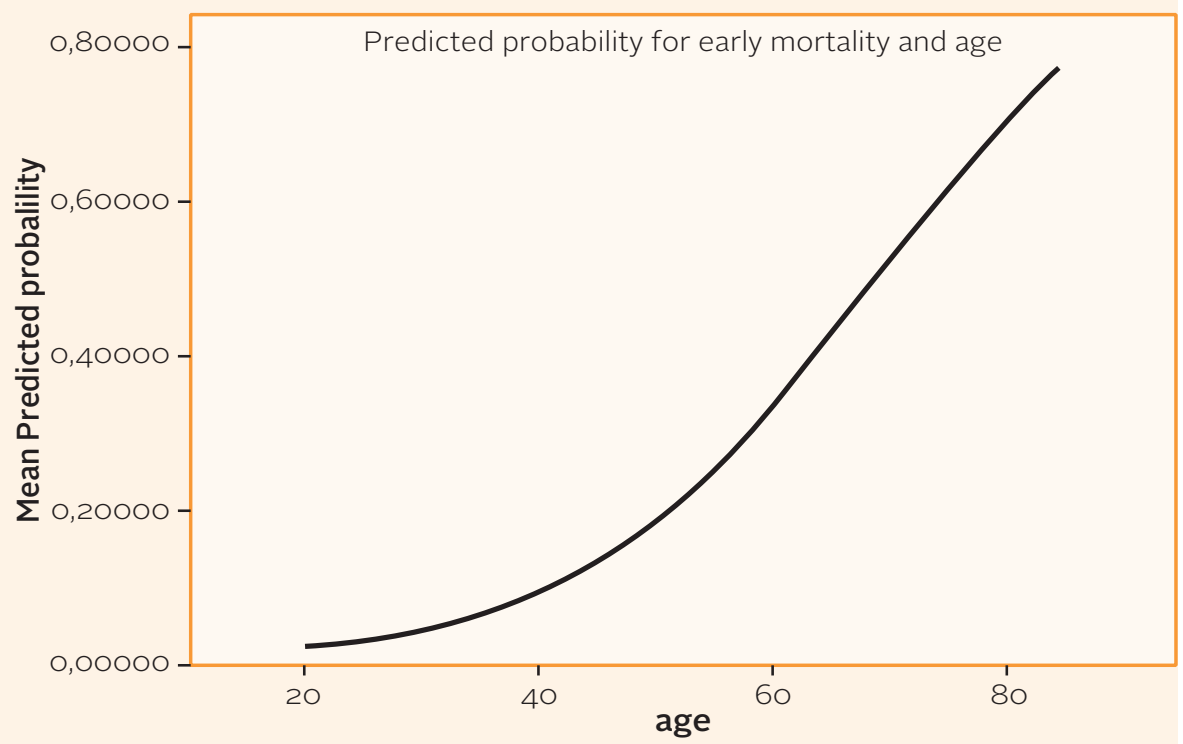

Kaplan Meier survival curves for age groups are shown in figure 2. It revealed a significant difference between age 70-75 compared to age <66 ( $p$-value =.013), for age $>75$ compared to age $<66$ ( $p$-value <.0001) and for age $>75$ compared to age 66-70 (p-value $=.030)$.

Figure 2. KAPLAN MEIER SURVIVAL CURVES FOR AGE COHORTS

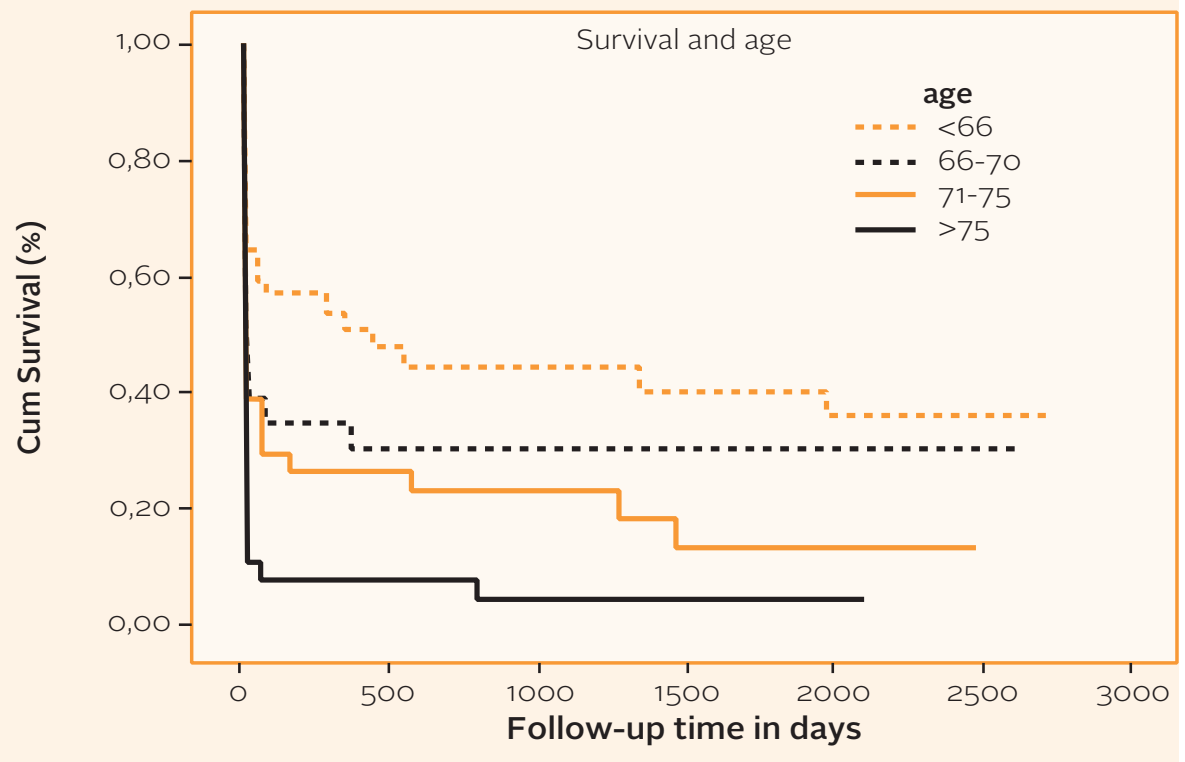


Of the 31 surviving patients at the end of follow-up, 4 patients were on permanent dialysis, 9 patients had a serum creatinine level of less than $1.13 \mathrm{mg} / \mathrm{dL}, 12$ patients had a level of $1.13-1.69 \mathrm{mg} / \mathrm{dL}, 2$ patients had a level of $1.7-2.26 \mathrm{mg} / \mathrm{dL}$ and 4 patients had a serum creatinine level of more than $2.26 \mathrm{mg} / \mathrm{dL}$.

\section{CONCLUSIONS}

This study demonstrates that renal failure requiring renal replacement therapy (RRT) after cardiac surgery is a serious complication with high mortality. According to our results, age $>75$ years predicts higher 30 -day and late mortality in patients who need RRT after cardiac surgery. Undergoing isolated or combined CABG was also identified as a significant predictor of mortality in these patients.

Several studies have reported the most important parameters that predict outcome in this category of patients [11]. Rahmanian et al.[2] developed a logistic risk model based on the outcome data of 2,511 consecutive on-pump patients to predict postoperative AKI requiring RRT after cardiac surgery. In their study, AKI requiring RRT occurred in $3.9 \%$ of patients and hospital mortality among RRT patients was 37.8\%, compared to $1.3 \%$ in patients without this complication. Multivariate analysis showed pulmonary hypertension, preoperative renal dysfunction, cardiopulmonary bypass time (>120 min), peripheral vascular disease, previous myocardial infarction, atrial fibrillation diabetes and age $>75$ years to be independent predictors for postoperative AKI requiring RRT. In the present study, early mortality in patients undergoing postoperative RRT for AKI was relatively high $(n=72(52 \%))$. This high mortality illustrates the negative impact of the need for dialysis on outcomes following cardiac surgery. Previous clinical series confirmed our findings and reported a hospital mortality ranging from 30\% to 80\%[12-14]. The exact mechanism for why AKI after cardiac surgery leads to higher mortality are related to volume overload, impaired host immunity and infections[15, 16].

Lagercrantz et al. ${ }^{[17]}$ investigated the duration and outcome of the ICU stay of 4086 cardiac surgery patients. In 141 patients, the ICU stay was longer than 10 days. Long-term survival and functional status were encouraging but there was a moderate loss of quality of life compared to the general population. Postoperative RRT and advanced age were both risk factors for early mortality in their study.

When comparing our data to previous studies, it seems that the incidence of AKI after cardiac surgery remains unchanged despite the advances in perioperative management and surgical technique achieved during the last decade [2]. This may be explained by the increased complexity of cardiac procedures as well as preoperative risk profile of patients accepted for cardiac surgery[18]. The substantially high EuroSCORE (19\%) in our study population seem to substantiate these developments.

In the present study, we only found age to be a risk factor for 30-day mortality. However, older age predicts mortality in the general cardiac surgery population as well[19]; 
as older patients more frequently suffer from other cardiac risk factors such as hypertension, atherosclerosis, peripheral vascular disease (PVD) as well as renal dysfunction. A novel finding of our study is that $63 \%$ of this patient group $(n=87)$ underwent a CABG procedure either isolated or in combination with other procedures. Moreover, undergoing $C A B G$ either alone or in association with any other procedure was a significant predictor of 30-day mortality. According to Conlon et al.[20], the incidence of dialysis-dependent renal dysfunction among patients undergoing isolated CABG is only $0.7 \%$. In another study including solely CABG patients, Bucerius et al. reported an incidence of postoperative dialysis of $4.1 \%$ [21]. In the study by Rahmanian et al.[2], the overall incidence of postoperative dialysis was 3.9\%. They described a high rate of renal failure necessitating RRT in patients undergoing complex procedures (9.5\%), particularly aortic arch surgery. It has been suggested that patients undergoing valvular or combined procedures present a twofold or threefold risk of having postoperative renal dysfunction that may mainly relate the prolonged CPB times, with the associated inflammatory, hemodynamic, and embolic phenomena ${ }^{[22,23]}$. In patients undergoing CABG, the incidence of other comorbidities such as hypertension, diabetes and PVD is relatively higher ${ }^{[24]}$ and may add to the risk of increased mortality. We could not identify procedures such as aortic valve replacement, mitral valve surgery, or aortic surgery, alone or in combination as predictors of mortality. This was also reported by Caynak et al. ${ }^{[25]}$ who found preoperative patients characteristics to be more important in determining morbidity and survival than the type of surgery.

In the field of cardiac surgery, multiple risk factors contribute to a prolonged intensive care unit (ICU) stay ${ }^{[12]}$. Mangano and colleagues ${ }^{[24]}$ first observed that ICU stay and hospitalization were significantly increased among AKI patients requiring dialysis and patients who had AKI without replacement therapy compared with patients who had neither.

Many authors have investigated the long-term survival and quality of life in patients admitted to the ICU[12, 26, and 27]. In the past decade, the optimal methods of RRT have been investigated in order to improve outcome for ICU patients. [28] However, there is no consensus on the intensity and timing of RRT and the impact on outcome of ICU patients. ${ }^{[29,30]}$ In our institution, as in other institutions in the Netherlands, it is a common practice to use continuous veno-venous hemofiltration (CVVH) as RRT in the ICU in patients who meet the RIFLE criteria. However, RRT is an intensive and costly treatment that leads to prolonged ICU stay and therefore puts a large burden on the ICU capacity.[31]

In an earlier report of our group [32], we have identified the perioperative risk factors for postoperative deterioration of renal function in CABG patients. These factors include age, diabetes, PVD, emergency operations, previous cardiac surgery, lower preoperative $\mathrm{Hb}$ level, higher preoperative CRP level, perioperative myocardial infarction, re-exploration for any cause and the number of RBC unit transfusions. 
Considering these factors during preoperative screening could improve patient selection and decrease the incidence of postoperative renal dysfunction. The preoperative mean EuroSCORE of the present patient population was relatively high; (19 \pm 19$)$ indicating the high-risk profile of this study group. Moreover, 49 patients (35.5\%) underwent combined procedures, with increased CPB time and possible myocardial stunning postoperatively. On the other hand, renal damage is often precipitated by postoperative low cardiac output syndrome with decreased renal perfusion.

In the present study, the duration of RRT was not statistically correlated with the overall mortality. This finding is in agreement with Karvellas et al. [353 who concluded that only earlier institution of RRT in critically ill patients with AKI might have a beneficial impact on survival. The duration of RRT was not a significant predictor of mortality in their study either.

The high mortality rate in our present results in older patients ( $>75 \mathrm{yrs}$ ) receiving renal replacement therapy after cardiac surgery, may put this therapy in older patients in a different clinical perspective. In our daily practice, going on with the adequate treatment of the patient would be discussed with the relatives when the prognosis is such poor.

Recent studies have also investigated the impact of preoperative contrast nephropathy following coronary angiography on postoperative AKI.[34-36] Garcia et al.[34] found contrast-induced nephropathy to be an independent predictor for mortality after cardiac surgery. Recently, Kramer et al.[35] suggested to increase the interval between cardiac catheterization and surgery, if allowed by the clinical condition and urgency of surgery, as an attempt to modify predisposing factors for AKI. An important limitation of the present study is that we were not able to retrieve the exact time interval between preoperative coronary angiography and the day of the operation. The negative impact of preoperative contrast nephropathy on the outcome of these patients cannot be excluded. Considering our present results, it might seem plausible to recommend delaying elective surgery after coronary angiography especially at the age higher than 75 years. However, this recommendation needs to be addressed in future studies. Other limitations of the present study include the retrospective nature that should be acknowledged with the interpretation of the results. The primary end-point of the study was all-cause mortality. We were not able to retrieve the cause of death, which could be equally important. Furthermore, the data are derived from one single center and therefore the local protocols agreed upon by the local team of anesthesiologists, intensivists, and cardiac surgeons may bias the results. This may especially be important for the criteria on which renal replacement therapy is initiated in the postoperative period and which technique for veno-venous hemofiltration is employed. 
1. Robert AM, Kramer RS, Dacey LJ et al. Cardiac surgery-associated acute kidney injury: a comparison of two consensus criteria. Ann Thorac Surg 2010;90:1939-43

2. Rahmanian PB, Kwiecien G, Langebartels G, Madershahian N, Wittwer T, Wahlers T. Logistic risk model predicting postoperative renal failure requiring dialysis in cardiac surgery patients. Eur J Cardiothorac Surg 2011;40:701-7

3. Rodrigues AJ, Evora PR, Bassetto $S$ et al. Risk factors for acute renal failure after heart surgery. Rev Bras Cir Cardiovasc 2009;24:441-6

4. Thakar CV, Arrigain S, Worley S, Yared JP, Paqanini EP. A clinical score to predict acute renal failure after cardiac surgery. J Am Soc Nephrol 2005;16:162-8

5. Pickering JW, Endre ZH. GFR shot by RIFLE: errors in staging acute kidney injury. Lancet 2009;373:1318-9

6. Mariscalco G, Lorusso R, Dominici C, Renzulli A, Sala A. Acute kidney injury: a relevant complication after cardiac surgery. Ann Thorac Surg 2011;92:1539-47

7. Roy AK, Mc Gorrian C, Treacy C et al. A comparison of traditional and novel definitions (RIFLE, AKIN, and KDIGO) of acute kidney injury for the prediction of outcomes in acute decompensated heart failure. Cardiorenal Med 2013;3:26-37

8. Arnaoutakis GJ, Bihorac A, Martin TD et al. RIFLE criteria for acute kidney injury in aortic arch surgery. J Thorac Cardiovasc Surg 2007;134:1554-60

9. Bouman CS, Oudemans-van-Straaten HM. Timing of renal replacement therapy in critical ill patients with acute kidney injury. Curr Opin Crit Care 2007;13:656-61

10. Nashef SA, Roques F, Michel P, Gauducheau E, Lemeshow S, Salamon R. European system for cardiac operative risk evaluation (EuroSCORE). Eur J Cardiothorac Surg 1999;16:9-13

11. Hein OV, Birnbaum J, Wernecke K, England M, Konertz W, Spies C. Prolonged intensive care unit stay in cardiac surgery: risk factors and long-term-survival. Ann Thorac Surg 2006;81:880-5

12. Filsoufi F, Rahmanian PB, Castillo JG, Silvay G, Carpentier A, Adams DH. Predictors and early and late outcomes of dialysis-dependent patients in contemporary cardiac surgery. J Cardiothorac Vasc Anesth 2008;22:522-9

13. Bove T, Calabrò MG, Landoni G, et al. The incidence and risk of acute renal failure after cardiac surgery. J Cardiothorac Vasc Anesth 2004;18:442-5

14. Chertow GM, Levy EM, Hammermeister KE, Grover F, Daley J. Independent association between acute renal failure and mortality following cardiac surgery. Am J Med 1998;104:343-8

15. Hoste EA, De Waele JJ. Physiologic consequences of acute renal failure on the critically ill. Crit Care Clin 2005;21:251-60

16. Thakar CV, Yared JP, Worley S, Cotman K, Paqanini EP Renal dysfunction and serious infections after open-heart surgery. Kidney Int 2003;64:239-46 
17. Lagercrantz E, Lindblom D, and Sartipy U. Survival and quality of life in cardiac surgery patients with prolonged intensive care. Ann Thorac Surg 2010;89:490-5

18. Ferguson TB Jr, Hammill BG, Peterson ED, DeLong ER, Grover FL. A decade of change-risk profiles and outcomes for isolated coronary artery bypass grafting procedures, 1990-1999: a report from the STS National Database Committee and the Duke Clinical Research Institute. Society of Thoracic Surgeons. Ann Thorac Surg 2002;73:480-9

19. Roques F, Nashef SA, Michel P, et al. Risk factors and outcome in European cardiac surgery: analysis of the EuroSCORE multinational database of 19030 patients. Eur J Cardiothorac Surg 1999;15:816-22

20. Conlon PJ, Stafford-Smith M, White WD, et al. Acute renal failure following cardiac surgery. Nephrol Dial Transplant 1999;14:1158-62

21. Bucerius J, Gummert JF, Walther T, et al. On-pump versus off-pump coronary artery bypass grafting: impact on postoperative renal failure requiring renal replacement therapy. Ann Thorac Surg 2004;77:1250-6

22. Boldt J, Brenner T, Lehmann A Suttner SW, Kumle B, Isgro F. Is kidney function altered by the duration of cardiopulmonary bypass? Ann Thorac Surg 2003;75:906-12

23. Sreeram GM, Grocott HP, White WD, Newman MF, Stafford-Smith M. Transcranial Doppler emboli count predicts rise in creatinine after coronary artery bypass graft surgery. J Cardiothorac Vasc Anesth 2004;18:548-51

24. Mangano CM, Diamondstone LS, Ramsay JG, Aggarwal A, Herskowitz A, Mangano DT. Renal dysfunction after myocardial revascularization: risk factors, adverse outcomes, and hospital resource utilization. The Multicenter Study of Perioperative Ischemia Research Group. Ann Intern Med 1998;128:194-203

25. Caynak B, Bayramoğlu Z, Onan B, et al. The impact of non-dialysis-dependent renal dysfunction on outcome following cardiac surgery. Heart Surg Forum 2011;14:E214-20

26. Gaudino M, Girola F, Piscitelli M, et al. Long-term survival and quality of life of patients with prolonged postoperative intensive care unit stay: unmasking an apparent success. J Thorac Cardiovasc Surg 2007:134:465-9

27. Uchino S, Kellum JA, Bellomo R, et al. Acute renal failure in critically ill patients: a multinational, multicenter study. JAMA 2005;294:813-8

28. Ronco C. Recent evolution of renal replacement therapy in the critically ill patient. Crit Care 2006;10:123

29. Palevsky PM, Zhang JH, O'Connor TZ, et al. Intensity of renal support in critically ill patients with acute kidney injury. N Eng J Med 2008;359:7-20

30. Bellomo R, Cass A, Cole L, et al. Intensity of continuous renal-replacement therapy in critically ill patients. N Eng J Med 2009;361:1627-38

31. Dasta JF, Kane-Gill SL, Durtschi AJ, Pathak DS, Kellum JA. Costs and outcomes of acute kidney injury (AKI) following cardiac surgery. Nephrol Dial Transplant 2008;23:1970-74 
32. van Straten AH, Hamad MA, van Zundert AA, Martens EJ, Schönberger JP, de Wolf AM. Risk factors for deterioration of renal function after coronary artery bypass grafting. Eur J Cardiothorac Surg 2010;37:106-11

33. Karvellas CJ, Farhat MR, Sajjad I, et al. A comparison of early versus late initiation of renal replacement therapy in critically ill patients with acute kidney injury: a systematic review and meta-analysis. Crit Care 2011;15:R72

34. Garcia S, Ko B, Adabag S. Contrast-induced nephropathy and risk of acute kidney injury and mortality after cardiac operations. Ann Thorac Surg 2012;94:772-6

35. Kramer RS, Quinn RD, Groom RC, et al. Same admission cardiac catheterization and cardiac surgery: Is there an increase incidence of acute kidney injury? Ann Thorac Surg 2010;90:1418-23

36. Lee EH, Chin JH, Joung KW, et al. Impact of the time of coronary angiography on acute kidney injury after elective off-pump coronary artery bypass surgery. Ann Thorac Surg 2013;96:1635-41 


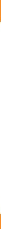


Part 3 - SUPPORT IN OUTCOME PREDICTION 



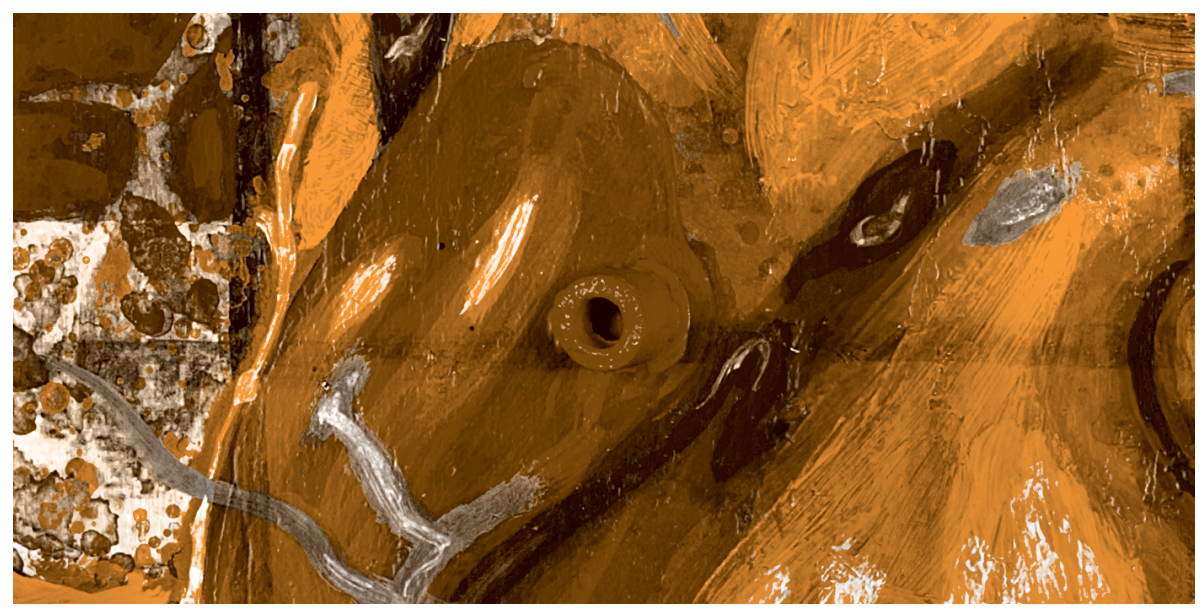

\section{Use of Postoperative Peak Arterial after Cardiac Surgery}

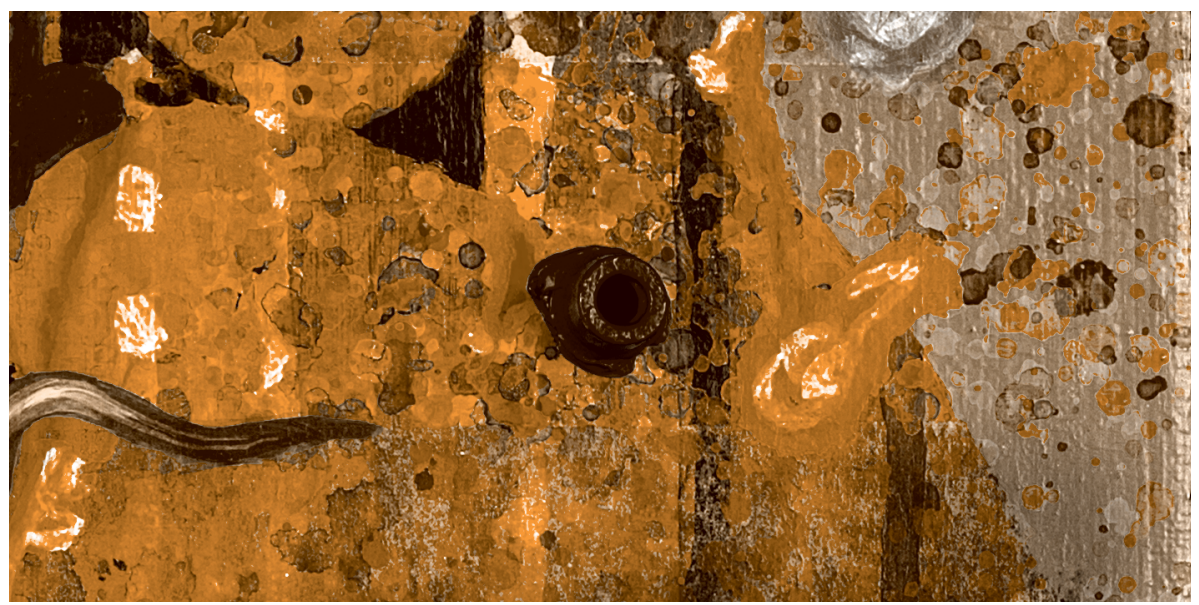





\title{
USE OF POSTOPERATIVE PEAK
}

\section{ARTERIAL LACTATE LEVEL TO PREDICT OUTCOME AFTER CARDIAC SURGERY}

\author{
Marco C. Haanschoten, MD[1, 2]; Herman G. Kreeftenberg, MD[2]; \\ R. Arthur Bouwman, MD PhD[1, 2]; Albert H.M. van Straten, MD PhD[3]; \\ Wolfgang F. Buhre, MD, PhD[4]; Mohamed A. Soliman Hamad, MD PhD[3] \\ Catharina hospital, Eindhoven, The Netherlands
1. Department of Anesthesiology and
2. Intensive care unit, Catharina Hospital, Eindhoven, The Netherlands.
3. Department of Cardio-Thoracic Surgery, Catharina Hospital, Eindhoven, The Netherlands
4. Department of Anaesthesiology Maastricht university Hospital, The Netherlands 


\section{ABSTRACT}

Objectives: In the present study, we investigated the predictive value of postoperative peak arterial lactate levels for early and late mortality after cardiac surgery.

Design: Retrospective analysis of prospectively collected data

Setting: Single-centre study in an educational hospital

Participants: Adult patients who underwent cardiac surgery between 2004 and 2014 $(n=16376)$

Interventions: Different cardiac surgical procedures

Measurements and Main Results: Patients were classified according to the peak arterial lactate level (PALL) within 3 days postoperatively. Logistic regression analysis and cox regression analysis were performed to identify postoperative peak arterial lactate level as a predictor for early and late mortality respectively.

In 8460 patients (51.7\%), lactate was not measured postoperatively because these patients were managed according to the fast-track protocol. These patients constituted group 1 in our population but were excluded from the regression analysis. The remaining patients ( $n=7916 ; 48.3 \%$ ) were divided according to the postoperative peak arterial lactate level (PALL): PALL of $<5 \mathrm{mmol} / \mathrm{L}$ (group2), PALL of 5-10 mmol/L (group 3) and PALL of $>10 \mathrm{mml} / L$ (group 4). Early mortality was 3.7\%, 20.4\% and 62.9\% in groups 2, 3 and 4 respectively $(p<0.0001)$. This mortality rate was significantly higher than that of group 1 (1.6\%); $p<0.0001$. Multivariate regression analyses revealed postoperative peak arterial lactate as a significant predictor of 30-day mortality (odds ratio $=1.44$ [1.39-1.48], $p<0.001$ ) as well as for late mortality (Hazard ratio $=1.05$ [1.01-1.10], p<0.025).

Conclusions: Postoperative peak arterial lactate level in patients undergoing cardiac surgery is an independent predictor for both early and late mortality.

Key words: cardiac surgery, hyperlactatemia, mortality; survival analysis 


\section{Introduction}

Increased lactate levels during and following cardiac surgery are frequently encountered and the clinical impact has been subject of considerable discussion in the literature. ${ }^{[1-8]}$ While the exact mechanism for hyperlactataemia during cardiac surgery is not known, the role of lactate levels to detect the severity of perioperative circulatory failure in patients recovering from cardiac surgery has been advocated. [5-7] Several reports substantiate that increased perioperative lactate levels associate with postoperative complications including mortality. ${ }^{[8-10]}$ It has been advocated that multiple factors contribute to lactate metabolism after cardiac surgery. Pre-existing liver and kidney function, splanchnic circulation during the cardiopulmonary bypass, intra-operative anaesthetic management of hemodynamics during cardiac surgery might contribute to postoperative hyperlactatemia. On the other hand, postoperative cardiac performance and reduced oxygen delivery to critical organs substantial contribute to lactate production. ${ }^{[1,7]}$ It is generally accepted that the clinical impact of postoperative hyperlactatemia because of tissue hypoxia is worse compared to non-hypoxic causes. However, both mechanisms are reported to occur in cardiac surgery and this may question the predictive reliability of postoperative lactate levels with regard to outcome. ${ }^{[2]}$ Furthermore, most reports focused on early complications and mortality after cardiac surgery, while previous evidence suggests that perioperative factors and management also influence the long-term outcome. ${ }^{[11]}$ Preoperative stratification models such as the European System for Cardiac Operative Risk Evaluation (EuroSCORE) do not consider these perioperative factors. ${ }^{[11]}$ Postoperative monitoring of cardiac surgical patients using serial blood markers such as arterial lactate could also be used to predict the prognosis. However, timing and frequency of blood sampling for lactate monitoring during and after cardiac surgery is controversial., $1,7,9]$ In this study, we investigated the hypothesis that postoperative peak arterial lactate level (PALL) within three days postoperatively can predict early and late mortality in patients undergoing cardiac surgery.

\section{PATIENTS AND METHODS}

In this study, data of all patients undergoing cardiac surgery in the Catharina Hospital in Eindhoven (the Netherlands) between January 2004 and April 2014 were analysed. Our institutional database contains prospectively collected data including all clinical data, demographic data, risk factors and laboratory data of all patients undergoing cardiac surgery in our institution. The institutional review board (Catharina Hospital, Eindhoven, and the Netherlands) approved the study and waived the need for informed consent. 
For the present analysis, postoperative peak arterial lactate level (PALL) within the first 3 days postoperatively was considered. In 8460 (51.6\%) patients, PALL was not collected because most of these patients were managed according to the fast-track protocol. Postoperative management of the fast-track patients does not include arterial lactate measurement. They were all transferred to the ward within 24 hours after the operation. Although these patients were not considered in the regression analysis of the present study, we have chosen to address their data of baseline characteristics, operative information and outcome. These patients are presented as group 1 but are not included in the analysis because their arterial lactate was not measured postoperatively. The rest of the patient population ( $n=7916 ; 48.4 \%$ ) stayed longer than 24 hours in the ICU. Serial measurements of arterial lactate are performed as a standard care for all patients in the ICU. Our time-based protocol is to measure lactate at least twice daily. Repeated lactate measurements are guided by the degree of hyperlactatemia with or without hemodynamic instability. These patients were arbitrarily classified into 3 groups according to PALL within the first three days postoperatively: group 2 (PALL<5 mmol/L), group 3 (PALL= 5-10 mmol/L) and group 4 (PALL> $10 \mathrm{mmol} / \mathrm{L}$ ). The primary endpoints of the study are early mortality, defined as all-cause mortality within 30 days after surgery; and late mortality, defined as all-cause mortality later than 30 days postoperatively. Follow-up data concerning late mortality were gathered using database of our institution that includes information of health care insurance companies, general practitioners and databases of local government authorities. Mortality data are regularly checked through a direct link with the local government authority.

\section{Anesthetic and operative techniques}

All patients were treated according to our cardiac anesthesia protocol with the standard preoperative medication, and a routine ventilation protocol.

In brief, anesthesia was induced with fentanyl, etomidate, midazolam and rocuronium and maintained with continuous administration of propofol and alfentanil. All patients received a central venous catheter, a radial artery catheter and depth of anesthesia was monitored with Bispectral index monitor ${ }^{\circledR}$ (Philips Medical System, Best, The Netherlands). Ventilation parameters were set to achieve tidal volumes between 6 and $10 \mathrm{ml} / \mathrm{kg}$, positive end-expiratory pressure of $5 \mathrm{cmH}_{2} \mathrm{O}$ and end-tidal $\mathrm{CO}_{2}$ levels between 4 and $5 \%$.

After institution of cardiopulmonary bypass (CPB) using normothermic nonpulsatile flow, cardiac arrest was induced with cold antegrade crystalloid cardioplegia (St Thomas solution) or warm intermittent antegrade blood cardioplegia according to the surgeon's preference.

Patient were weaned from the CPB only when the nasal temperature was $\geq 37.0^{\circ} \mathrm{C}$ and the rectal temperature was $\geq 36.0^{\circ} \mathrm{C}$. If necessary, dobutamine, noradrenalin or 
milrinone was used for hemodynamic support to facilitate weaning. The operative mean aortic pressure was maintained $\geq 60 \mathrm{~mm} \mathrm{Hg}$ during CPB.

\section{ICU management}

In our institution, postoperative care for patients after cardiac surgery is standardized and carried out according to our institutional post-cardiac surgery protocol. In the intensive care unit (ICU), a daily standard time-based protocol was used for blood sampling and laboratory diagnostics including arterial lactate measurement. Additional sampling of arterial lactate is performed in case of initial hyperlactatemia or when one of the following criteria of hemodynamic instability and decreased organ flow was present: low blood pressure (mean under $60 \mathrm{mmHg}$ ), low peripheral temperature $\left(\mathrm{T}<30^{\circ} \mathrm{C}\right.$ ), low urine output $(<30 \mathrm{ml} / \mathrm{hr}$ ), low venous saturation ( $\mathrm{SvO} 2<60 \mathrm{mmHg}$ ) or the use of inotropic agents. Hypovolemia was treated with infusion of crystalloids (ringer's lactate) or transfusion of red blood cell units if haemoglobin (HB) level was $<5 \mathrm{mmol} / \mathrm{L}(8 \mathrm{~g} / \mathrm{dL})$ or hematocrit of $<25$. A haemoglobin level of $<6 \mathrm{mmol} / \mathrm{L}$ (9.5 g/dL) was adopted for hemodynamically unstable patients, patients with postoperative cardiac ischemia or excessive bleeding. In all patients, cell saver was used intraoperatively for standard local blood management. When hemodynamic support was indicated, dobutamine, noradrenalin and milrinone were used as an inotropic support.

\section{STATISTICAL ANALYSIS}

Numerical data are presented as mean \pm standard deviation or median with interquartile range. Categorical data are presented as numbers or percentages. In case of normal distribution, groups were compared using unpaired Student's t-tests and analyses of variance (ANOVA). Non-parametric data were compared with Mann Whitney $U$ - or Kruskal Wallis test in case of multiple comparisons.

Univariate and multivariate logistic regression analyses were performed to investigate the value of PALL in predicting early mortality. Cox proportional hazard regression analyses were performed to evaluate the value of PALL in determining late mortality. If significant at a p-value below 0.05 , confounding variables were included in the multivariate logistic and Cox regression analyses to predict mortality. The cumulative survival was depicted using the Kaplan-Meier method. 'Time zero' was used to designate the time of end of operation. For all tests, a p-value of 0.05 was taken as indicating statistical significance. Odds ratios (OR) and hazard ratios (HR) was reported with 95\% confidence intervals ( $\mathrm{Cl}$ ). The sensitivity and specificity of lactate as a predictor of outcome was assessed using the receiver operating characteristic curve (ROC) and the area under the curve (AUC) expressed as the $C$ index and accompanied by 95\% confidence intervals. All statistical analyses were performed using SPSS version 20.0 (Chicago IL) 


\section{RESULTS}

Between January 2004 and April 2014, 16376 patients underwent cardiac surgery at the Catharina Hospital. The maximal follow up was 3800 days (10.4 years) with a mean of $4.9 \pm 2.9$ years. Fifty-seven patients were lost to follow-up.

Table 1 shows the baseline characteristics of the 4 patient groups. In comparison with group 2, patients with extremely high PALL (group 4) had more frequently a history of peripheral vascular disease (PVD), prior cardiac surgery, an ejection fraction (EF) of $<35 \%$, lower preoperative hemoglobin (HB) levels, higher preoperative creatinine levels and higher EuroSCORE (Table 1). In addition, in patients in the high PALL group (groups $3 \& 4$ ), aortic cross clamp times and cardiopulmonary bypass times were longer compared to group 2. These patients suffered more frequently from perioperative infarctions and more often underwent re-exploration.

Table 1. Preoperative baseline characteristics

\begin{tabular}{|c|c|c|c|c|c|}
\hline Variable & $\begin{array}{c}\text { Group } 1 \\
\text { Unknown } \\
n=8460\end{array}$ & $\begin{array}{c}\text { Group } 2 \\
\text { PALL < 5.0 } \\
\text { mmol/L } \\
n=7037\end{array}$ & $\begin{array}{c}\text { Group } 3 \\
\text { PALL=5-10 } \\
\text { mmol/L } \\
n=701\end{array}$ & $\begin{array}{c}\text { Group } 4 \\
\text { PALL >10 } \\
\text { mmol/L } \\
n=178\end{array}$ & $\mathrm{p}$-value \\
\hline Male gender & 6235 (73,7\%) & $4864(69.1 \%)$ & $445(63.5 \%)$ & $131(73.6 \%)$ & $<.0001$ \\
\hline Age, year & $65.4 \pm 10.1$ & $67.2 \pm 10.6$ & $68.2 \pm 10.7$ & $66.0 \pm 12.7$ & $<.0001$ \\
\hline Hypertension & $4150(49.1 \%)$ & $3770(53.6 \%)$ & $356(50.8 \%)$ & $87(48.9 \%)$ & $<.0001$ \\
\hline COPD & $955(11.3 \%)$ & $817(11.6 \%)$ & $94(13.4 \%)$ & $18(10.1 \%)$ & .347 \\
\hline PVD & $1055(12.5 \%)$ & $953(13.5 \%)$ & $120(17.1 \%)$ & $27(15.2 \%)$ & .002 \\
\hline CVA & $354(4.2 \%)$ & $421(6.0 \%)$ & $58(8.3 \%)$ & $7(3.9 \%)$ & $<.0001$ \\
\hline Diabetes & $1730(20.4 \%)$ & $1459(20.7 \%)$ & $155(22.1 \%)$ & $36(20.2 \%)$ & .760 \\
\hline $\begin{array}{l}\text { Prior cardiac } \\
\text { surgery }\end{array}$ & $402(4.8 \%)$ & $574(8.2 \%)$ & $123(17.5 \%)$ & $44(24.7 \%)$ & $<.0001$ \\
\hline LVEF<35\% & $223(2.6 \%)$ & $380(5.4 \%)$ & $63(9.0 \%)$ & $22(12.4 \%)$ & $<.0001$ \\
\hline $\mathrm{HB}, \mathrm{mmol} / \mathrm{L}$ & $8.6 \pm 0.9$ & $8.4 \pm 1.0$ & $8.1 \pm 1.1$ & $8.0 \pm 1.2$ & $<.0001$ \\
\hline $\begin{array}{l}\text { Serum } \\
\text { creatinine, } \\
\text { umol/L }\end{array}$ & $96.2 \pm 31.2$ & $107.4 \pm 64.1$ & $111.4 \pm 56.5$ & $100.6 \pm 48.8$ & $<.0001$ \\
\hline $\begin{array}{l}\text { Logistic } \\
\text { EuroSCORE }\end{array}$ & $4.6 \pm 5.4$ & $7.7 \pm 9.7$ & $16.5 \pm 16.6$ & $23.8 \pm 22.9$ & $<.0001$ \\
\hline
\end{tabular}

Data are presented as frequency (\%) or mean \pm SD

COPD, chronic obstructive pulmonary disease; CVA, cerebro- vascular accident; HB, Hemoglobin; LVEF, left ventricular ejection fraction; PALL, peak arterial lactate level; $P V D$, peripheral vascular disease 
Table 2 shows the perioperative data of the 4 patients' groups.

TABle 2. Perioperative data

\begin{tabular}{|c|c|c|c|c|c|}
\hline PALL group & $\begin{array}{c}\text { Group } 1 \\
\text { Unknown } \\
n=8460\end{array}$ & $\begin{array}{c}\text { Group } 2 \\
\text { PALL < 5.0 } \\
\text { mmol/L } \\
n=7037\end{array}$ & $\begin{array}{c}\text { Group } 3 \\
\text { PALL=5-10 } \\
\text { mmol/L } \\
n=701\end{array}$ & $\begin{array}{c}\text { Group } 4 \\
\text { PALL >10 } \\
\text { mmol/L } \\
n=178\end{array}$ & $\mathrm{p}$-value \\
\hline $\begin{array}{c}\text { No. of valves } \\
\text { operated }\end{array}$ & & & & & \\
\hline 1 valve & $2214(26 \%)$ & 2238 (32\%) & $302(43 \%)$ & $68(38 \%)$ & \\
\hline 2 valve & $181(2.1 \%)$ & $473(6.7 \%)$ & $79(11 \%)$ & $19(1 \%)$ & \\
\hline 3 valve & $12(0.1 \%)$ & $40(0.6 \%)$ & $25(3.6 \%)$ & $3(1.7 \%)$ & $<.0001$ \\
\hline 4 valve & O & $1(0.0 \%)$ & o & 0 & \\
\hline AVR & $1748(21 \%)$ & $1719(24 \%)$ & $234(33 \%)$ & $58(33 \%)$ & $<.0001$ \\
\hline MVP & $446(5.3 \%)$ & $743(11 \%)$ & $105(15 \%)$ & $22(12 \%)$ & $<.0001$ \\
\hline MVR & $250(3.0 \%)$ & $434(6.2 \%)$ & $100(14.3 \%)$ & $14(7.9 \%)$ & $<.0001$ \\
\hline $\begin{array}{l}\text { Ascending } \\
\text { aorta } \\
\text { surgery }\end{array}$ & $204(2.4 \%)$ & $349(5.0 \%)$ & $112(16 \%)$ & $41(23 \%)$ & $<.0001$ \\
\hline $\begin{array}{c}\text { Cross-clamp } \\
\text { time (min) }\end{array}$ & $48 \pm 29$ & $57 \pm 41$ & $77 \pm 51$ & $86 \pm 62$ & $<.0001$ \\
\hline ECC duration & $69 \pm 43$ & $85 \pm 59$ & $133 \pm 84$ & $149 \pm 107$ & $<.0001$ \\
\hline Re-exploration & $275(3.3 \%)$ & $666(9.5 \%)$ & $178(26 \%)$ & $69(39 \%)$ & $<.0001$ \\
\hline $\begin{array}{l}\text { Perioperative } \\
\text { infarction }\end{array}$ & $133(1.6 \%)$ & $308(4.4 \%)$ & $56(8.0 \%)$ & $24(14 \%)$ & $<.0001$ \\
\hline
\end{tabular}

Data are presented as frequency (\%) or mean \pm SD.

AVR, aortic valve replacement; ECC, extracorporeal circulation; MVP, mitral valve repair; MVR, mitral valve replacement; PALL, peak arterial lactate level.

Overall mortality in the whole population included 651patients (4.0\%) for early mortality (table 3) and 2277 patients (14.5\%) for late mortality. Compared to the low PALL group, early mortality was increased in the intermediate- and high-PALL groups. Early mortality was $3.7 \%$ in the group with PALL $<5$ mmol/L (group2). In the patient group with PALL of 5-10 mmol/L (group 3), early mortality was $20.4 \%$ and in patients with PALL >10 mmol/L (group 4), early mortality was 62.9\% (table 3). 
TABLE 3. EARLY MORTALITY IN THE 4 GROUPS

\begin{tabular}{|l|c|c|c|c|c|c|}
\hline PALL group & $\begin{array}{c}\text { Group 1 } \\
\mathrm{n}=\mathbf{8 4 6 0}\end{array}$ & $\begin{array}{c}\text { Group 2 } \\
\mathrm{n}=\mathbf{7 0 3 7}\end{array}$ & $\begin{array}{c}\text { Group 3 } \\
\mathrm{n}=\mathbf{7 0 1}\end{array}$ & $\begin{array}{c}\text { Group 4 } \\
\mathrm{n}=178\end{array}$ & $\begin{array}{c}\text { Total } \\
\mathrm{n}=16376\end{array}$ & p-value \\
\hline $\begin{array}{c}\text { Early } \\
\text { mortality }\end{array}$ & $136(1.6 \%)$ & $260(3.7 \%)$ & $143(20.4 \%)$ & $112(62.9 \%)$ & $651(4.0 \%)$ & $<.0001$ \\
\hline
\end{tabular}

PALL, peak arterial lactate level

Risk factors identified for early mortality using logistic regression analysis are shown in table 4. Univariate analyses identified lactate level as well as female gender, poor left ventricular function, age, chronic obstructive pulmonary disease (COPD), PVD, diabetes, re-operation, preoperative $\mathrm{HB}$, serum creatinine and aortic cross clamp time as predictors for early mortality.

TABLE 4. LOGISTIC REGRESSION ANALYSIS FOR PREDICTORS OF EARLY MORTALITY

\begin{tabular}{|c|c|c|c|c|}
\hline \multirow[b]{2}{*}{ Risk factor } & \multicolumn{2}{|c|}{ Univariate analysis } & \multicolumn{2}{|c|}{ Multivariate analysis } \\
\hline & OR $(95 \% \mathrm{Cl})$ & $p$-value & OR $(95 \% \mathrm{Cl})$ & $p$-value \\
\hline PALL $^{*}$ & $1.44(1.40-1.49)$ & $<.001$ & $1.49(1.41-1.58)$ & $<.001$ \\
\hline Gender, female & $1.65(1.40-1.93)$ & $<.001$ & $1.09(0.79-1.50)$ & .616 \\
\hline LVEF $<35 \%$ & $3.54(2.77-4.53)$ & $<.001$ & $1.11(0.66-1.85)$ & .697 \\
\hline Age & $1.05(1.04-1.06)$ & $<.001$ & $1.06(1.04-1.08)$ & $<.001$ \\
\hline Hypertension & $0.87(0.74-1.01)$ & .073 & & \\
\hline COPD & $2.11(1.74-2.57)$ & $<.001$ & $2.14(1.50-3.06)$ & $<.001$ \\
\hline PVD & $1.42(1.16-1.75)$ & .001 & $0.89(0.60-1.32)$ & .559 \\
\hline CVA & $1.33(0.96-1.82)$ & .083 & & \\
\hline Diabetes & $1.29(1.07-1.54)$ & .006 & $1.60(1.14-2.24)$ & .007 \\
\hline Re-operation & $4.36(3.59-5.29)$ & $<.001$ & $1.73(1.19-2.51)$ & $<.004$ \\
\hline Hemoglobin & $0.48(0.45-0.53)$ & $<.001$ & 0.69 (0.60-0.81) & $<.001$ \\
\hline Serum creatinine & $1.01(1.00-1.01)$ & $<.001$ & $1.00(1.00-1.01)$ & $<.001$ \\
\hline Cross-clamp time & $1.02(1.01-1.02)$ & $<.001$ & 1.001 (0.999-1.003) & 3). 309 \\
\hline
\end{tabular}

* entered as a continuous variable.

COPD, chronic obstructive pulmonary disease; CVA, cerebro-vascular accident;

LVEF, left ventricular ejection fraction; PALL, peak arterial lactate level;

$P V D$, peripheral vascular disease

These factors were entered in the multivariate logistic regression analyses. In addition to lactate levels, age, COPD, diabetes, re-operation, preoperative HB and serum creatinine were determined to be independent risk factors for early mortality. 
This regression analysis was also performed using PALL as a categorical variable. Using group 2 as a reference group, PALL was also identified as a significant independent predictor for early mortality with an odds ratio of 6.680 (5.352-8.337) and 44.232 (31.851-61.427) for groups 3 and 4 respectively.

Univariate Cox regression identified PALL as a risk factor for late mortality (table 5). Other risk factors included gender, age, hypertension, COPD, PVD, status after CVA, diabetes, re-operation, preoperative $\mathrm{HB}$, serum creatinine, poor left ventricular function and aortic cross clamp time. Subsequent multivariate analyses revealed PALL as an independent risk factor for late mortality. In addition, age, COPD, PVD, diabetes, re-operation, preoperative $\mathrm{HB}$, serum creatinine and poor left ventricular function were independent risk factors for late mortality.

TABLE 5. COX REGRESSION ANALYSIS FOR PREDICTORS OF LATE MORTALITY

\begin{tabular}{|l|cccr|}
\hline \multirow{2}{*}{ Risk factor } & \multicolumn{3}{|c}{ Univariate analysis } & \multicolumn{2}{c}{ Multivariate analysis } \\
\cline { 2 - 5 } PALL* & HR $(95 \% \mathrm{CI})$ & p-value & HR $(95 \% \mathrm{CI})$ & p-value \\
Gender, male & $1.09(1.06-1.12)$ & $<.001$ & $1.05(1.01-1.10)$ & .025 \\
Age & $1.16(1.06-1.27)$ & $<.001$ & $1.07(0.89-1.28)$ & .466 \\
Hypertension & $1.07(1.06-1.07)$ & $<.001$ & $1.05(1.04-1.06)$ & $<.001$ \\
COPD & $1.16(1.07-1.26)$ & $<.001$ & $1.06(0.90-1.25)$ & .504 \\
PVD & $1.89(1.70-2.10)$ & $<.001$ & $1.64(1.34-2.00)$ & $<.001$ \\
CVA & $2.02(1.83-2.24)$ & $<.001$ & $1.55(1.28-1.89)$ & $<.001$ \\
Diabetes & $1.91(1.64-2.22)$ & $<.001$ & $1.23(0.91-1.66)$ & .181 \\
Re-operation & $1.63(1.48-1.78)$ & $<.001$ & $1.48((1.23-1.78)$ & $<.001$ \\
Hemoglobin & $1.79(1.57-2.05)$ & $<.001$ & $1.34(1.07-1.68)$ & .010 \\
Serum creatinine & $0.66(0.63-0.69)$ & $<.001$ & $0.80(0.74-0.87)$ & $<.001$ \\
LVEF<35\% & $1.004(1.003-1.004)<.001$ & $1.002(1.001-1.003)$ & $<.001$ \\
Cross-clamp time & $2.28(1.95-2.66)$ & $<.001$ & $1.48(1.15-1.91)$ & .003 \\
\hline
\end{tabular}

*entered as a continuous variable.

COPD, chronic obstructive pulmonary disease; CVA, cerebro-vascular accident;

HR, hazard ratio; LVEF, left ventricular ejection fraction; PALL, peak arterial lactate level;

PVD, peripheral vascular disease

Figure 1 shows predicted probability of early mortality according to PALL. In patients with a PALL of $>5 \mathrm{mmol} / \mathrm{L}$, the predicted probability for mortality increases rapidly to reach a level of almost $100 \%$ at a PALL of 25 mmol/L. 
FIGURE 1. PREDICTED PROBABILITY FOR EARLY MORTALITY ACCORDING TO POSTOPERATIVE PEAK LACTATE LEVELS

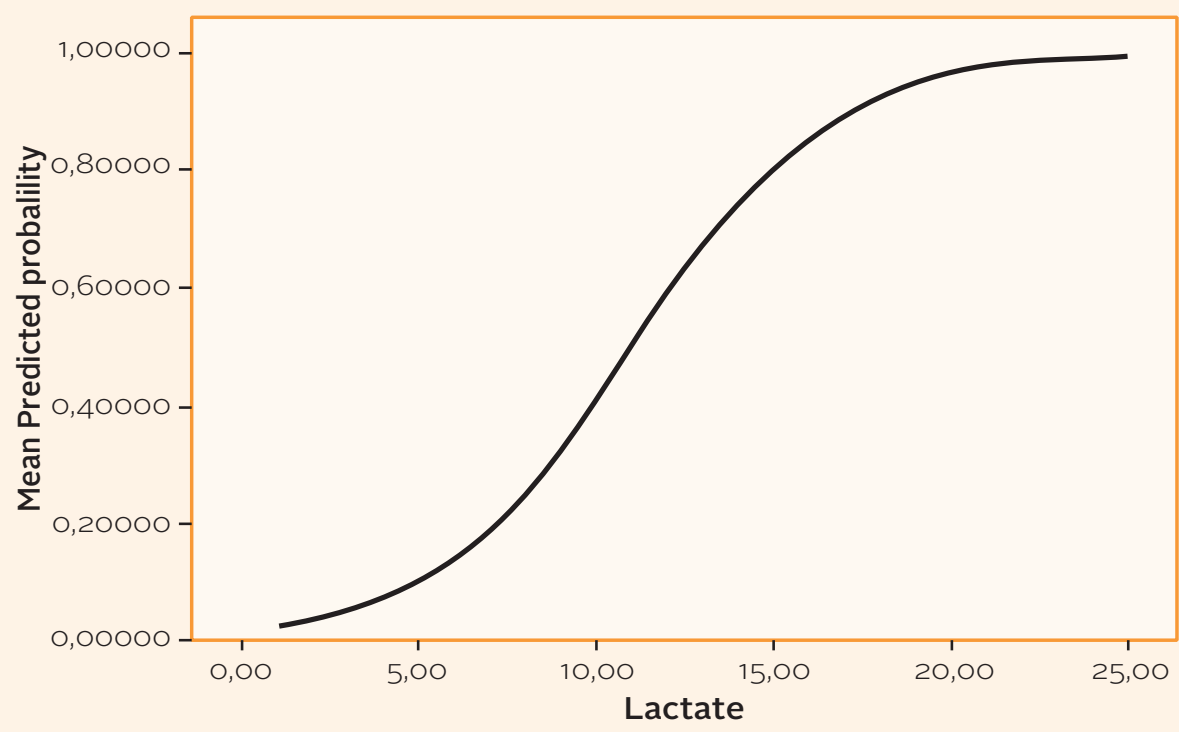

The Kaplan-Meier curves in figure 2 show patient survival stratified by postoperative peak lactate levels.

Figure 2. KAPLAN-MEIER CuRVES For the PATIENTS' GROUPS

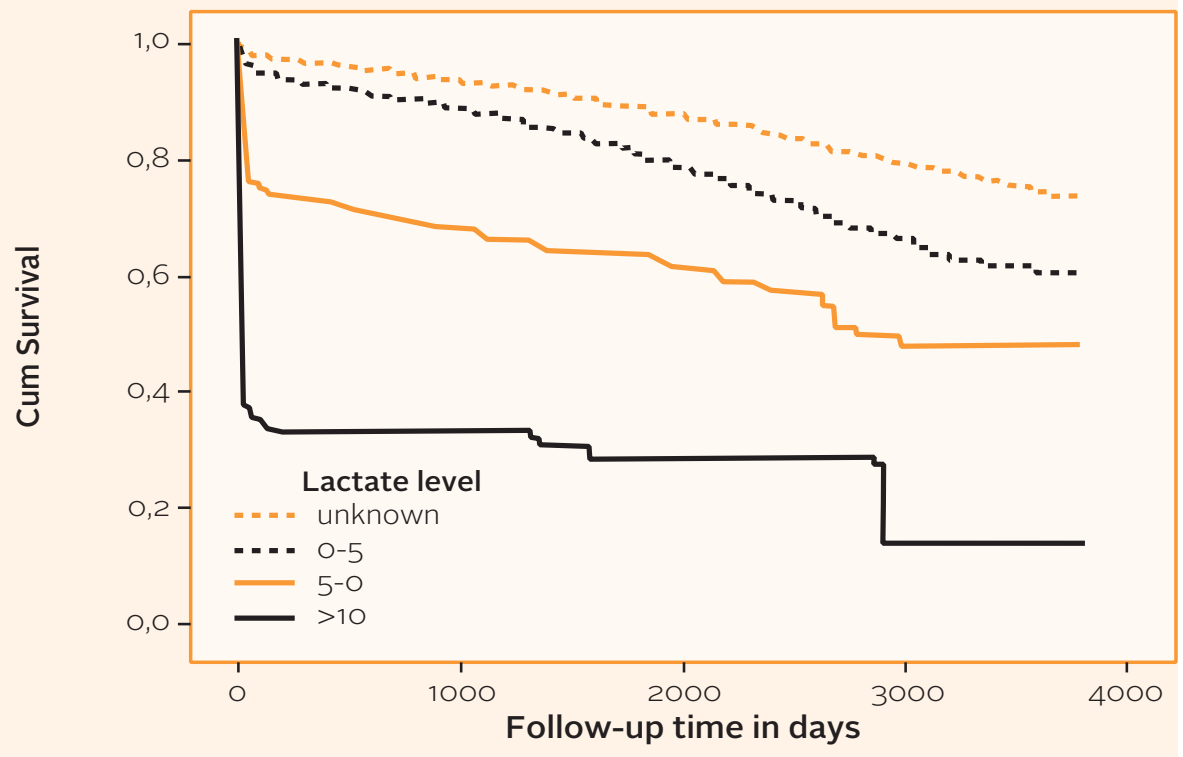


Patients at risk:

\begin{tabular}{|rrrrrr|}
\hline & 1 year & 3 years & 5 years & 7 years & 10 years \\
Group 1 & 8178 & 7701 & 5788 & 3299 & 212 \\
Group 2 & 5285 & 2591 & 1302 & 548 & 31 \\
Group 3 & 376 & 181 & 108 & 43 & 1 \\
Group 4 & 41 & 16 & 9 & 2 & 0 \\
\hline
\end{tabular}

Figure 3 shows the corrected survival curves for late survival in all the 4 lactate groups.

FIGURE 3. LATE SURVIVAL FUNCTION CURVES FOR THE PATIENTS' GROUPS, ADJUSTED TO ALL FACTORS INCLUDED IN THE MULTIVARIATE REGRESSION ANALYSIS

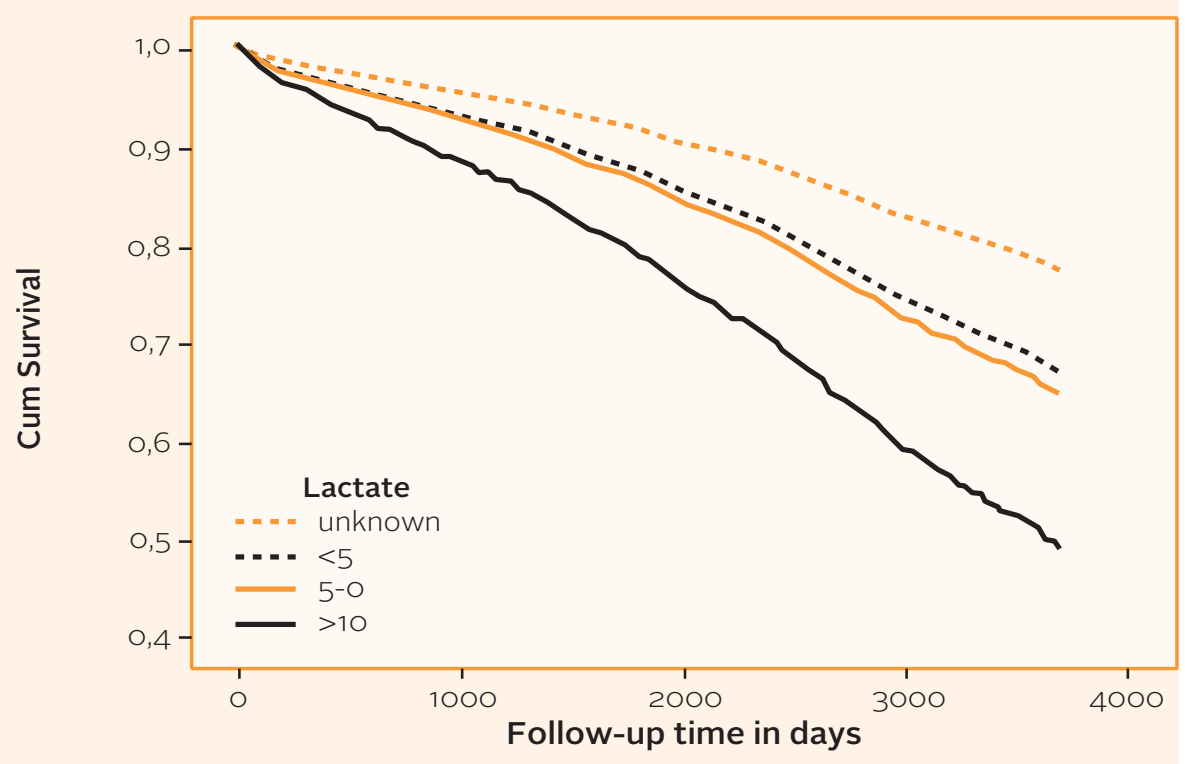

Figure 4 shows the receiver operating characteristic (ROC) curve of PALL as a predictor of mortality. The area under the curve (AUC) is 0.802 which indicates a good discriminatory power for PALL as outcome significant predictor of mortality. 
FigurE 4. RECEIVER OPERATING CHARACTERISTICS (ROC) CURVE FOR LACTATE AS A PREDICTOR OF MORTALITY

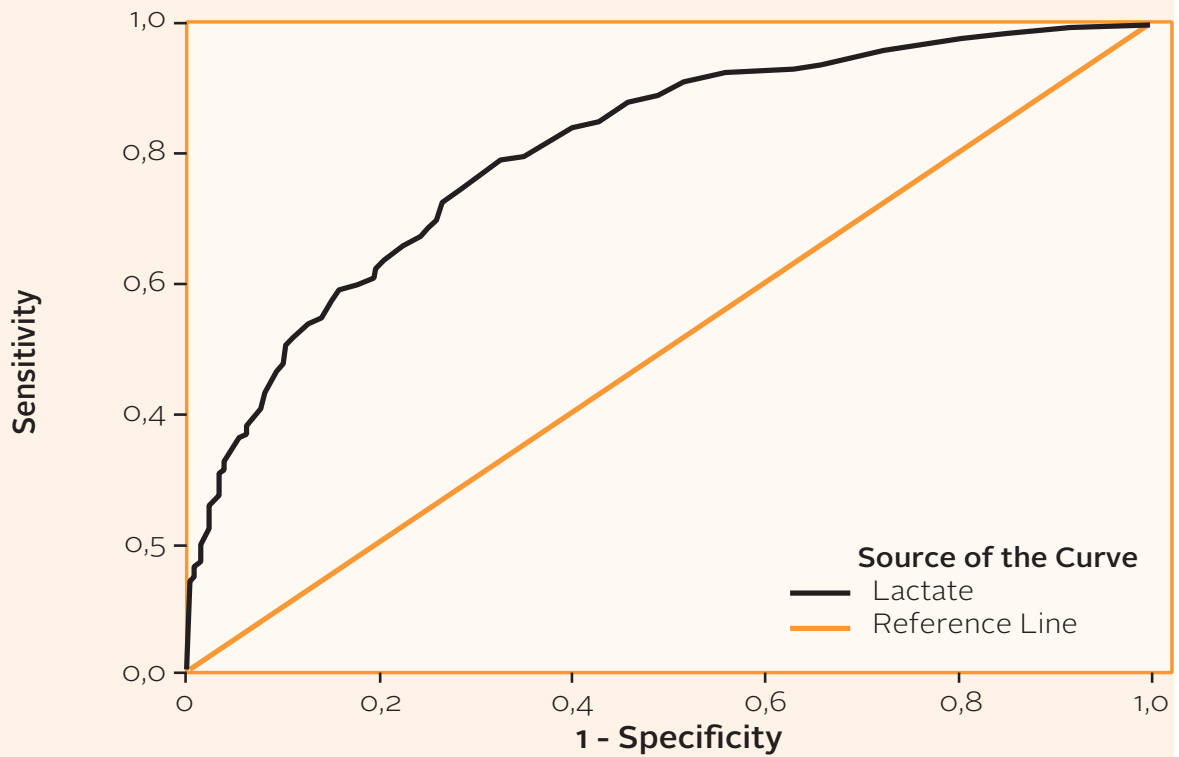

Diagonal segments are produced by ties.

\section{DISCUSSION}

The present study showed that the peak arterial lactate level (PALL) within the first three postoperative days predicted both early and late mortality after cardiac surgery. In our study population, postoperative peak arterial lactate levels above $5 \mathrm{mmol} / \mathrm{L}$ substantially increased the risk for mortality. Our results substantiate the importance of postoperative serial lactate measurements not only to monitor patients after cardiac surgery but to predict their prognosis as well.

While the exact mechanism cannot be delineated, the hyperlactatemia is probably a result of both higher production and lower clearance due to the pathological process during complicated cardiac surgery. This mechanism is eventually combined with the presence of renal or hepatic organ dysfunction. Elevated lactate level as a marker have been previously addressed in several patient categories, including cardiac surgical patients. In critically ill patients with sepsis or after trauma, the prognostic value of high lactate levels for unfavourable outcome and hospital mortality is generally acknowledged ${ }^{[12-16]}$. In addition, elevated lactate levels after successful resuscitation after cardiac arrest and ruptured abdominal aortic aneurysm repair associate with mortality $[17,18]$. 
Patients undergoing cardiac surgery should be analysed as a relatively different patient category which may be explained by the nature of cardiac surgical procedures using cardiopulmonary bypass ${ }^{[2,3]}$ and the resultant different mechanisms for lactate production. In these patients, the genesis and pathophysiology of hyperlactatemia is multifactorial $[1,4,7,11]$ and there is a distinction in early and late onset of high lactate levels depending on its origin. Perioperative lactate production in cardiac surgery patients which is associated with prolonged ICU stay and postoperative mortality is due to hepatosplanchnic region and other tissue ischemia ${ }^{[1,11]}$. Lactate elevation later than one day after cardiac surgery, measured over a longer period is a less wellunderstood $[1,11]$ and is probably associated with cardiac output and oxygen delivery. In the later phase after surgery, the prolonged use of catecholamines in hemodynamic instable patients and the occurrence of septic situations stimulates glycolysis which also may play a role in the source of lactate acidosis ${ }^{[19]}$. Delayed clearance of lactate because of non-ischemic hepatic and renal dysfunction may contribute in the cause of high lactate levels as well[7].

With regard to prediction of outcome, the predictive value of late onset hyperlactatemia after cardiac surgery is less well-studied[1, 2, 7, 11, and 19]. Several authors demonstrated a clear association between high arterial lactate concentration, as an indicator of global tissue hypoxia, and patient's outcome. Badreldin et al.[5] reported that arterial lactate measurement in the ICU is an accurate predictor of mortality after cardiac surgery at both individual as cohort level based on a study of 4.000 patients. Maillet et al.[6] identified a lactate threshold of $3 \mathrm{mmol} / \mathrm{l}$ as an indicator for morbidity and mortality risk after cardiac surgery. Hajjar et al. ${ }^{[9]}$ reported hyperlactatemia in the first hours of ICU admission to be an independent risk factor for worse outcome and 30-day all-cause mortality in 502 adult cardiac surgery patients.

O'Connor et al.[1] studied perioperative lactate abnormalities and identified hyperglycaemia, long cardiopulmonary bypass time and elevated endogenous catecholamines as risk factors for late onset hyperlactataemia which occurs 4 to 24 hours after completion of surgery. Although their data showed longer duration of ventilation and length of stay in the ICU in these patient, an increase of mortality was not demonstrated. On the other hand, most studies concerning increased lactate levels after cardiac surgery reported a significant correlation between lactate and outcome.[7, 8, 10, 11, 19-21]

Previous studies demonstrated that several factors contribute to the controversy and discussion on predictive value of increased lactate levels after cardiac surgery in the ICU[2, 3, 22, and 23]. A clear cut-off value for postoperative lactate levels has not been identified and may differ in different studies ${ }^{[24]}$. For cardiac surgical patients, values of 2.0 - $4.0 \mathrm{mmol} / \mathrm{L}$ have been reported for predicting major complications and early mortality [7, 8, 9, 10, and 25]. In our study population, we have arbitrarily chosen 
for a cut-off point of $5.0 \mathrm{mmol} / \mathrm{L}$ based on our daily practice. Our results showed that postoperative PALL above $5.0 \mathrm{mmol} / L$ substantially increased the risk for mortality that can reach almost 100\% when PALL is higher than $20.0 \mathrm{mmol} / \mathrm{L}$. The results of the receiver operating characteristic analysis with an AUC of 0.82 indicates a good discriminatory power of our method for predicting mortality.

Hajjar en colleagues[9] studied the impact of lactate levels on a longer time interval than immediately after the operation. They suggested to keep levels of arterial lactate below $3.0 \mathrm{mmol} / \mathrm{L}$ in the first 6 hours and below $2.0 \mathrm{mmol} / \mathrm{L}$ after 12 hours of admission to the ICU. Lactate levels above $3.0 \mathrm{mmol} / \mathrm{L}$ after 6 hours were independently associated with a 3.3 times higher risk of major complications, including death. Park and colleagues ${ }^{[26]}$ studied lactate as a monitor especially during and after initiation bypass and focussed on the 6-, 12- and 24 hour-measurements of blood lactate. They concluded that blood lactate can be a reliable tool for monitoring adequate tissue perfusion and is strongly predictive for mortality during and also shortly after extracorporeal circulation.

Besides the optimal cut-off value of lactate, there is also controversy about the optimal timing of serial measurement of lactate as a marker and predictor as well. Several studies have advocated that the use of serial lactate measurements over time may be clinically more reliable and relevant compared to single measurements[7,20].

In our opinion, multiple measurements are required, as our present analysis indicates the predictive value of peak lactate levels. Therefore, we suggest to monitor lactate during the following days after circulatory impairment in the ICU. Monitoring of peak arterial lactate concentration is crucial after decreased oxygen utilization at tissue level in the cardiac ICU patient. We decided to divide patients groups according to their peak arterial lactate value beyond the first 24 hours postoperatively and not only based on the dynamics of arterial lactate within 24 hours. Lopez-Delgado et al. ${ }^{[11]}$ studied 2935 patients after cardiac surgery and used the time of the peak level of arterial lactate as an independent variable. They concluded that 24-hour peak hyperlactatemia is a predictor of in hospital stay and late mortality after cardiac surgery. In our study, we have considered the postoperative PALL within 3 days postoperatively. In this way, additional hemodynamic events occurring in the ICU postoperatively are also taken into consideration.

We have also addressed a large group of patients who were managed using the fasttrack pathway ( $n=8460 ; 51.6 \%$ ). In these patients, arterial lactate was not measured postoperatively as they were transferred to the ward within 24 hours after surgery. This group is preoperatively highly selected for the fast-track protocol[27] ${ }^{[2}$ hich does not include postoperative lactate measurement. These patients had a relatively smooth postoperative course. The value of addressing this group in the present study is to elaborate the major impact of postoperative arterial lactate on the prognosis and outcome of the other 3 groups. 
The present study addresses the results of patients undergoing cardiac surgery over a relatively long duration (2004-2014). Improvement in surgical and anaesthetic techniques could have led to better outcome after cardiac surgery. In our institution, the fast-track management, the use of new cardiovascular medication and superior cardiopulmonary techniques, besides improvement of general cardio surgical approaches have taken place. These developments might have improved the outcome of our patients over the time.

The present study has some limitations. First, the retrospective nature of this observational study should be acknowledged. It is possible that we missed some preoperative or intraoperative factors that might have affected the results. The primary end point was all-cause mortality. We were not able to retrieve the cause of death which might be equally important. Finding out causes of postoperative hyperlactemia was not aim of this study and we did not distinguish intraoperative risk factors that could have prevented lactate rise either. The ROC curve did not include patients in group 1 due to unknown lactate levels. One would expect the sensitivity and specificity to be different from all comers to cardiac surgery.

\section{CONCLUSIONS}

In our group of 16376 patients, we identified postoperative peak arterial lactate level as an independent predictor of early and late mortality after cardiac surgery. In this study, we were able to depict a maximal postoperative blood lactate concentration of $5 \mathrm{mmol} / \mathrm{L}$ above which the risk of poor outcome is rapidly increasing. 
1. O'Connor E, Fraser JF. The interpretation of perioperative lactate abnormalities in patients undergoing cardiac surgery. Anaesth Intensive Care 2012;40:598-603

2. Takala J, Uusaro A, Parviainen I, Ruokonen E. Lactate metabolism and regional lactate exchange after cardiac surgery. New Horiz 1996;4:483-92

3. Landow L. Splanchnic lactate production in cardiac surgery patients. Crit Care Med 1993;21:S84-91

4. Joudi M, Fathi M, Soltani G, Izanloo A. Factors affecting on serum lactate after cardiac surgery. Anesth Pain Med 2014;4:e18514

5. Badreldin AM, Doerr F, Elsobky S et al. Mortality prediction after cardiac surgery: blood lactate is indispensable. Thorac Cardiovasc Surg 2013;61:708-17

6. Maillet JM, Le Besnerais P, Cantoni M et al. Frequency, risk factors, and outcome of hyperlactatemia after cardiac surgery. Chest 2003;123:1361-6

7. Attanà P, Lazzeri C, Picariello C, Dini CS, Gensini GF, Valente S. Lactate and lactate clearance in acute cardiac care patients. Eur Heart J Acute Cardiovasc Care 2012;1:115-21

8. Hu BY, Laine GA, Wang S, Solis RT. Combined central venous oxygen saturation and lactate as markers of occult hypoperfusion and outcome following cardiac surgery. J Cardiothorac Vasc Anesth 2012;26:52-7

9. Hajjar LA, Almeida JP, Fukushima JT et al. High lactate levels are predictors of major complications after cardiac surgery. J Thorac Cardiovasc Surg 2013;146:455-60

10. Laine GA, Hu BY, Wang S, Solis TR, Reul GJ Jr. Isolated high lactate or low central venous oxygen saturation after cardiac surgery and association with outcome. J Cardiothorac Vasc Anesth 2013;27:1271-6

11. Lopez-Delgado JC, Esteve F, Javierre C et al. Evaluation of serial arterial lactate levels as a predictor of hospital and long-term mortality in patients after cardiac surgery. J Cardiothorac Vasc Anesth 2015;29:1441-53

12. Nichol AD, Egi M, Pettila $\vee$ et al. Relative hyperlactatemia and hospital mortality in critically ill patients: a retrospective multi-center study. Crit Care 2010;14:R25

13. Zhang Z, Xu X. Lactate clearance as a useful biomarker for the prediction of all-cause mortality in critically ill patients: a systematic review and meta-analysis. Crit Care Med 2014;42:2118-25

14. Callaway DW, Shapiro NI, Donnino MW, Baker C, Rosen CL. Serum lactate and base deficit as predictors of mortality in normotensive elderly blunt trauma patients. J Trauma 2009;66:1040-4

15. Husain FA, Martin MJ, Mullenix PS, Steele SR, Elliott DC. Serum lactate and base deficit as predictors of mortality and morbidity. Am J Surg 2003;185:485-91

16. Khosravani H, Shahpori R, Stelfox HT, Kirkpatrick AW, Laupland KB. Occurrence and adverse effect on outcome of hyperlactatemia in the critically ill. Crit Care 2009;13:R9o 
17. Kliegel A, Losert H, Sterz F et al. Serial lactate determinations for prediction of outcome after cardiac arrest. Medicine 2004;83:274-9

18. Singhal R, Coghill JE, Guy A, Bradbury AW, Adam DJ, Scriven JM. Serum lactate and base deficit as predictors of mortality after ruptured abdominal aortic aneurysm repair. Eur J Vasc Endovasc Surg 2005;30:263-6

19. Lazzeri C, Valente S, Chiostri M, Gensini GF. Clinical significance of lactate in acute cardiac patients. World J Cardio 2015;7:483-9

20. Jabbari A, Banihashem N, Alijanpour E, Vafaey HR, Alereza H, Rabiee SM. Serum lactate as a prognostic factor in coronary artery bypass graft operation by on pump method. Caspian J Intern Med 2013;4:662-6

21. Toraman F, Evrenkaya S, Yuce M et al. Lactic acidosis after cardiac surgery is associated with adverse outcome. Heart Surg Forum 2004;7:E155-9

22. Inoue S, Kuro M, Furuya H. What factors are associated with hyperlactatemia after cardiac surgery characterized by well-maintained oxygen delivery and a normal postoperative course? A retrospective study. Eur J Anaesthesiol 2001;18:576-84

23. Kapoor P, Mandal B, Chowdhury U, Singh S, Kiran U. Changes in myocardial lactate, pyruvate and lactate-pyruvate ratio during cardiopulmonary bypass for elective adult cardiac surgery: Early indicator of morbidity. J Anaesthesiol Clin Pharmacol 2011;27:225-32

24. Svenmarker S, Häggmark S, Ostman M. What is a normal lactate level during cardiopulmonary bypass? Scand Cardiovasc J 2006;40:305-11

25. Demers P, Elkouri S, Martineau R, Couturier A, Cartier A. Outcome with high blood lactate levels during cardiopulmonary bypass in adult cardiac operation. Ann Thorac Surg 2000;70:2082-6

26. Park SJ, Kim SP, Kim JB, et al. Blood lactate level during extracorporeal life support as a surrogate marker for survival. J Thorac Cardiovasc Surg 2014;148:714-20

27. Haanschoten MC, van Straten AH, ter Woorst JF et al. Fast-track practice in cardiac surgery: results and predictors of outcome. Interact Cardiovasc Thorac Surg 2012;15:989-94 



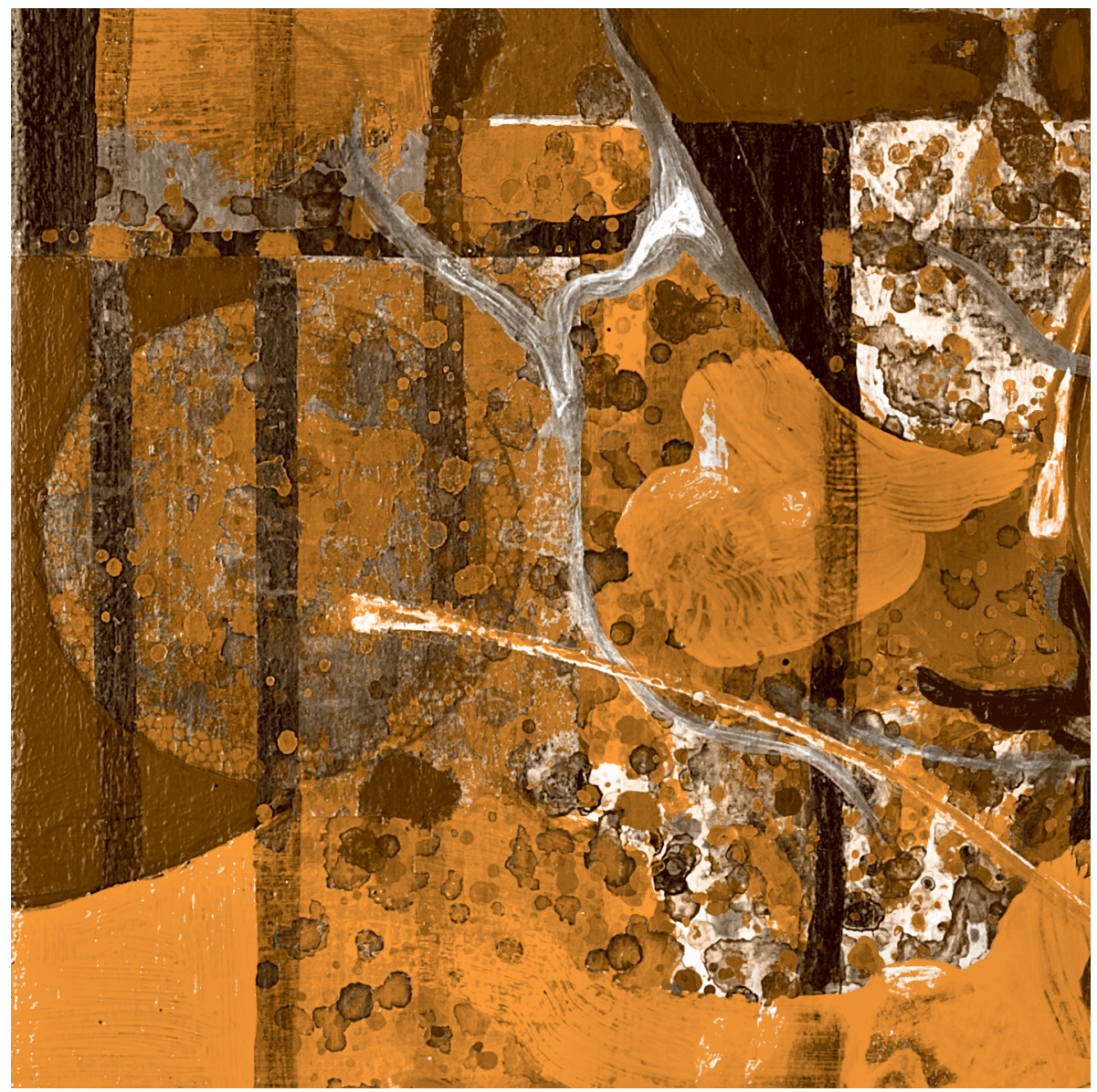

Total Cholesterol levels as a predictor of early outcome after cardiac surgery 



\section{TOTAL CHOLESTEROL LEVELS AS}

\section{A PREDICTOR OF EARLY OUTCOME}

\section{AFTER CARDIAC SURGERY}

Herman G. Kreeftenberg[1], Marco C Haanschoten[1], Mohamed A Soliman Hamad[2], Alexander JGH Bindels[1], Arnout N Roos ${ }^{[1]}$, Albert HM van Straten[2].

1. Dept of Intensive Care Medicine Catharina Hospital Eindhoven, The Netherlands

2. Dept of Cardio-Thoracic Surgery Catharina Hospital Eindhoven, The Netherlands

Keywords: Cholesterol, Cardio Thoracic surgery, risk factor, short-term mortality. 


\section{Introduction}

The postoperative course of patients undergoing cardiac surgery is often complicated when they have a lot of comorbidities. For a better understanding of the risk of the operation, several scoring systems have been developed ${ }^{11,2]}$. Unfortunately, not all scoring systems are sufficient. Arguably, preoperative risk stratification by the EuroSCORE can be improved. In addition to the EuroSCORE, more parameters are needed to evaluate patients who show a postoperative complicated course irrespective of their EuroSCORE. These are often patients who get an operative complication such as ischemia or infarction, or postoperative complications like infection or respiratory failure. The prognosis of these patients can not only be predicted by analysis of the patient-related factors (EuroSCORE). Finding specific markers that can daily guide the evaluation and management of the patient during the ICU stay could be of great value. Serum cholesterol levels in critically ill patients are correlated with the severity of illness especially in cases of sepsis[3]. Recently, the serum lipid profile, including cholesterol, has been correlated with the clinical outcome in severe sepsis[4]. In cardiac surgery patients, serum cholesterol levels within the postoperative 4-7 days have been described as prognostic factor after cardiac surgery[5]. It has also been suggested that lower cholesterol levels before cardiac surgery are associated with an increased risk

of sepsis and were an independent predictor of the outcome ${ }^{[6]}$. The latter statement raises the question whether cholesterol is a specific marker for sepsis or if it is a marker for the general condition of the patient.

Since 2009, our database included daily postoperative cholesterol levels of patients undergoing cardiac surgery. In this retrospective analysis, we sought to investigate whether postoperative cholesterol level is an independent prognostic risk factor for the outcome after cardiac surgery.

\section{PATIENTS AND METHODS}

\section{Patients}

Between January 2009 and December 2014, we performed 6072 cardiac operations in our institution. In 3860 of these operations, patients were managed using the fasttrack pathway in which the patients were discharged from the ICU on the same day of the operation. In patients who stayed longer in the ICU, daily cholesterol levels were measured until discharge to the cardiothoracic surgery ward. The lowest cholesterol level during the first 5 days postoperatively or until discharge from the ICU was collected from the database of the cardiothoracic surgery department. The primary endpoint of the study was all-cause mortality within 30 days (early mortality). The late mortality was defined as the mortality after 30 days and was also calculated as a secondary endpoint. 
The medical ethical institutional board approved the study and waived the need for an informed consent.

\section{Operative techniques}

All patients received short-acting anesthetic drugs to facilitate early extubation. Extra-corporal circulation (ECC) was performed using normothermic non-pulsatile flow. Cold crystalloid cardioplegia ("St Thomas" solution) or warm blood cardioplegia was used to induce and maintain cardiac arrest, according to the surgeons' preference.

\section{Postoperative cholesterol levels}

Postoperative cholesterol levels during the stay on the ICU until day 5 were retrieved from the laboratory databank into our database. From these obtained cholesterol levels, the minimal level during their stay was determined for each patient. Patients were classified according to these minimal cholesterol levels into the following groups: group 1 which included patients with cholesterol levels of $<1.8 \mathrm{mmol} / \mathrm{l}$, group 2 including patients with cholesterol levels of $1.8-2.3 \mathrm{mmol} / \mathrm{l}$, group 3 with cholesterol levels of $\geq 2.3 \mathrm{mmol} / \mathrm{l}$. The fourth group (group 4 ) included the fast-track patients who were discharged from the ICU to the ward on the same day of the operation. Because the standard care on the ward did not dictate the collection of cholesterol levels, these parameters could not be included. The cut-off values for groups 1, 2 and 3 were chosen arbitrarily to investigate which level of cholesterol could be correlated with prognosis.

\section{Intensive care unit}

The Catharina Hospital in Eindhoven has a 35 bed tertiary intensive care unit. About 40\% of our patients are primary cardiothoracic surgical patients.

\section{Statistical analysis}

Discrete variables were compared with the Chi-square test and are presented as numbers and percentages. Continuous variables were compared with analysis of variance and t test and are presented as means \pm standard deviations. Univariate and multivariate logistic regression analyses and Cox proportional hazard regression analyses were performed to investigate the impact of biomedical variables on mortality within 30 days (early mortality) and late mortality respectively. Univariate analyses were used to test for the potentially confounding effect of biomedical and demographic factors on outcome. If significant at $p<.05$, confounders were included into the multivariable regressions analyses. The cumulative incidence of death in cholesterol groups was estimated according to the Kaplan-Meier method, comparing differences between groups with the log-rank test. The zero time point indicates the time of CABG. A p-value <.05 was used for all test to indicate statistical significance. Odds ratios (OR) with 95\% confidence intervals $(\mathrm{CI})$ are reported. All statistical analyses were performed using SPSS Software (Statistical Product and Service Solutions, version 19, SPSS Inc, Chicago, IL, USA). 


\section{RESULTS}

Between 2009 and 2014, 6072 patients underwent cardiac surgery in our centre. Demographic and clinical data stratified by cholesterol groups are listed in table 1. Patients with lower cholesterol levels were more often males, had more often a re-exploration, had more often a decreased left ventricular ejection fraction (EF) and had more often a prior cerebro-vascular incident (CVA).

TABle 1: DemographiC AND CLINICAL DATA STRATIFIEd By CHOLESTEROL LEVEL

\begin{tabular}{|c|c|c|c|c|c|}
\hline Demographics & $\begin{array}{c}\text { Group } 1 \\
\text { Cholesterol } \\
\text { 0-1.8 mmol/l } \\
(n=150)\end{array}$ & $\begin{array}{c}\text { Group } 2 \\
\text { Cholesterol } \\
1.8-2.3 \mathrm{mmol} / \mathrm{l} \\
(\mathrm{n}=450)\end{array}$ & $\begin{array}{c}\text { Group } 3 \\
\text { Cholesterol } \\
>2.3 \mathrm{mmol} / \mathrm{l} \\
(\mathrm{n}=1612)\end{array}$ & $\begin{array}{c}\text { Group } 4 \\
\text { Cholesterol } \\
\text { unknown } \\
(n=3860)\end{array}$ & $P$ \\
\hline Age, years & $71.1 \pm 8.9$ & $69.9 \pm 9.9$ & $67.1 \pm 10.9$ & $66.3 \pm 10.1$ & $<.0001$ \\
\hline Male sex & $104(69.3 \%)$ & $308(68.4 \%)$ & $1012(62.8 \%)$ & $2897(75.1 \%)$ & $<.0001$ \\
\hline Hypertension & $83(55.3 \%)$ & $269(59.8 \%)$ & $859(53.3 \%)$ & $2137(55.4 \%)$ & .101 \\
\hline COPD & $14(9.3 \%)$ & $45(10 \%)$ & $187(11.6 \%)$ & $361(9.4 \%)$ & .091 \\
\hline PVD & $27(18 \%)$ & $72(16 \%)$ & $223(13.8 \%)$ & $480(12.4 \%)$ & .035 \\
\hline $\begin{array}{l}\text { Preop. } \\
\text { Creatinine }\end{array}$ & $137.9 \pm 176.1$ & $113.6 \pm 79.3$ & $109.4 \pm 96.2$ & $96.4 \pm 45.4$ & $<.0001$ \\
\hline Preop. Hb & $8.6 \pm 1.1$ & $8.6 \pm 1.0$ & $8.8 \pm 1.0$ & $8.9 \pm 0.8$ & $<.0001$ \\
\hline CVA & $5(3.3 \%)$ & $42(9.3 \%)$ & $88(5.5 \%)$ & $205(5.3 \%)$ & .003 \\
\hline $\begin{array}{l}\text { Prior cardiac } \\
\text { surgery }\end{array}$ & $22(14.7 \%)$ & $48(10.7 \%)$ & $177(11.0 \%)$ & $131(3.4 \%)$ & $<.0001$ \\
\hline $\begin{array}{l}\text { CPB time, } \\
\min \end{array}$ & $104.8 \pm 63.4$ & $100.8 \pm 65.0$ & $105.0 \pm 80.0$ & $68.5 \pm 45.6$ & $<.0001$ \\
\hline $\begin{array}{l}\text { X-clamp } \\
\text { timet, min }\end{array}$ & $67.8 \pm 43.2$ & $64.6 \pm 43.5$ & $67.1 \pm 43.8$ & $47.2 \pm 31.4$ & $<.0001$ \\
\hline $\begin{array}{l}\text { Re-explo- } \\
\text { ration }\end{array}$ & $22(14.7 \%)$ & $48(10.7 \%)$ & $177(11 \%)$ & $131(3.4 \%)$ & $<.0001$ \\
\hline$E F<35 \%$ & $9(6.0 \%)$ & $42(9.3 \%)$ & $107(6.6 \%)$ & $81(2.1 \%)$ & $<.0001$ \\
\hline $\begin{array}{l}\text { Log. } \\
\text { EurosCORE }\end{array}$ & $15.1 \pm 15.9$ & $11.8 \pm 13.3$ & $10.9 \pm 12.2$ & $4.8 \pm 6.4$ & $<.0001$ \\
\hline
\end{tabular}

Data are expressed as $n(\%)$ of patient or mean \pm SD

COPD = chronic obstructive pulmonary disease, CVA = cerebro-vascular accident;

$\mathrm{Hb}=$ hemoglobin; $\mathrm{PVD}=$ Peripheral vascular disease; $\mathrm{X}$-clamp time= cross-clamp time.

$\mathrm{EF}=$ left ventricular ejection fraction; $\mathrm{CPB}=$ cardiopulmonary bypass 
Figure 1 shows the distribution of the postoperative minimal Cholesterol level in the whole population. The median value was $2.64 \mathrm{mmol} / \mathrm{L}$; and the mean was $2.79 \pm 0.79 \mathrm{mmol} / \mathrm{L}$.

FIGURE 1: DISTRIBUtion OF THE POSTOPERATIVE MINIMAL CHOLESTEROL LEVEL IN THE WHOLE POPULATION

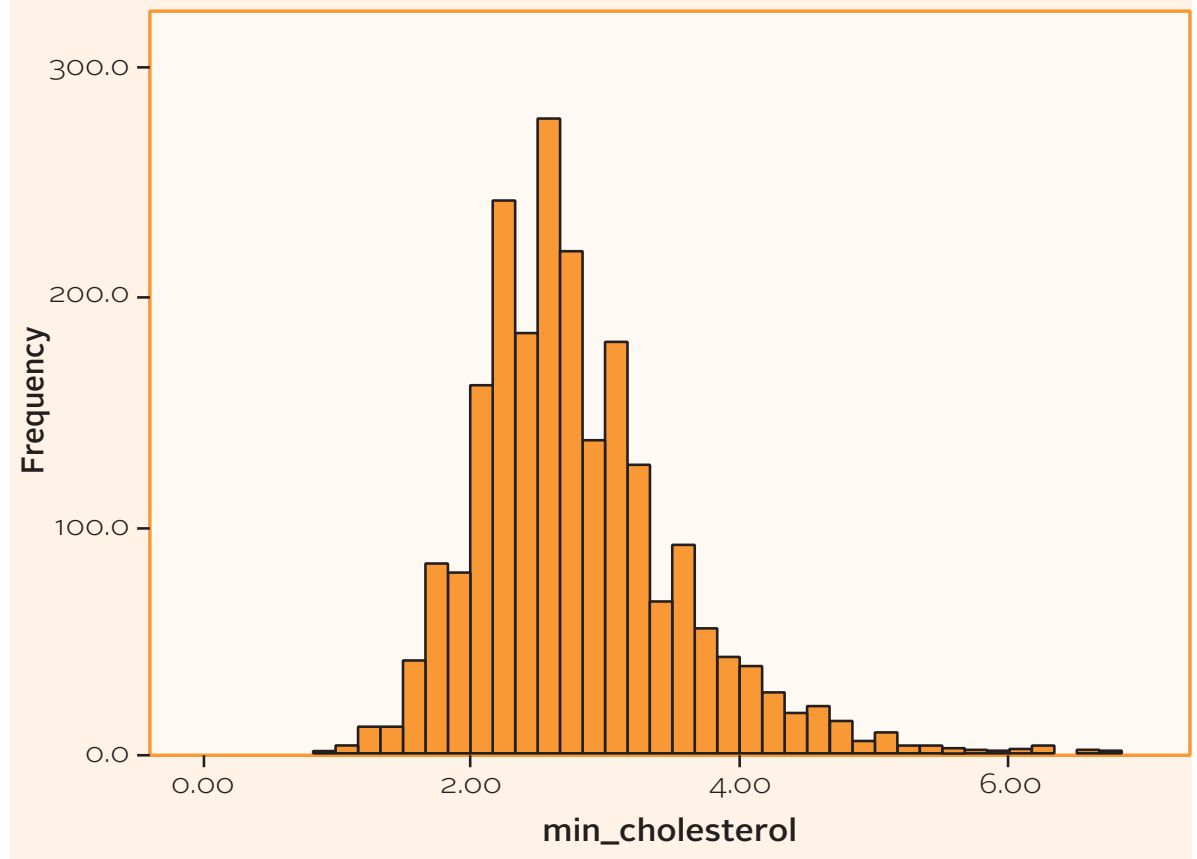

Early mortality rates stratified by cholesterol groups are shown in table 2. Early mortality rates increased significantly with the decrease in the minimal postoperative cholesterol level.

TABLE 2: EARLY MORTALITY STRATIFIED BY CHOLESTEROL GROUPS

\begin{tabular}{|c|c|c|c|c|c|}
\hline & $\begin{array}{c}\text { Group } 1 \\
\text { Cholesterol } \\
\text { 0-1.8 mmol/I } \\
(n=150)\end{array}$ & $\begin{array}{c}\text { Group } 2 \\
\text { Cholesterol } \\
1.8-2.3 \mathrm{mmol} / \mathrm{I} \\
(\mathrm{n}=450)\end{array}$ & $\begin{array}{c}\text { Group } 3 \\
\text { Cholesterol } \\
>2.3 \mathrm{mmol} / \mathrm{l} \\
(\mathrm{n}=1612)\end{array}$ & $\begin{array}{c}\text { Group } 4 \\
\text { Cholesterol } \\
\text { unknown } \\
(n=3860)\end{array}$ & $P$ \\
\hline $\begin{array}{l}\text { Early } \\
\text { mortality }\end{array}$ & $36(24 \%)$ & $41(9.1 \%)$ & 79 (4.9\%) & $68(1.8 \%)$ & $<.0001$ \\
\hline
\end{tabular}


Univariate logistic regression analyses revealed postoperative cholesterol level both as continuous variable and as a dichotomous variable (groups 1 and 2 compared to group 3) as a risk factor for early mortality (table 3). Other patient-related risk factors that were identified include: EF < 35\%, age, preoperative haemoglobin (HB), reoperation, peripheral vascular disease (PVD), creatinine clearance, male gender and Logistic EuroSCORE. On the other hand, CVA, hypertension and chronic obstructive pulmonary disease (COPD) were not identified as risk factors for early mortality.

TABLE 3: PREDICTORS OF EARLY MORTALITY, UNIVARIATE AND MULTIVARIATE

\begin{tabular}{|l|llll|}
\hline \multirow{2}{*}{ Risk factor } & \multicolumn{3}{|c}{ Univariate analysis } & \multicolumn{2}{c|}{ Multivariate analysis } \\
\cline { 2 - 5 } Total Cholesterol & OR $(95 \% \mathrm{Cl})$ & p-value & OR $(95 \% \mathrm{Cl})$ & p-value \\
Group $1^{* *}$ & $0.365(.275-.485)$ & $<.001$ & $0.337(.236-.482)$ & $<.001$ \\
Group $2^{* *}$ & & & $6.134(3.928-10.371)$ & $<.001$ \\
EF<35\% & & & $1.961(1.219-3.154)$ & .005 \\
Age & $3.817(2.510-5.804)$ & $<.001$ & $1.880(.967-3.656)$ & .063 \\
Preop Hb & $1.037(1.022-1.053)$ & $<.001$ & $1.047(1.021-1.073)$ & $<.001$ \\
X-clamp time & $0.725(.617-.854)$ & $<.001$ & $0.842(.690-1.027)$ & .09 \\
Re-operation & $1.008(1.004-1.012)$ & .002 & $1.007(1.003-1.011)$ & .002 \\
CVA & $4.426(3.150-6.129)$ & $<.001$ & $3.686(2.307-5.889)$ & $<.001$ \\
Cr.Cl & $1.405(.846-2.333)$ & .189 & $0.801(.391-1.640)$ & .544 \\
Sex & $1.003(1.002-1.004)$ & $<.001$ & $1.002(1.000-1.003)$ & .008 \\
PVD & $0.706(.534-.932)$ & .014 & $0.749(.491-1.143)$ & .181 \\
Hypertension & $1.691(1.209-2.365)$ & .002 & $0.990(.586-1.672)$ & .970 \\
COPD & $0.733(.801-1.371)$ & .733 & & \\
Log. EurosCORE & $1.356(.909-2.022)$ & .135 & & \\
\hline
\end{tabular}

COPD, chronic obstructive pulmonary disease; $\mathrm{PVD}=$ peripheral vascular disease;

CVA, cerebral vascular accident; $\mathrm{Hb}$, hemoglobine concentration; $\mathrm{Cr} \mathrm{Cl}$, creatinine blood concentration clearance.

*Entered as a continuous variable

${ }^{* *}$ Compared to Group 3

All risk factors that were identified with univariate logistic regression analysis were entered into the multivariate logistic regression model. Minimal cholesterol level as a continuous variable did prove to be an independent risk factor for early mortality. Other independent risk factors were: Age, duration of aortic occlusion, reoperation, and preoperative creatinine clearance.

When cholesterol level was entered in a multivariate model as dichotomous parameter using the same variables, it was also identified as an independent risk factor for early mortality. 
Univariate analysis of the effect of a low postoperative cholesterol on late mortality showed no significance. The other factors which did reach significance for late mortality in the univariate analysis are also shown in table 4.

TABLE 4: PREDICTORS OF LATE MORTALITY BY UNIVARIATE ANALYSIS

\begin{tabular}{|l|cc|}
\hline \multirow{2}{*}{ Risk factor } & Univariate & \\
\cline { 2 - 3 } Cholesterol & HR (95\% CI) & p-value \\
Sex, Male & $0.826(0.677-1.007)$ & .059 \\
Age & $1.16(1.06-1.27)$ & .001 \\
Hypertension & $1.07(1.06-1.07)$ & $<.001$ \\
COPD & $1.16(1.07-1.26)$ & .001 \\
PVD & $1.89(1.70-2.10)$ & $<.001$ \\
Status after CVA & $2.02(1.83-2.24)$ & $<.001$ \\
Diabetes & $1.91(1.64-2.22)$ & $<.001$ \\
Lactate & $1.63(1.48-1.78)$ & $<.001$ \\
Re-operation & $1.09(1.06-1.12)$ & $<.001$ \\
Preop. Hb & $1.79(1.57-2.05)$ & $<.001$ \\
Preop. Creat & $0.66(0.63-0.69)$ & $<.001$ \\
ED<35\% & $1.004(1.003-1.004)$ & $<.001$ \\
X-clamp time & $2.28(1.95-2.66)$ & $<.001$ \\
\hline
\end{tabular}

COPD, chronic obstructive pulmonary disease; PVD, peripheral vascular disease; CVA, cerebral vascular accident; $\mathrm{Hb}$, hemoglobine concentration; Creat, creatinine blood concentration.

Survival according to the Kaplan-Meier method stratified by cholesterol is plotted in figure 2. 
Figure 2: SURVIVAL STRATIFIED BY CHOLESTEROL GROUPS (KAPLAN-MEIER)

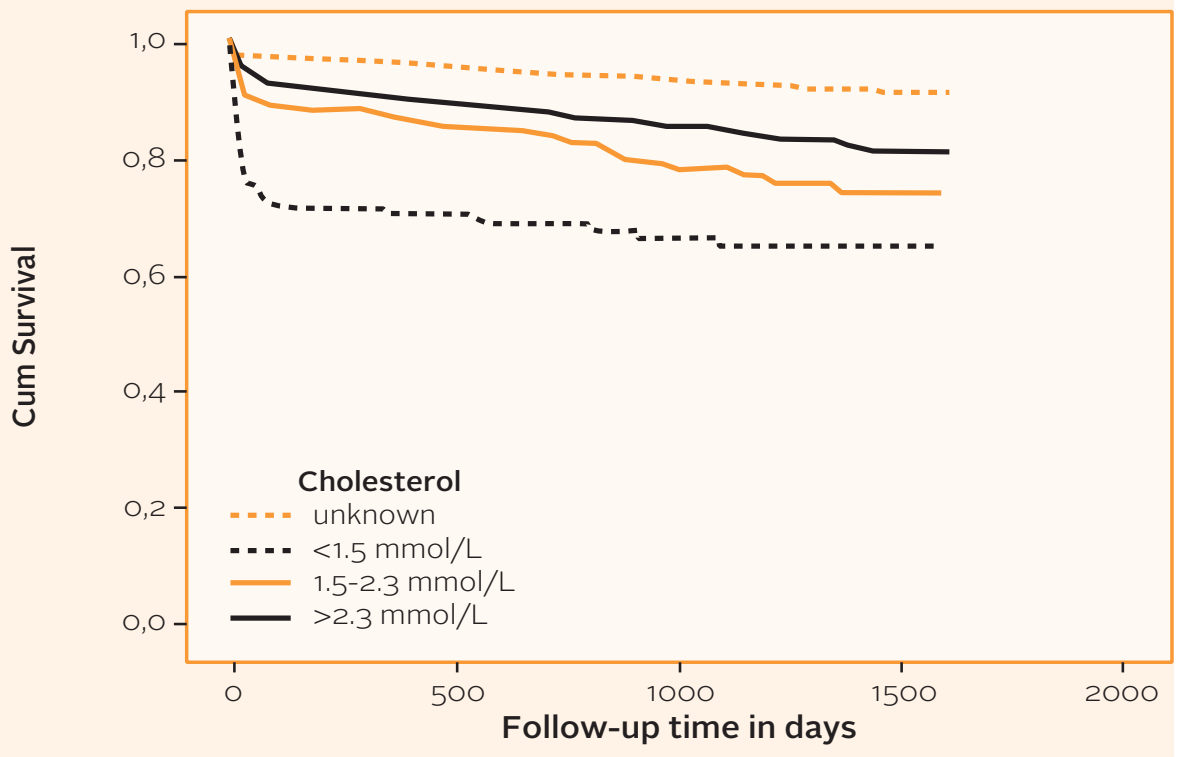

Figure 3 shows the predicted probability of early mortality according to the mean minimal postoperative cholesterol level a cut-off point of $2 \mathrm{mmol} / \mathrm{L}$ indicates a poor prognosis.

FIGURE 3: PREDICTED PROBABILITY OF EARLY MORTALITY ACCORDING TO MINIMAL POSTOPERATIVE CHOLESTEROL LEVEL

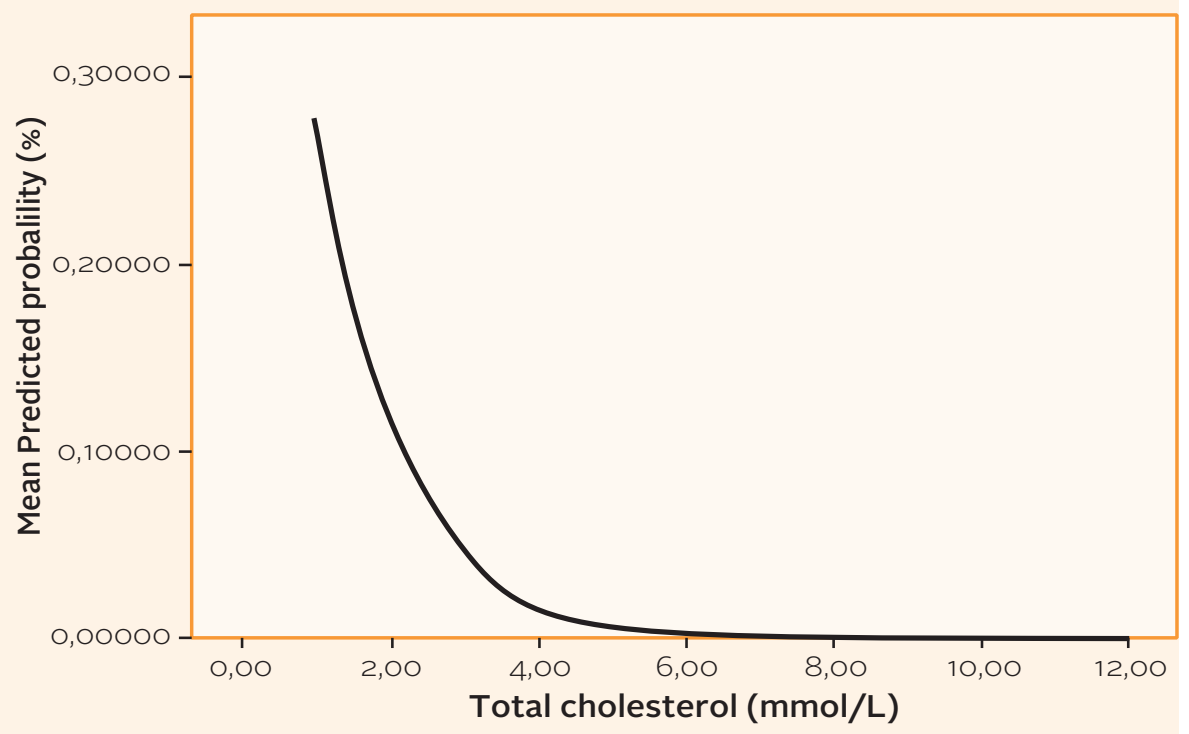


This study showed that postoperative cholesterol level is an independent risk factor for early mortality after cardiac surgery. We have performed a multivariate regression analysis to exclude the impact of other confounding factors like comorbidities and postoperative complications on the incidence of mortality. Other factors which have comparable odds ratios in early mortality are re-operation and a low preoperative EF. In contrast to early mortality, cholesterol has no prognostic value in late mortality. This is also shown in the Kaplan-Meier curves (fig 2). In these graphs, the initial developing difference between the groups in mortality does not change significantly beyond 30 days.

The contrast between being an independent risk factor in early mortality and having no prognostic value in late mortality requires interpretation.

The sort duration of the correlation with mortality seems to identify cholesterol as a prognostic parameter during ICU stay which can be used to assess the burden of the operation on the body organs. This burden manifests itself via the systemic inflammatory processes initiated by the body. These processes in turn depend on the extent of the operation as well as the individual systemic inflammatory response of the patients (SIRS). This SIRS has been known to differ significantly between individuals[7]. When the initial response to the operation has been overcome, the non-significant correlation with late mortality suggests that the changes for survival equalize and the real benefit of an operation can be established

In earlier studies[5], low levels of cholesterol have been described as a prognostic indicator for poor outcome after cardiac surgery. In a case control study, it has been shown that the serum cholesterol levels between day 4 and day 7 postoperatively have a significant correlation with mortality[5]. In the same study, 75\% of the deceased patients died within 12 days and the remaining $25 \%$ died within 90 days postoperatively. Low cholesterol levels in the deceased patients were present with or without sepsis. Recently, Lagrost et al. reported a correlation between cholesterol and outcome after cardiac surgery[6]. In their study, cholesterol levels where collected before the surgical intervention. These cholesterol levels along with a few other parameters were followed during surgery especially during cardio-pulmonary bypass (CPB). Cholesterol levels were also measured 24 hours after surgery. When analyzing the results, patients who developed postoperative sepsis had lower preoperative levels of cholesterol compared to the patients without sepsis. The cholesterol levels in the sepsis group remained low 24 hours after the operation. The authors hypothesized that patients with low cholesterol levels where more susceptible to the effects of endotoxemia due to translocation from the gut during CPB.

The continuous correlation of low cholesterol levels with mortality found in our study (fig. 3) in combination with the above mentioned studies underline the predictive value of a low cholesterol in patients undergoing cardiac surgery. Because cholesterol 
shows to be an independent predictor of all-cause mortality, we argue that cholesterol is more than a predictor for sepsis alone. It seems to be a parameter for the general functional status of the patient. This is also endorsed by the finding from Stachon[5] of an inverse correlation between CRP and cholesterol and by Lagrost ${ }^{[6]}$ who showed that low preoperative cholesterol levels influence outcome after surgery. The latter implying a diminish overall condition of the patient before surgery. Earlier publications also reported low levels of cholesterol in several different diseases and in several different patient categories including surgery[3, 4, 5, 8-14].

The pathophysiology of this decline is partially elucidated. The total cholesterol is a reflection of HDL and LDL cholesterol and Triglycerides. In compromised patients, it is known that LDL reaches its minimum early after an event. In surgery within a few hours [13,14]. The probable cause is diminished synthesis and efflux from the liver[3, 16-17], part of a process referred to as metabolic shutdown ${ }^{[18]}$ There is also a upregulated uptake of LDL in the cell[19]. HDL changes from constitution during diseases and surgical interventions. As a reaction to the critical condition, the core of the HDL particle incorporates serum amyloid $A$. This is a protein which has chemoattractant properties promoting migration and tissue infiltration. Together with upregulated enzymes which promote tissue receptor binding this causes low levels of HDL in the blood[20-23]. As far as TG are concerned, there are contradicting reports of whether this is elevated or lowered during critical conditions $[3,16,24]$.

These three components together explain the decrease of total cholesterol this group of patients.

The time frame in which the minimal level of cholesterol after surgery is reached, is difficult to establish. This is important because it could enable the treating physicians to determine the start of the recovery period.

In the earlier emphasized studies, the alteration of cholesterol levels differs in time. Our study showed a minimum cholesterol level between day 1 and 5 whereas the study of Stachon et al.|[5] showed a minimum between day 4 and 7. Lagrost ${ }^{[6]}$ reported that patients with only a SIRS reaction had increasing cholesterol levels within 24 hours after surgery.

Another problem that arises is that earlier published studies, in which a correlation of cholesterol with disease severity has been reported, do not involve patients after cardiac surgery but involve blended groups of patients. For example, medical patients with hematologic malignancies or human immunodeficiency virus (HIV) as well as surgical patients. Even the prevalence of hypocholesterolemia in general hospitalized patients has been mentioned $[3,4,5,8-15]$. The time frame in which these minimum levels occur probably depends on the diagnosis and probably differs between individuals. For future studies, it will be interesting to investigate whether day to day improvement of cholesterol is also associated with a day-to-day increase in chance of survival. This could lead to the identification of a cheap marker for the evaluation of postoperative therapy. 
This study has some limitations. First, this is a retrospective observational study. Therefore, caution is warranted in drawing conclusions.

For example, bias could be induced by not taking into account the hemodilution by volume replacement therapy. However other studies have shown that volume replacement therapy alone is not responsible for the decrease in cholesterol[6]. Also heparinisation during bypass could induce decreasing cholesterol levels, although surgical patients without heparin therapy also show a decrease in postoperative cholesterol.

The second limitation is that most of the patients had an uneventful stay on the ICU and could be discharged to the ward on the same day as the operation. cholesterol was not determined on the ward. The cholesterol levels of these patients could potentially influence outcome and correlation. However, Kaplan-Meier curves show a direct correlation between the level of cholesterol and survival. Therefore, it is plausible to assume that our group of patients with an uneventful postoperative course also have the highest cholesterol values. The number of patients in group 1 was relatively small, which might have made our results underpowered. 
1. Nashef SA, Roques F, Michel P, Gauducheau E, Lemeshow S, Salamon R. European system for cardiac operative risk evaluation (EuroSCORE). Eur J Cardiothorac Surg 1999;16:9-13

2. Roques F, Michel P, Goldstone AR, Nashef SA. The logistic EuroSCORE. Eur Heart J 2003;24:881-2

3. van Leeuwen, Heezius EC, Dallinga GM, van Strijp JA, Verhoef J, van Kessel KP. Lipoprotein metabolism in patients with severe sepsis. Crit Care Med 2003;31:1359-66

4. Lekkou A, Mouzaki A, Siagris D, Ravani I, Gogos CA. Serum lipid profile, cytokine production, and clinical outcome in patients with severe sepsis. J Crit Care 2014;29:723-7

5. Stachon A, Böning A, Weisser H, Laczkovics A, Skipka G, Krieg M. Prognostic Significance of Low Serum Cholesterol after Cardiothoracic Surgery. Clin Chem 2000;46:1114-20

6. Lagrost L, Girard C, Grosjean S et al. Low Preoperative Cholesterol Level Is a Risk Facor of Sepsis and Poor Clinical Outcome in Patients Undergoing Cardiac Surgery With Cardiopulmonary Bypass. Crit Care Med 2014;42:1065-73

7. Stephens RC, O'Malley CM, Frumento RJ, Mythen MG, Bennett-Guerrero E. Low-dose endotoxin elicits variability in the inflammatory response in healthy volunteers. J Endotoxin Res 2005;11:207-12

8. Kreeftenberg HG, Roos AN, Bindels AJGH, Scharnhorst V. Cholesterol in the ICU: a cheap and reliable marker for illness severity? Netherlands Journal of Critical Care 2015;20:17-20

9. Wattanasuwan N, Khan IA, Gowda RM, Vasavada BC, Sacchi TJ. Effect of acute myocardial infarction on cholesterol ratios. Chest 2001;120:1196-9

10. Marini A, Carulli G, Azzarà A, Grassi B, Ambrogi F. Serum cholesterol and triglycerides in hematological malignancies. Acta Haematol 1989;81:75-9

11. Bologa RM, Levine DM, Parker TS et al. Interleukin-6 predicts hypoalbuminemia, hypocholesterolemia, and mortality in hemodialysis patients. Am J Kidney Dis 1998;32:107-14

12. Muller CP, Wagner AU, Maucher C, Steinke B. Hypocholesterolemia, an unfavorable feature of prognostic value in chronic myeloid leukaemia. Eur J Haematol 1989;43:235-9

13. Gui D, Spada PL, De Gaetano A, Pacelli F. Hypocholesterolemia and risk of death in the critically ill surgical patient. Intensive Care Med 1996;22:790-4

14. Aufenanger J, Walter $\mathrm{H}$, Kattermann R. Alteration in lipid and lipoprotein metabolism after surgical trauma. Langenbecks Arch Chir 1993;378:41-8

15. Oster P, Muchowski H, Heuck CC, Schlierf G. The prognostic significance of hypercholesterolemia in hospitalised patients. Klin Wochenschr 1981;59:857-60

16. Ettinger WH, Varma VK, Sorci-Thomas M et al. Cytokines decrease apolipoprotein accumulation in medium from Hep G2 cells. Atheroscler Thromb 1994;14:8-13

17. Chen Y, Zhao L, Chen Y et al. Inflammatory stress exacerbates hepatic cholesterol accumulation via disrupting cellular cholesterol export. J Gastroenterol Hepatol 2012;27:974-84 
18. Singer M, De Santis V, Vitale D, Jeffcoate W. Multiorgan failure is an adaptive, endocrinemediated, metabolic response to overwhelming systemic inflammation. Lancet 2004;364:545-8

19. Fraunberger P, Pilz G, Cremer P, Werdan K, Walli AK. Association of tumer necrosis factor levels with decrease of cholesterol during septic shock. Shock 1998;10:359-63

20. Badolato R, Wang JM, Murphy WJ et al. Serum amyloid A is a chemoattractant: induction of migration, adhesion and tissue infiltration of monocytes and polymorphonuclear leucocytes. J Exp Med 1994;180:203-9

21. Hoffman JS, Benditt EP. Plasma clearance kinetics of amyloid-related high density lipoprotein apoprotein, serum amyloid protein (apoSAA), in mouse. Evidence for rapid apoSAA clearance. J Clin Invest 1983:71:926-34

22. Badellino KO, Wolfe ML, Reilly MP, Rader DJ. Endothelial lipase is increased in vivo by inflammation in humans. Circulation 2008;117:678-85

23. McCoy MG, Sun GS, Marchadier D, Maugeais C, Glick JM, Rader DJ. Characterization of the lipolytic activity of endothelial lipase. J Lipid Res 2002;43:921-9

24. Nonogaki K, Fuller GM, Fuentes NL et al. Interleukin-6 stimulates hepatic triglyceride secretion in rats. Endocrinology 1995;136:2143-9 



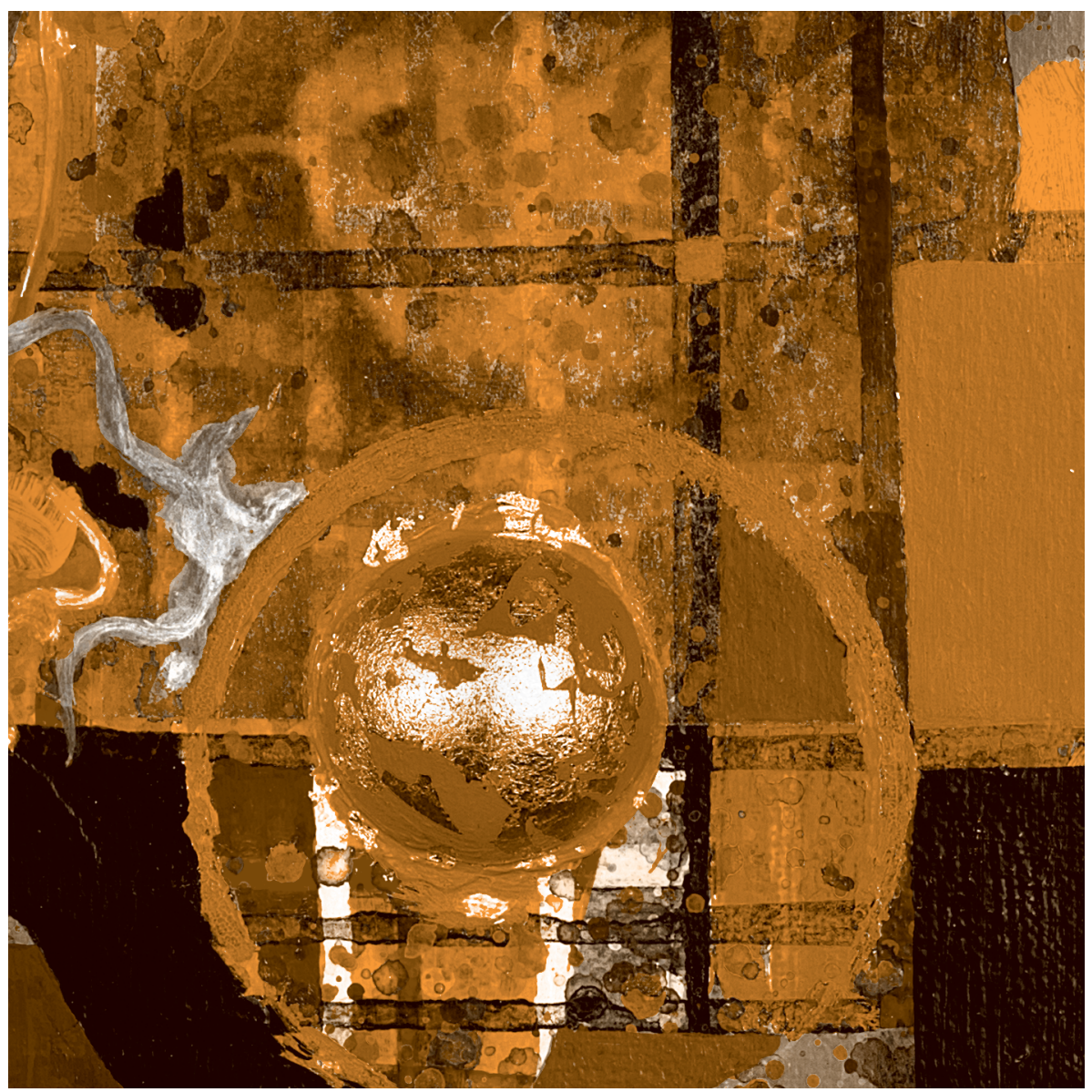





\section{General discussion and conclusions}

\section{FUTURE TARGETS IN CARDIAC SURGERY}

This thesis shows that apart from outcome prediction based on preoperative assessment, $[1,2]$ it is possible to predict outcome after cardiac surgery, using classical, daily used biomarkers in the postoperative period. In case of unpredicted renal replacement therapy after surgery the outcome of older patients is worse. The resources, necessary for the cardiac surgery process can be limited by conscientious decisionmaking concerning patient's clinical pathway after surgery and the policy concerning the use of perioperative blood products.

While surgical procedures as treatment for cardiovascular diseases are one of the most common in the world, innovative techniques in this field provide a view on a better future. ${ }^{[3]}$ However, cardiovascular disease and its treatment, are costly and constitute a significant part of the overall national health expenditures. ${ }^{[4]}$ Developments with focus on safety and efficiency in cardiac surgery are requested to create optimal use of available resources. Furthermore evolvement of logistically optimised models for postoperative care are important challenges in the future. It is expected that the demand for more resources will also rise because of the growing co-morbidity of the population in the last decades and expansion of the use of technical devices in daily clinical practise. In order to meet these future challenges, further exploration on several topics is warranted. We tried to focus on risk reduction, safety and effective practice to move forward in the discussion. A clear example is the in the literature well described fast-track pathways in cardiac surgery. $[5,6,7]$

\section{FAST-TRACK MODELS}

Previous studies showed the advantage of a shortened postoperative pathway in a selected group of cardiac surgery patients. These so-called fast-track clinical pathways to enhance recovery for cardiac surgery facilitate early discharge from expensive postoperative care units to save hospital resource and costs.[5] However, the quality of postoperative care of such fast-track clinical pathways need to be ensured. We started applying the fast-track pathway in our own centre in a selected group of cardiac surgery patients. Out of 11895 patients, 5367 (45.2\%) were selected for the fast-track pathway. Out of these patients 4510 patients (84\%) succeeded the protocol with no mortality, no readmission to the ICU and no take-back to the operation room for re-exploration. These results show the safety and efficiency of this optimised model for postoperative care after cardiac surgery. Predictors of failure of this strategy were older age and patients with left ventricle dysfunction (ejection 
fraction below 35\%). While early extubation has been discussed in literature as the most important issue in fast-track models, ${ }^{[6,7]}$ our results has shown that results can be achieved by paying attention to multifactorial aspects. Important for success is use of a combination of short acting opioid anesthetic drugs for general anesthesia without a regional technique as well as discontinuation of anesthetic drugs before leaving the operating room. ${ }^{[6]}$ Hemodynamic stability during the procedure, reduction of perioperative stress response and the use of anti-inflammatory and hemostatic agents have major impact on achieving rapid discharge from the intensive care. ${ }^{[7]}$ Furthermore, a critical preoperative patient screening and careful monitoring in the first 24 hours by experienced and appropriately trained nurses is crucial. In order to be able to optimize the fast-track pathway, we paid attention to re-warming, pain-free and stress-free awakening of the patient in addition to stabilization of hemodynamic parameters.

By monitoring all critically parameters, early extubation is possible after two or three hours in the PACU. Age, as a significant limiting factor in applying the PACU strategy could be explained by the increased sensitivity of older people for anesthetic drugs. Their pharmacological ability to eliminate agents may be diminished because of impaired kidney- and liver-function. Advanced age is associated with decreased physiologic reserve and significant comorbidity in cerebral, respiratory and hemodynamic function. This may delay postoperative recovery from anesthesia and suggests that careful postoperative titration of postoperative analgesia is warranted. Among limiting factors, referred to in the literature, we found left ventricular function to be a second significant risk factor to predict the success of fast-track. The limited number of preoperative predictors of failure of this protocol, compared to the literature, can be explained by a critical clinical assessment in the preoperative surgical workup. The challenge of an accurate assessment is of utmost importance for a fast-track protocol. The relevance of a critical and balanced fast-track model for the future may be underestimated. The global share of older people (aged 60 or more) increased from $9.2 \%$ in 1990 to $11.7 \%$ in 2013 and will continue to grow reaching more than $20 \%$ by 2050 . Globally, the share of older persons aged 80 years or over within the older population was 14\% in 2013 and is expected to reach 19\% in 2050.[8] The demand for cardiac surgery will rise in such a population. Implementation of a fast-track protocol may reduce costs also in a 1-year-follow-up as described in a prospective randomised study. ${ }^{[9]}$ In this thesis we did not focus on costs of the cardiac surgery program. More studies regarding cost-effective strategies and risk scores with predictive quality for this aging population are needed, because recently some studies questioned the effort of fast-track protocols. Costs may be shifted towards other parts of the health care system.[10] The outcome, more importantly will however depend on preoperative assessment besides the process of the perioperative multidisciplinary care itself. Limiting resources in the health care system in the future will ask for challenging efforts of all involved clinicians. 


\section{BLOOD RESOURCES IN CARDIAC SURGERY}

Patients frequently require transfusion of blood products during or after cardiac surgery. However, perioperative blood transfusion associates with more infection, morbidity, mortality, hospitalization and costs $[11,12,13]$ in a recent guideline, updated recommendation for clinicians are provided regarding perioperative blood transfusions in order to reduce risk of adverse outcome. ${ }^{14]}$ implementing critical blood management strategies in cardiac surgery patient's results in fewer transfusion and better outcome. According to some studies ${ }^{[15]}$ the severity of worse outcome increases with every donated red blood cell (RBC) unit perioperatively, while others doubt the superiority of a restricted transfusion threshold on morbidity and health care costs. ${ }^{[16]}$ Using earlier data from our group, we identified patients with a relatively low risk for blood transfusion. [17] Consequently, we tried to redefine our criteria for direct availability of red blood cells in the operating room. Our 'No Elective Red Cells (NERC)program' for primary isolated coronary artery bypass grafting patients and single aortic valve surgery patients seemed to be safe with the condition that blood cell units would be available in the operation room within 20 minutes when needed. In $81 \%$ of the patients transfusion was avoided. However female gender, decreased left ventricular ejection fraction (<35\%) and a higher EuroSCORE predicted risk of blood transfusion. Non-used RBC units have to be returned to the blood bank. During the reservation and transportation of these units, the quality of these RBC units could be disturbed. In the literature, some controversy has risen, concerning the quality of stored blood and its influence on outcome. ${ }^{[18,19,20,21]}$ This subject was not one of the endpoints of our study. In a letter to the editor, this is discussed together with the limitation of this study due to the absence of a control group. Nonetheless, it seems unethical to perform such a trial in classical randomized fashion if the zero hypothesis is that the trial has a high rate of success. Therefore, we decided to perform a proof of concept trial with respect for safety margins. Selection of patients and a rapid delivery of blood from the local blood bank when needed are crucial. The avoidance of wasting red blood cells and improvement of provision of blood stock is a preferable practice, given the fact that blood cannot be used after a maximum of 42 days.[22] We believe that blood saving strategies and blood management protocols can contribute to improved outcome. The number of patients that did not receive any blood cells perioperatively has increased $150 \%$ in that period and the number of patients who needed 1 to 3 units of red blood cells perioperatively decreased by 50\% in the last 15 years. Changing the logistical policy and thereby reducing costs in the progress of blood supply to the hospital has been optimized and we were able to apply a safe new program for blood supply in the operating room for selected patients. 
Acute kidney injury may occur in $40 \%$ of all cardiac surgery patients, and despite changing surgical management and improved surgical techniques, the incidence of renal failure after cardiac surgery has been stable over the years.[23]

In general, renal failure prolongs intensive care stay and hospitalization and has a major effect on long-term outcome and quality of life.[24] Moreover, once renal replacement is needed ( $1 \%$ of patients) as additional treatment, morbidity, mortality, hospitalization and costs are increasing [25] As cardiac surgery poses a particular large insult to kidney function, because of the use of cardio-pulmonary bypass, perioperative volume (over) loading, frequent occurrence of hemodynamic instability and the frequent use of intravenous contrast in the perioperative period,[24, 26, 27, 28, 29] cardiac surgery patients are frequently regarded as a separate group. In our study out of 11.899 cardiac patients only 26 (18\%) patients had preoperative renal dysfunction; more than half of this group died within 30 days after the operation (52\%). Kidney dysfunction with additional renal replacement therapy occurred in a group of 138 patients (1,2\%). In this subgroup of patients, 107 patients died (77,5\%).

Our study shows that the high mortality in older patients (above 75 years of age) may put renal replacement therapy after cardiac surgery in a different perspective. As a result, this influences the decision-making process in the aging group of cardiac surgery patients with regard to life expectancy. ${ }^{[30]}$ in the discussion about outcome intensive care physicians, together with surgeons and nurses have to address these findings. Consequently this affects the information supply to the relatives of the post cardiac surgery patient, which should reflect a realistic view on outcome and quality of life. However, selection of patients remains important to achieve better outcome, especially in case of age- related changes in organ subsystems and relevant to perioperative management of the aged cardiac surgery patient.[31]

At this moment there may be no ultimate scoring system for excellent outcome prediction. For cardiac surgery in a selected group of octogenarians, optimal outcome may be possible by combining preoperative assessments, including frailty and disability scoring and goal directed critical perioperative care. In our study the outcome for the older was significant worse, once unexpected renal replacement was indicated. More future studies are needed to evaluate these issues.

\section{OUTCOME PREDICTION}

Critically ill patients in the intensive care units frequently need critical diagnostic evaluation. Disease-specific biomarkers, applicable in point of care devices or in blood samples are subject of interest for a prediction of outcome in daily clinical practice. [32] In the cardiac surgery patient group serial measurement of lactate as a surrogate 
marker for end-organ dysfunction and hypoperfusion is of prognostic value for early and late mortality [33, 34] In most studies blood lactate concentrations are measured in the first 24 hours after surgery. In contrast with this time interval, we analyzed 16376 cardiac surgery patients according to the peak level of serum lactate concentration within three days after surgery. In our study lactate was studied as a categorical parameter and patients were divided on an arbitrary basis. We also found peak serum lactate to be an independent factor for both 30-day and late mortality. Several causes may contribute to the mechanisms of the lactate production. [35] while prolonged catecholamine use and hemodynamic instability refer to cardiac output and oxygen delivery, the occurrence of sepsis initiates glycolysis, which itself contributes to lactate acidosis. Delayed clearance of lactate because of non-ischemic hepatic and renal dysfunction may also lead to higher blood lactate. The aetiology of lactate production is multifactorial determined and cardiac patients have different overall preoperative morbidity. We suggest to take postoperative serial blood lactate samples and use peak lactate levels in the overall prediction of outcome after cardiac surgery. However, more studies that prospectively collect lactate levels immediately after surgery until the end of the postoperative intensive care period are needed to build a sustained predictive model. Consequently, in combination with other hemodynamic parameters, blood lactate as a biomarker may play a more precise role in care redirection or resource realignment to improve surgical outcome.

Serum Cholesterol levels in critically ill patients reflects the severity of illness especially in cases of sepsis. ${ }^{[36]}$ Within the postoperative days 4-7 after cardiac surgery, serum cholesterol levels have been described as a prognostic factor for in-hospital mortality.[37] It has been suggested that lower cholesterol levels before cardiac surgery are associated with an increased risk of sepsis and form an independent predictor for early mortality. Patients with low cholesterol levels are more susceptible for the effects of endotoxemia due to translocation from the gut during $\mathrm{CPB}^{\left[{ }^{[38]}\right.}$ we found that the blood cholesterol level postoperatively was an independent predictor of early mortality, but not for late mortality. These results are confirmed by several other observations in the literature[37,38] Low levels of cholesterol implies diminished overall condition before or after surgery. Although the role of serum cholesterol levels as a predictive biomarker in the field of cardiac surgery is uncertain, it seems to be a parameter for the general functional status of the patient.[39] Multiple underlying mechanisms like sepsis or systemic inflammatory response syndrome (SIRS), diminished synthesis and efflux from the liver and critical clinical condition of the patient may contribute to the cholesterol metabolism.[40] Weather these phenomena exist in the cardiac surgery patient need to be established. Future studies are needed to investigate the role of cholesterol metabolism in relationship to the chances of survival. It is interesting to identify cholesterol as a practical marker for the evaluation of postoperative care in 
the cardiac patient. Serum cholesterol as an early predictor of mortality together with serial serum lactate peak levels may have the potency in the judgement of illness in these group of patients. Cholesterol is solely a predictor of early mortality while lactate is a predictor of both early and late mortality. The compromising period during major surgery has its influence on cholesterol levels and it seems cholesterol may imply the impact of the operation on the physiology of the patient. Lactate levels during the process of cardiac surgery and the postoperative period however more reflects the overall condition of the patient, which may determine outcome. The preoperative condition of the patient may also be reflected by the development of lactate levels in the postoperative period.

Most scoring systems used for clinical outcome were not designed for application in cardiac patients. The European System for Cardiac Operative Risk Evaluation (EuroSCORE II) and the cardiac surgery score (CASUS) for clinical outcome in patients after cardiac surgery specifically focus on the cardiac surgery patient2. EuroSCORE is limited to preoperative variables and does not take into account intraoperative or postoperative complications. More studies therefore will be needed to investigate the relation of preoperative variables as well as per- and postoperative clinical data to build more reliable scoring systems like Apgar Score ${ }^{[41]}$ in relationship with cardiac surgery.

\section{FUTURE PERSPECTIVES}

The number of patients who will be referred for cardiac disease is increasing. In addition, the number of high-risk patients, especially older patients, undergoing surgery is also increasing. Our challenge is to use all clinical resources to comply with increasing future health care demands for this group of patients in a reasonable way. In this thesis, we describe the limitations of elderly patients to integrate in an fast-track protocol for cardiac interventions. For the future it is interesting to investigate the application of fast-track practice for a greater variety of less invasive cardiac procedures, like catheter related valve replacements and the relationship with age and co-morbidity. Perioperative blood transfusion should be limited to ameliorate quality of life and outcome. The described logistical policy of absence of direct available red blood cell units in the operating room was safe in cardiac surgery in a selected group of patients. To evaluate the use and safety of this applicable method of blood management in a greater variety of cases, more studies are needed.

Once postoperative complications appear after surgery a prolonged ICU and hospital stay and hence increase costs are the consequence. In this thesis, we have shown that the need of postoperative renal replacement therapy significantly increased mortality. This effect is more pronounced in the elderly. Reliable decision-making concerning the daily management of these patients is imperative for social acceptance of high economic expenditure in this part of health care. 
Cardiac procedures in the elderly will frequently be carried out by less invasive approaches because of high-risk preoperative assessments. We think that specific markers like lactate and cholesterol may have potential value in the daily guide of evaluation and management of the patient during the intensive care stay in this group of patients. These biomarkers may have the potency in the judgement of illness in patients. Lactate could be indicative for quality of organs and reserve capacity, while cholesterol could be a measure for intensity of procedure. More studies are needed to address the importance of these laboratory parameters in addition to the Euro SCORE to evaluate patients who show a postoperative complicated course irrespective of their Euro SCORE.

The responsibility of physicians for future health care should cover excellent care for our patents, accurately turning to account the resources while attempting the wright amount of support for an increasing number of aging people. In this light we have to search for adequate, efficient and effective medical programs and protocols to achieve good quality of life for our patients. With this thesis we have tried to make a contribution to this goal. 
1. Geissler HJ, Hölzl P, Marohl S et al.: Risk stratification in heart surgery: Comparison of six score systems. Eur J Cardiothorac Surg 2000;17:400-6

2. Exarchopoulos T, Charitidou E, Dedeilias P, Charitos C, Routsi C. Scoring systems for outcome prediction in a cardiac surgical intensive care unit: A comparative study. Am J Crit Care 2015;24:327-34

3. Ford ES, Ajani UA, Croft JB et al. Explaining the decrease in U.S. deaths from coronary disease, 1980-2000. N Engl J Med 2007;356:2388-98

4. Heidenreich PA, Trogdon JG, Khavjou OAHeidenreich et al. Forecasting the future of cardiovascular disease in the United States: a policy statement from the American Heart Association. Circulation 2011;123:933-44

5. Royston D. Patient selection and anesthetic management for early extubation and hospital discharge: CABG. Journal Cardiothoracic Vasc Anesth 1998; 12:11-9

6. Cheng DC, Karski J, Peniston C et al. Early tracheal extubation after coronary artery bypass graft surgery reduces costs and improves resource use: A prospective, randomized, controlled trial. Anesthesiology 1996;85:1300-10

7. Engelman RM, Rousou JA, Flack JE 3rd et al. Fast-track recovery of the coronary bypass patient. Ann Thorac Surg 1994;58:1742-6

8. World Population Ageing. 2013. United Nations report• New York, 2013 Department of Economic and Social Affairs.

9. Cheng DC, Wall C, Djaiani G et al. Randomized assessment of resource use in fast-track cardiac surgery 1-year after hospital discharge. Anesthesiology 2003;98:651-7

10. Hansen LS, Hjortdal VE, Jakobsen CJ. Relocation of patients after cardiac surgery: is it worth the effort? Acta Anaesthesiol Scand 2016;60:441-9

11. Murphy GJ. Reeves BC, Rogers CA, Rizvi SI, Culliford L, Angelini GD. Increased Mortality, postoperative morbidity, and cost after red blood cell transfusion in patients having cardiac surgery. Circulation 2007;116:2544-52

12. van Straten AH, Bekker MW, Soliman Hamad MA et al. Transfusion of red blood cells: the impact on short-term and long-term survival after coronary artery bypass grafting, a ten-year follow-up. Interact Cardiovasc Thorac Surg 2010;10:37-42

13. Koch CG, Li L, Duncan Al et al. Morbidity and mortality risk associated with red blood cell and blood-component transfusion in isolated coronary artery bypass grafting. Crit Care Med 2006;34:1608-16

14. Practice guidelines for perioperative blood management : An updated report by the American Society of Anesthesiologists Task Force on perioperative blood management. Anesthesiology 2015;122:241-75

15. Gross I, Seifert B, Hofmann A, Spahn DR. Patient blood management in cardiac surgery results in fewer transfusions and better outcome. Transfusion 2015;55:1075-81 
16. Murphy GJ, Pike K, Rogers CA et al. Liberal or restrictive transfusion after cardiac surgery. N Engl J Med 2015;372:997-1008

17. van Straten AH, Kats S, Bekker MW et al. Risk factors for red blood cell transfusion after coronary artery bypass graft surgery. J Cardiothorac Vasc Anesth 2010;24:413-7

18. van Straten AH, Soliman Hamad MA, van Zundert AA et al. Effect of duration of red blood cell storage on early and late mortality after coronary artery bypass grafting. J Thorac Cardiovasc Surg 2011;141:231-7

19. Koch CG, Li L, Sessler DI et al. Duration of red-cell storage and complications after cardiac surgery. N Engl J Med 2008;358:1229-39

20. Salaria ON, Barodka VM, Hogue CW et al. Impaired red blood cell deformability after transfusion of stored allogeneic blood but not autologous salvaged blood in cardiac surgery patients. Anesth Analg 2014;118:1179-87

21. Sanders J, Patel S, Cooper J et al. Red blood cell storage is associated with length of stay and renal complications after cardiac surgery. Transfusion 2011;51:2286-94

22. Aubron C, Nichol A, Cooper DJ, Bellomo R. Age of red blood cells and Transfusion in critically ill patients. Ann Intensive Care 2013;3:2

23. Rahmanian PB, Kwiecien G, Langebartels G, Madershahian N, Wittwer T, Wahlers T. Logistic risk model predicting postoperative renal failure requiring dialysis in cardiac surgery patients. Eur J Cardiothorac Surg 2011;40:701-7

24. Mangano CM, Diamondstone LS, Ramsay JG Aggarwal A, Herskowitz A, Mangano DT. Renal dysfunction after myocardial revascularization: risk factors, adverse outcomes, and hospital resource utilization. The Multicenter Study of Perioperative Ischemia Research Group. Ann Intern Med 1998;128:194-203

25. Mariscalco G, Lorusso R, Dominici C, Renzulli A, Sala A. Acute kidney injury: a relevant complication after cardiac surgery. Ann Thorac Surg 2011;92:1539-47

26. Lagercrantz E, Lindblom D, Sartipy U. Survival and quality of life in cardiac surgery patients with prolonged intensive care. Ann Thorac Surg 2010;89:490-5

27. Chertow GM, Levy EM, Hammermeister KE, Grover F, Daley J. Independent association between acute renal failure and mortality following cardiac surgery. Am J Med 1998;104:343-8

28. Bove T, Calabro MG, Landoni $G$ et al. The incidence and risk of acute renal failure after cardiac surgery. J Cardiothorac Vasc Anesth 2004;18:442-5

29. Boldt J, Brenner T, Lehmann A, Suttner SW, Kumle B, Isgro F. Is kidney function altered by the duration of cardiopulmonary bypass? Ann Thorac Surg 2003;75:906-12

30. Gjeilo KH, Wahba A, Klepstad P, Lydersen S, Stenseth R. Recovery patterns and healthrelated quality of life in older patients undergoing cardiac surgery: a prospective study. Eur J Cardiovasc Nurs 2012;11:322-30

31. Silvay G, Castillo JG, Chikwe J, Flynn B, Filsoufi F. Cardiac anesthesia and surgery in geriatric patients. Semin Cardiothorac Vasc Anesth 2008;12:18-28 
32. Kempsell KE, Ball G, Szakmany T. Issues in biomarker identification, validation and development for disease diagnostics in Public Health. Expert Rev Mol Diagn 2016;16:383-6

33. Lazzeri C, Valente S, Chiostri M, Gensini F. Clinical significance of lactate in acute cardiac patients. World J Cardiol 2015;7:483-9

34. Lopez-Delgado JC, Esteve F, Javierre C et al. Evaluation of serial arterial lactate levels as a predictor of hospital and long-term mortality in patients after cardiac surgery. J Cardiothorac Vasc Anesth 2015;29:1441-53

35. Attanà P, Lazzeri C, Picariello C, Dini CS, Gensini GF, Valente S. Lactate and lactate clearance in acute cardiac care patients. Eur Heart J Acute Cardiovasc Care 2012;1:115-21

36. van Leeuwen HJ, Heezius EC, Dallinga GM, van Strijp JA, Verhoef J, van Kessel KP. Lipoprotein metabolism in patients with severe sepsis. Crit Care Med 2003;31:1359-66

37. Stachon A, Böning A, Weisser H, Laczkovics A, Skipka G, Krieg M. Prognostic significance of low serum cholesterol after cardiothoracic surgery. Clin Chem 2000;46:1114-20

38. Lagrost L, Girard C, Grosjean S et al. Low preoperative cholesterol level is a risk factor of sepsis and poor clinical outcome in patients undergoing cardiac surgery with cardiopulmonary bypass. Crit Care Med 2014;42:1065-73

39. Gui D, Spada PL, De Gaetano A, Pacelli F. Hypocholesterolemia and risk of death in the critically ill surgical patient. Intensive Care Med 1996;22:790-4

40. Chen Y, Chen Y, Zhao L. et al. Inflammatory stress exacerbates hepatic cholesterol accumulation via disrupting cellular cholesterol export. J Gastroenterol Hepatol 2012;27:974-84

41. Sakan S, Pavlovic DB, Milosevic M et al. Implementing the Surgical Apgar Score in patients with hip fracture. Injury 2015;46:S61-6 




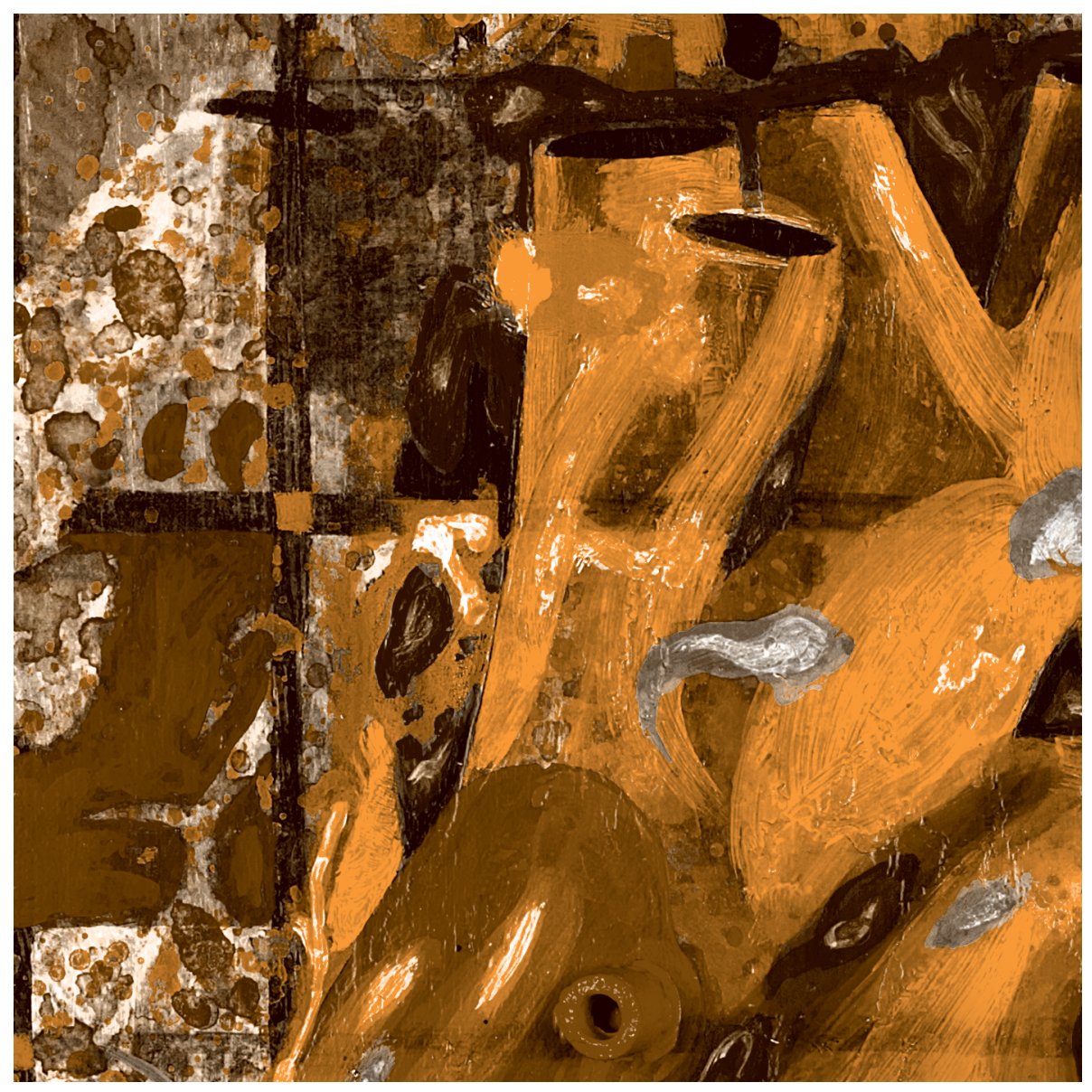





\section{Summary}

Cardiac surgery depends on multi-disciplinary teamwork. The considerable interference of the anesthesiologist on the Operating room as well as on the intensive care makes perioperative care the competence of these professionals. The ultimate goal of the total cardiac surgery team is outcome and good quality of life for a rising number of patients, expected to enter the Hospitals with cardio vascular disease in the future. To meet an increasing demand for optimal use of resources, manpower and medical facilities, fast-track protocols regimes proof to fulfil these requirements.

Chapter $\mathbf{2}$ describes a safe and efficient protocol for postoperative care of 45,2\% (5.367 patients) of 11.905 patients after cardiac surgery on a postoperative anesthesia care unit. Preoperative patient screening and critical patient selection, besides careful monitoring within the first 24 hours postoperatively are important contributory factors for successful cardiac surgery with general anesthesia. Time to extubation itself was not critical in determining the success of the fast-track protocol. However good rewarming of the patient, optimal hemodynamic stabilization and use of non-opioid and short acting anesthetic drugs during and after surgery are essential. Age and left ventricular dysfunction are significant independent risk factors for failure of this protocol. Older patients may need more time to clear their body systems of the anesthetic medication. Besides age, other factors as vitality, cognitive function and renal function should be taken into consideration before accepting older patients for a fast-track pathway.

In Chapter $\mathbf{3}$ and Chapter $\mathbf{4}$ a policy is described to reduce the direct availability of red blood cells (RBC's) on the operating room in a selected group of cardiac surgery patients. The safety of application of a restricted program for blood supply on operating rooms is tested. Preservation of blood is efficient and effective and leads to considerable reduction of cross-matching and diminishes the damage of non-used RBC's. This study consisted of 500 isolated primary coronary artery bypass grafting, aortic valve or mitral valve patients. Preoperative univariate predictors of the need for postoperative RBC transfusion were female gender, left ventricular function $(L V E F<35 \%)$ and the EuroSCORE. The criteria for patient selection are of utmost importance. Blood transfusion prolongs ICU stay and hospital stay and is associated with an increase of morbidity and mortality after cardiac surgery. In this study only $19 \%$ of the cardiac surgery patients needed RBC transfusion during whole hospital stay. With this protocol we avoided blood transfusion in $81 \%$ of the patients. We achieved to reduce costs for our hospital and the Dutch blood bank because less RBC units needed to be in stock. Consequently a subsequent part can be delivered to management for 
optimizing blood cell quality. By preoperative typing and screening on a routine basis of all patients logistics is facilitated. Thus it makes it possible to deliver RBC's within 10 minutes if it is requested in emergencies intra-operatively.

The survival of patients is studied in Chapter 5, which shows the impact of age, once unexpected renal replacement therapy after cardiac surgery is needed. 138 patients $(1,2 \%)$ of 11.899 patients underwent unintentional renal replacement therapy after cardiac surgery. The 30-day mortality included 72 patients (52\%) and the total overall mortality 107 patients (77,5\%). Early mortality (odds ratio $=1,08$ [1,03 to 1,12] as well as late mortality (odds ratio $=1,05[1,02$ to 1,07$]$ is predicted by age. The patient group above 75 years old may put this postoperative therapy in a different perspective. However how risk factors interact on outcome, once acute kidney injury has developed remains to be established. Future studies have to evaluate the impact of these therapies in the aged group of patients.

In Chapter 6 the predictive value of serial lactate measurements during 3 postoperative days for outcome after cardiac surgery is studied. Post cardiac surgery, as a marker of end-organ dysfunction and tissue hypo perfusion lactate is a prognostic value for early and late mortality. We analyzed retrospectively 16.376 patients and studied peak lactate levels after cardiac surgery. To avoid discussion on the time interval of measurements we suggested to take peak levels during the first days after surgery on the intensive care. We found serum lactate to be an independent factor for both 30-day and late mortality. We believe that serial measured blood peak lactate levels should play a role in the architecture and creation of future risk stratification models.

The objective of Chapter $\mathbf{7}$ was to determine the role of cholesterol in prediction of early mortality after cardiac surgery. Preoperative risk stratification by the EuroSCORE can be improved by measurement of additional parameters like blood cholesterol levels. Evaluation of the impact of an cardiac procedure and postoperative management of ICU stay is important to estimate outcome. We studied the value of cholesterol in the determination of survival after coronary artery bypass surgery in 6.072 patients, of which 3.860 patients underwent a fast-track procedure after operation. In patients who stayed longer in the ICU, daily cholesterol levels were measured during first 5 days postoperatively. Multivariate analysis presented cholesterol level as an independent risk factor of considerable influence for early mortality after cardiac surgery. A cut-off point of $2 \mathrm{mmol} / \mathrm{L}$ indicated a poor prognosis. Cholesterol had no prognostic value in late mortality. This can be explained by the impact of a cardiac operation on the individual systemic inflammatory response of the patient. It seems to be a parameter for general functional status of the patient. In future studies it is interesting to investigate whether day to day cholesterol measurement is a cheap marker for evaluation of therapy in post cardiac procedure periods on intensive cares. 




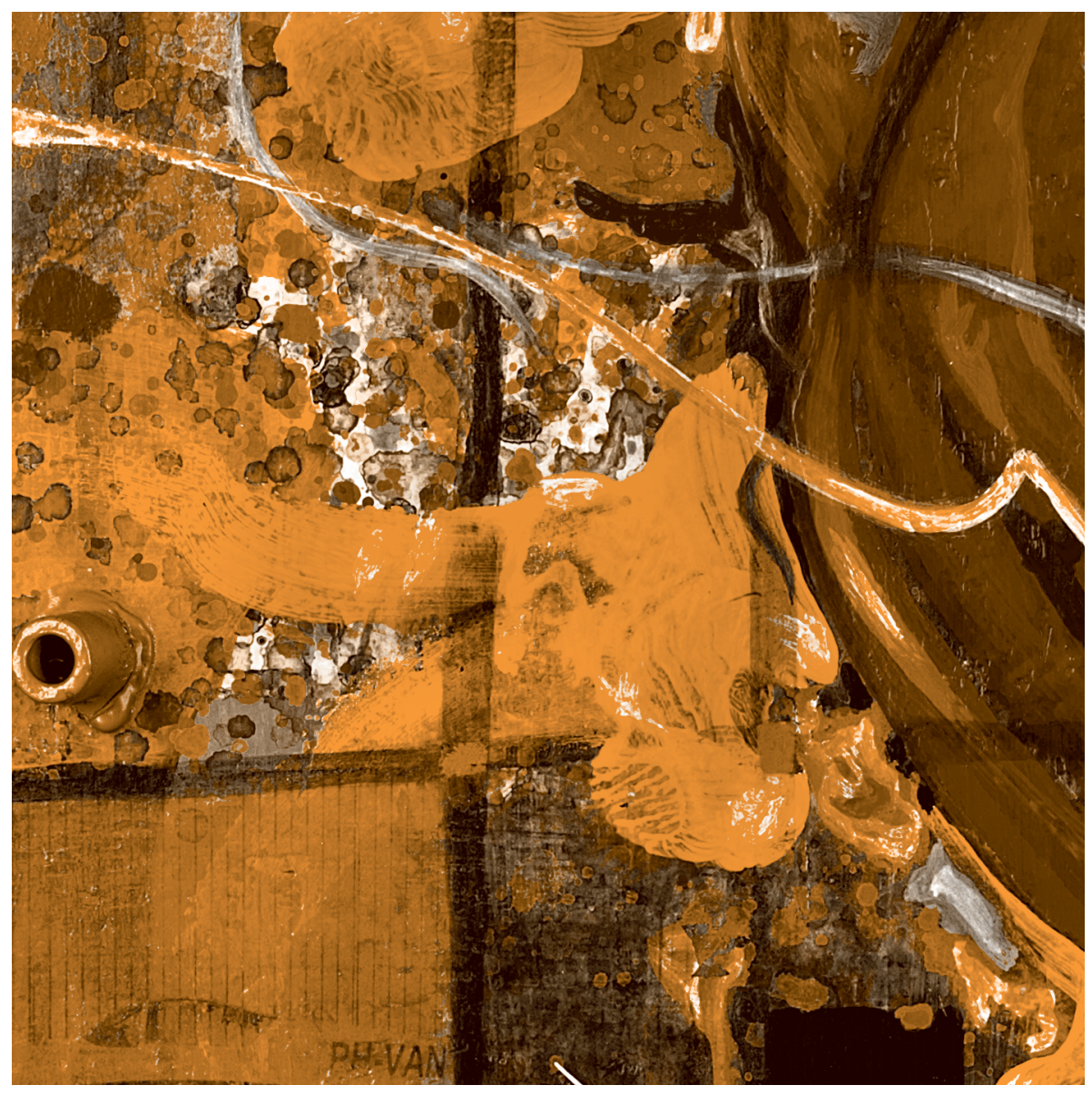

10

Nederlandse samenvatting 



\section{Nederlandse Samenvatting}

Hartchirurgie is afhankelijk van multidisciplinair teamwerk. De aanzienlijke bemoeienis van de anesthesioloog op de operatiekamer als ook op de intensive care maakt de perioperatieve zorg de competentie van dit soort professionals. Het ultieme doel van het totale cardiochirurgie team is prognose en goede kwaliteit van leven voor een toenemend aantal patiënten, die in de toekomst met cardiovasculaire ziekten in de ziekenhuizen zal worden opgenomen.

Om aan een toenemende vraag naar optimaal gebruik van middelen, mankracht en medische faciliteiten te voldoen, is de invoer van fast-track protocollen een manier om aan deze eisen te kunnen voldoen.

Hoofdstuk 2 beschrijft een veilig en efficiënt protocol voor postoperatieve zorg in 45,2\% (5.367 patiënten) van de 11.905 patiënten na hartchirurgie op een postoperatieve intensive care. Preoperatieve patiënten screening en kritische patiënten selectie, naast precieze monitoring aan het bed in de eerste 24 uur na de operatie zijn belangrijk bijdragende elementen voor succes in de hartchirurgie onder algehele narcose. De tijdsspanne tot extubatie op zich zelf, was niet de kritische factor welke leidt tot succes bij dit fast-track protocol. Echter goede opwarming van de patiënt, optimale hemodynamische stabilisatie en het gebruik van niet-opioid achtige, kort werkende analgetische medicatie gedurende en na chirurgie zijn essentieel. Leeftijd en slechte linker ventrikel functie zijn significant onafhankelijke risicofactoren om het protocol te laten falen. Oude patiënten hebben mogelijk meer tijd nodig om de anesthesiologische medicatie uit hun lichaamssysteem te klaren. Naast de leeftijd dient er rekening te worden gehouden met andere factoren zoals vitaliteit, cognitieve functie en niefunctie, alvorens men oudere patiënten accepteert voor een fast-track protocol.

In Hoofdstuk 3 en Hoofdstuk 4 wordt een beleid beschreven om de directe aanwezigheid van rode bloedcellen ('packed cells') op de operatiekamer te reduceren in een geselecteerde groep van patiënten die voor hartchirurgie komen. De veiligheid van de toepassing van een gereduceerd bloedproducten bevoorradings systeem op operatiekamers wordt getest. Preservatie van bloed is hierbij efficiënt en effectief en leidt tot aanzienlijke reductie van bloedgroep kruisproeven en verlaagt de schade aan niet gebruikte rode bloedcellen. Deze studie behelsde 500 geïsoleerde primaire CABG, Aorta klep of Mitraal klep patiënten. Preoperatieve univariate voorspellers van de noodzaak van postoperatieve rode bloedceltransfusie was het vrouwelijke geslacht, linker ventrikel functie (LVEF < 35\%) en de EuroSCORE. De criteria voor patiënt selectie zijn van ongelofelijk belang. Bloedtransfusie verlengt de opname duur op de intensive care en in het ziekenhuis en wordt geassocieerd met een verhoging van de 
morbiditeit en mortaliteit na hartchirurgie. In deze studie hadden slechts 19\% van de hart chirurgie patiënten rode bloed cel transfusie nodig gedurende de hele opname in het ziekenhuis. Met dit protocol hebben we transfusie voorkomen in $81 \%$ van de patiënten. We waren succesvol in het beperken van de kosten voor het ziekenhuis en de Nederlandse bloedbank omdat we minder zakken rode bloedcellen in voorraad nodig hadden. Dientengevolge heeft dit ook invloed op het beleid ten aanzien van management ter optimalisering aangaande de kwaliteit van bloed. Door de preoperatieve typering en screening op een routinematige basis van alle patiënten wordt de logistiek vergemakkelijkt. Dus wordt het mogelijk binnen 10 minuten packed cells af te leveren als er in intra-operatieve situaties met spoed om gevraagd wordt.

De overleving van patiënten wordt bestudeerd in Hoofdstuk 5, alwaar de invloed van leeftijd wordt getoond als er onverwacht niervervangingstherapie (nierdialyse) na hartchirurgie noodzakelijk is. 138 patiënten (1,2\%) van de 11.899 patiënten kregen onverwacht een nierfunctie vervangingsbehandeling na hartchirurgie. Mortaliteit binnen 30 dagen trad op bij 72 patiënten (52\%) en de totale alles includerende mortaliteit was 107 patiënten (77,5\%). Vroege mortaliteit (odds ratio=1,08 [1,03-1,12] als ook late mortaliteit (odds ratio=1,05 [1,02-1,07] wordt voorspeld door leeftijd. De patiëntengroep boven de 75 jaar oud zou een ander licht op deze postoperatieve therapie kunnen werpen. Evenwel moet er worden vastgesteld hoe risicofactoren invloed hebben op de prognose indien er nierfalen is opgetreden. Toekomstige studies moeten evalueren wat de impact van deze niervervangende therapieën is op patiënten groepen met hoge leeftijd.

In Hoofdstuk 6 wordt de voorspellende waarde op de prognose bestudeerd van aaneen volgende metingen van lactaat gedurende drie dagen postoperatief na hart chirurgie. Na hartchirurgie is lactaat een maat voor eindorgaan dysfunctie en vermindering van doorbloeding van weefsel en heeft een voorspellende waarde voor vroege en late mortaliteit. Wij analyseerden retrospectief 16.376 patiënten en bestudeerden piek lactaat niveaus na hartchirurgie. Om discussie omtrent tijdsintervallen van metingen te voorkomen, stelden we voor om piekniveau af te nemen gedurende de eerste 3 dagen postoperatief na chirurgie op de intensive care. We vonden dat serum lactaat een onafhankelijke factor is voor zowel 30-dagen mortaliteit als late mortaliteit. We geloven dat opeenvolgende metingen in het bloed van piek lactaat waarden een rol zou moeten spelen in de opzet en ontwikkeling van toekomstige risico stratificatie modellen.

Het doel van Hoofdstuk 7 was om te bepalen wat de rol is van cholesterol in voorspelling van vroege mortaliteit na hart chirurgie. Preoperatieve risico stratificatie door de EuroSCORE kan verbeterd worden door meting van aanvullende parameters zoals bloed cholesterol niveaus. 
De evaluatie van de impact van een cardiale procedure en het postoperatieve beleid tijdens in de intensive care periode is belangrijk om de prognose te bepalen. We bestudeerden de waarde van cholesterol in de bepaling van overleving na coronaire arterie bypasschirurgie in 6.072 patiënten, van welke 3.860 patiënten een fast-track procedure na operatie doorliepen. In de patiënten die langer op de intensive care verbleven werd dagelijks cholesterol niveaus in het bloed gemeten gedurende de eerste 5 dagen. 

Valorisatie 



\section{Valorisatie}

Hartchirurgie in zijn huidige vorm is een complexe materie en een belangrijke en arbeidsintensieve tak van medische beroepsuitoefening. Sinds 1896 heeft het een enorme vooruitgang laten zien. De maatschappelijke impact was en is nog steeds fors en behaalde resultaten halen geregeld de pers. Dit is niet verbazingwekkend aangezien vele patiënten lijden aan hartziekten met als gevolge hoge zorgkosten. Van 1960 tot 1970 verloopt de innovatie van openhartchirurgie via hartklep implantaties, kransslagader chirurgie in allerlei vormen tot uiteindelijk harttransplantatie. De jaren daarna ontwikkelde zich een technische revolutie ten aanzien van allerlei bruikbare hulpmiddelen zoals de cardiopulmonaire bypassmachine, de pacemaker, de intra-aortale ballonpomp, de assist devices, dialyse, diverse beademingsvormen en de Swan Ganz katheter. Op hemodynamisch gebied zijn er vele verbeteringen doorgevoerd in deze specifieke zorg, zoals ontwikkeling van moderne medicamenten met het doel de perioperatieve begeleiding van de patiënt te optimaliseren. Gespecialiseerde teams werden noodzakelijk en specialisatie op dit terrein werd een eis. Dien ten gevolge bleken er in toenemende mate grotere en ingewikkeldere ingrepen mogelijk waarbij de leeftijdsgrens voor dergelijke majeure correcties opliep. Tegenwoordig behoort een aortaklepvervanging boven de 80 jaar niet meer tot de bijzonderheden binnen het vak.

De ontwikkeling van de laatste jaren voltrekt zich in toenemende mate naar minder chirurgie en meer katheter gerelateerde technieken waarbij hartkleppen vervangen of gerepareerd worden al of niet onder algehele narcose. De anesthesiologische specialisatie met betrekking tot de hartchirurgie heeft een aanzienlijke rol gespeeld bij de behaalde successen op deze terreinen. Teamwerk met goede communicatie tussen de onderlinge disciplines zowel op de operatiekamer als op de intensive care is een belangrijke vereiste geworden voor resultaat. Men is eigenlijk steeds meer als team bezig om successen om te zetten in aantoonbare verbetering van gezondheidswinst. Mate van morbiditeit en mortaliteit als eindpunten van onderzoek worden veelvuldig beschreven in studies; outcome gerelateerde risico scores worden gewogen met het oog op verbeterde Quality of Life na interventie. Uiteraard is deze Quality of Life uitgedrukt in aantal jaren welke men met een redelijke kwaliteit van leven kan doorbrengen na een ingreep een belangrijk maatschappelijke waarde. Zeker gezien de toenemende kosten die gemoeid zijn met deze hoogwaardige medische behandelingsmogelijkheden is efficiëntie en effectiviteit van werken in de zorg een vereiste om de hoge investeringen maatschappelijk te verantwoorden. 
In dit proefschrift wordt er verslag gedaan van een aantal onderzoeken waarbij grote aantallen hartchirurgische patiënten bestudeerd zijn. In Hoofdstuk 2 wordt gesteld dat een groot aantal tevoren zorgvuldig geselecteerde patiënten via een verkort postoperatieve zorgpad een veilige en efficiënte nabehandeling kunnen krijgen. Hiervoor is een gereduceerd intensive care zorgpad beschreven als protocol om doorstroming van patiënten goed efficiënt en veilig te laten doorlopen. Het zal duidelijk zijn dat de kosten in personeel, middelen en ruimte voor het ziekenhuis daarbij gereduceerd worden, alhoewel dit pur sang niet is onderzocht. Ruim 45\% van de patiënten in het ziekenhuis konden via deze weg tussen 2004 en 2010 worden behandeld waarbij het succes percentage $84 \%$ was. Beperkingen voor dit protocol worden gevormd door de leeftijd van de patiënt en door aanwezige dysfunctie van het hart. Daarmee is duidelijk dat met name oudere patiënten en de mensen met een slechte linker hartkamer een minder grote kans hebben om via deze weg met succes een hartoperatie kunnen ondergaan. Echter met de juiste selectie van patiënten vooraf, is er een enorme winst te behalen ten aanzien van eisen aan de postoperatieve intensieve zorg. Dit zorgpad is eerder als innovatief traject in de literatuur beschreven en blijkt de laatste jaren door de ouder wordende patiëntengroep en tevens ziekere en slechter hartchirurgische patiënten in aantallen weer enigszins op zijn retour te zijn. Het is echter belangrijk de beperkingen van een dergelijk protocol te kennen zodat beter en efficiënter kan worden gepland, waarmee de logistiek in een ziekenhuis beter vorm krijgt.

Hoofdstuk 3 en 4 beschrijven een logistiek model op de operatiekamer bij het gebruik van bloedproducten. Het werkelijk aanwezig hebben van bloed bij primaire kransslagaderchirurgie en enkelvoudige klepoperaties blijkt niet nodig, waarbij veiligheid een eerste vereiste is. Transfusie bleek in $81 \%$ van de gevallen niet nodig. Dit prospectieve onderzoek beschrijft een manier van werken waarbij met minimale belasting van de bloedbank toch veilig hartchirurgie kan worden uitgevoerd. De hoeveelheid bloed dat moest worden teruggezonden naar de bloedbank en de mate van kwaliteitsverlies van de rode bloedcellen zijn daarbij niet onderzocht. Een van de voordelen van dit logistiek model is dat er minder bloed in voorraad behoeft te worden gehouden door de bloedbank hetgeen ongetwijfeld kosteneffectief zal zijn. Er zal ook minder vraag naar donatie optreden. In ons ziekenhuis hebben we de bloeddonatie rondom openhartchirurgie in 15 jaar kunnen reduceren; 150\% meer patiënten hebben hierdoor geen bloed ontvangen in deze tijdspanne. De patiënten die 1 tot 3 eenheden rode bloedcellen nodig had is in 15 jaar gehalveerd. Er is zo kostenreductie voor ons ziekenhuis gerealiseerd. In een tijd waarin in toenemende mate gebruik wordt gemaakt van trombocyt aggregatie remmers en stollingsremmers zijn we in staat geweest met een brede focus op transfusiebeperking een aanzienlijke efficiëntie te bewerkstelligen in de bloedtransfusie bij openhartchirurgie. Dit heeft blijkens de literatuur gezondheidswinst tot gevolg en kan met dit model veilig worden uitgevoerd. 
Hoofdstuk 5 handelt eveneens omtrent gebruik van middelen op de intensive care waarbij leeftijd een duidelijke rol speelt. Reeds jaren is bekend dat langdurige grote hartoperaties gepaard gaan met dysfunctie van sommige organen, waaronder de nier veel aandacht krijgt wegens hoge incidentie van functiestoornis na hartchirurgie. De literatuur spreekt over een percentage tot $25 \%$ van alle op de intensive care opgenomen patiënten. Na hartchirurgie is een nierfunctie stoornis een bekende complicatie die zorgt voor de behoefte aan niervervangende therapie (dialyse) in 1\% van alle patiënten. Het is dan ook van belang de risico's hierop te kennen. In de diverse risico score systemen telt deze complicatie zwaar mee. Echter niet in alle gevallen is de voorspelling juist, zodat men soms onverwacht toch niervervangende therapie behoeft na hartchirurgie op de intensive care. Nu blijkt uit het onderzoek beschreven in hoofdstuk 4 dat van de 11.899 patiënten die zijn geopereerd in het Catharina ziekenhuis te Eindhoven tussen januari 2004 en december 2010 de incidentie van nierfunctiestoornis met noodzaak van niervervangende therapie 1,2\% (138 patiënten) is. Meer dan de helft (52\%) van deze patiënten is overleden binnen 1 maand. De leeftijdsgroep van 70-75 jaar liet een significant hogere sterfte zien dan de groep patiënten met een leeftijd van onder de 66 jaar. Leeftijd is dus een belangrijke maat om de prognose te bepalen van onverwachte niervervangende therapie na hartchirurgie op de intensive care. Terwijl tegenwoordig steeds oudere patiënten worden geaccepteerd voor een hartchirurgische operatie is het van belang om de risico's goed in te schatten. Daarom is deze kennis waardevol bij de behandeling van deze patiënten voor de intensivisten en de familie als het gaat om voorspelling van de kwaliteit en duur van leven.

Voorspelbaarheid van ziekte of overlijden na hartchirurgie is van belang voor de maatschappij om een juiste afweging te kunnen maken betreffende de hoeveelheid inzet van middelen, materiaal, ruimte en mensen in de gezondheidszorg en om dat ook te kunnen rechtvaardigen. Indien met eenvoudige laboratorium gegevens een uitspraak gedaan kan worden omtrent prognose zou dat weinig aan investeringskosten met een mogelijk hoge informatie opbrengst als resultaat. Hoofdstuk 6 en 7 handelen over bekende laboratorium data op de intensive care en hun impact op prognose bepaling na hartchirurgie. In Hoofdstuk 6 wordt beschreven dat met bloed lactaat bepaling in de eerste 3 dagen na hartchirurgie een uitspraak kan worden gedaan over de vroege en late mortaliteit. Daartoe zijn 16.376 patiënten gevolgd waarvan bij de helft een onderverdeling is gemaakt op basis van hoogte van lactaat in het bloed. Hieruit is af te leiden dat hoge lactaat waarden gepaard gaan met slechte uitkomst. Met een relatief eenvoudig en goedkope manier van meten kan zo een uitspraak worden gedaan over de kans van overleven na hartchirurgie. 
Evenzo is cholesterol een maat voor outcome na hartchirurgie, hetgeen in Hoofdstuk 7 wordt besproken. Hier wordt duidelijk dat cholesterol in te lage concentratie in het bloed een maat is voor hogere vroege sterfte. De bepaling van deze parameter is eenvoudig en goedkoop. Op een relatief eenvoudige en goedkope manier is dus een voorspelling te doen omtrent outcome. Deze is echter niet absoluut of bepalend, maar kan meehelpen in de discussie over morbiditeit en mortaliteit.

Met dit proefschrift is getracht antwoorden te vinden op specifieke vragen rond veiligheid, efficiëntie, effectiviteit en risicoreductie van zorg bij ingrepen bij de hartpatiënt. Een terugkerend facet blijkt de leeftijd van de patiënt te zijn. De toegenomen leeftijd van de patiënt waarbij tegenwoordig wordt overgegaan tot een operatieve ingreep heeft zijn grenzen. Gelet op de mogelijkheden die technisch uitvoerbaar zijn is kennis van de risico's en grenzen van belang. Zo lang medici rekening houden met deze grenzen en duidelijk communiceren met elkaar en de patiënt, omtrent veiligheid en risico's, is er veel mogelijk in de hedendaagse nog steeds innoverende zorg voor de cardiale patiënt.

In ogenschouw moet worden genomen dat deze thesis uitdrukkelijk niet beschrijft hoe de kostenstructuur van de zorg eruit ziet. Noch is er onderzoek gedaan op economisch vlak. Een absolute uitspraak ten aanzien van uitkomsten is nooit te geven, ook niet in deze thesis. Echter een handleiding bij besluitvorming vormt het zeker wel. Daarbij zijn vele andere bronnen, bewezen risicoanalyses en scores van belang als het gaat om veilige en betere inschatting van uitkomst na interventie. Daarmee zijn dokters beter in staat om verantwoord om te gaan met de resources die de maatschappij biedt in een toenemende technisch innoverende patiëntenzorg. 


Curriculum Vitae 



\section{Curriculum Vitae}

Marius Cornelis Haanschoten was born on the second of July in 1961 in Oostzaan in the Netherlands. In 1980 he graduated from high school, 'Ichthus college Enschede' and started his medical training at the State University of Utrecht. After graduating as a doctor he joined the Military in 1987 as a 'resident-anesthesiologist' and continued his education in anesthesiology at the department of Anesthesiology of the University of Utrecht under supervision of Prof. Dr. B. Smalhout.

After graduating as an anesthesiologist in September 1992 he was invited to start a training in cardiac-anesthesiology at the same Academic Hospital of Utrecht (AZU) which was followed by a training in children cardiac anesthesiology in the Wilhelmina Children's Hospital (WKZ) in Utrecht. The subsequent 9 years were spend, working as a children cardiac anesthesiologist and intensivist in the WKZ and AZU. During this period, together with collogues some papers were published, concerning the cardiac surgery and intensive care program of very young children. From January 1996 to August 1999 he was secretary and vice-president of the Section Cardiac Anesthesiology of the Dutch Society of Anesthesiology.

In the February 2000 he started to join the medical staff as a cardiac-anesthesiologist and intensivist in the Catharina Hospital of Eindhoven, where he joined the board of the medical staff for nearly 5 years as secretary and vice -president from 2001 until 2005. From 2006 until now he is representative of the staff of this Hospital in the Society of Dutch Specialists Pension Fund.

In 2010 he became owner of a PPL (Privat Pilot Licence) of the EASA (European Aviation Safety Agency; Eu-FCL) and since this moment he continues his experiences in Flying an aircraft.

In 2015 together with collegues he founded the 'Cooperation Anesthesiology Intensive Care and Pain Medicine Groot Eindhoven U.A'.

From 2011 until this moment the papers in this thesis were published and the manuscript of this thesis was written.

Marius Cornelis Haanschoten is married and has 3 children. 

List of Publications 


\section{List of Publications}

1. Post-dural puncture headache in young patients. A comparative study between the use of $0.52 \mathrm{~mm}$ (25-gauge) and $0.33 \mathrm{~mm}$ (29-gauge) spinal needles.

Acta Anaesthesiologica Scandinavica 1990; 34(5):350-356.

Geurts JW, Haanschoten MC, van Wijk RM, Besse TC.

2. Abstract:

7e internationale congres neuromusculaire ziekten München. Journal of the neurological sciences; September 1990:vol.98; nr 4.6.13 en 4.6.14:

"Anaesthetic implications of spinal surgery in patients with neuromuscular disease"

"Retrograde endotracheal intubation with the use of a catheter in children with neuro muscular disease".

3. Capnography does not reliably detect double-lumen endotracheal tube malplacement Journal of Clinical Monitoring 1992;8(3):236-237.

Vries de JW, Haanschoten MC.

4. Capnography does not reliably detect double-lumen endotracheal tube malplacement Journal of Clinical Monitoring and Computing 1993; 9(3):207-208.

Kumar AY, Shankar KB, Moseley HSL, Haanschoten MC.

5. Autologous tissue cardiac valve: Implantation in children Journal of Thoracic and Cardiovascular Surgery 1996; 112(3):846-848.

Wal de HJCM, Bennink GBWE, Haanschoten MC, Meijboom EJ.

6. Resuscitation in pediatric balloon valvuloplasty: Effects on cerebral perfusion and oxygenation

Journal of Cardiothoracic and Vascular Anesthesia 2000: 14(5):581-583.

Vries de JW, Haanschoten MC.

7. The anatomical position of three extraglottic airway devices in patients with clear airways Anaesthesia 2006; 61(9):891-895.

Zundert van AA, Brimacombe J, Kamphuis R, Haanschoten MC.

8. Type B Aortic Dissection resulting in acute esophageal necrosis

Annals of Vascular Surgery 2011; 25(6):837 e1-837.e3.

Annals of Vascular Surgery 2013; 27(1):129-129.

Wal-Visscher van de W, Nieuwenhuijzen GAP, Sambeek van MRHM, Haanschoten MC,

Botman KJ, Hingh de IHJT.

9. Fast-track practice in cardiac surgery: Results and predictors of outcome Interactive Cardiovascular and Thoracic Surgery 2012; (0):1-6.

Haanschoten, MC, Straten van AHM, Woorst ter JF, Stepaniak PS, Meer van de AD,

Zundert van de AA, Soliman Hamad MA. 
10. Erratum: Type B Aortic Dissection Resulting in Acute Esophageal Necrosis(Annals of Vascular Surgery (2011) 25 (837)) January 2013; 27(1):129-129.

Wal-Visscher van de W, Nieuwenhuijzen GAP, Sambeek van MRHM, Haanschoten MC, Botman KJ, Hingh de IHJT.

11. The Impact of Postoperative Renal Replacement Therapy on Long-Term Outcome After Cardiac Surgery Increases with Age Journal of Cardiac Surgery 2014:29(4):4464-469.

Haanschoten MC, Straten van AHM, Bouwman RA, Bindels AJ, Zundert van AA, Soliman Hamad MA.

12. Reducing the immediate availability of red blood cells in cardiac surgery, a single-centre experience Netherlands Heart 2015: 23(1):28-32. Haanschoten MC, Straten, van AHM, Verstappen F, Kerkhof van de D, Zundert van AA, Soliman Hamad MA.

13. 'Red blood transfusion in patients undergoing cardiac surgery reply' Netherlands Heart Journal 2015; 23(6):346-346. Haanschoten MC, Straten van AHM, Soliman Hamad MA.

14. Use of calcium antagonist in preventing spasm of radial artery conduit during coronary artery bypass grafting: Verapamil vs Nicardipine. Conference paper Ned Vereniging voor Thoraxchirurgie April 2016 Basous S, Özdemir HI, Straten van AHM, Soliman Hamad MA.

15. Use of Postoperative Peak Arterial Lactate Level to Predict Outcome After Cardiac Surgery Journal of cardiothoracic and vascular Anesthesia 2016 Haanschoten MC, Kreeftenberg HG, Bouman RA, Straten van AHM, Buhre WF, Soliman Hamad MA. 

Dankwoord 



\section{Dankwoord}

Deze dissertatie is tot stand gekomen, mede door stimulerend enthousiasme van een aantal bijzondere mensen, die het verdienen hier bij uitstek genoemd te worden.

Dr. Van Straten, beste Bart, als collega en als vriend ken ik je als een nuchtere en goede dokter. De behandeling en eenvoudig ogende handelingen, door jou uitgevoerd als cardiopulmonaal chirurg op de operatiekamer, zijn van hoog niveau, hetgeen ik vele malen dagelijks heb mogen aanschouwen. Deze conclusie trek ik, na meer dan 25 jaar lang, de handvaardigheid van diverse hartchirurgen in Nederland te hebben bekeken. Hartchirurgie moet goed en snel gaan en ook in die volgorde. Je improviserend vermogen in moeilijke situaties heeft de patiënt dikwijls het leven gered. De door jou opgezette databank is van groot belang geweest voor de basis van dit proefschrift. Daarnaast heb je mij enorm gestimuleerd om deze thesis te schrijven. Dat heb ik zeer gewaardeerd. Dank daarvoor.

Dr. Soliman Hamad, beste Mohammed, jij bent voor mij van onschatbare waarde geweest met name door mij aan te zetten door te gaan met het schrijven van deze thesis. Telkens wanneer ik dacht dat er weer eens leeuwen en beren op de weg zouden verschijnen was je er voor een helder advies en heb je me gestimuleerd om de schouders er weer onder te zetten. Je werkelijk ongelofelijk talent om zaken helder te verwoorden en je visie op de lijn van het geheel zijn erg belangrijk voor me geweest. Ik ben je zeer dankbaar voor je begeleiding en ook erg trots op het feit dat je mijn co-promotor bent. Daarnaast ben je een optimistische en stimulerende collega en vriend voor mij. Laten we nog eens een vluchtje maken.

Prof.dr. Van Zundert, beste André, je ongelofelijke werklust heeft me altijd verbaasd. Hartelijk dank voor je aandeel in deze promotie en je aanwezigheid hier in Nederland als promotor van dit proefschrift. Overal ter wereld houdt het vak anesthesiologie je bezig. Immer ben jij aan het werk, hetgeen tot vele publicaties heeft geleid. Als het om het schrijven van artikelen gaat, kan men je altijd om advies vragen en je hebt overal een oplossing voor. Van die gave heb ik gebruik mogen maken. Dank.

Prof.dr. Buhre, beste Wolfgang, als promotor van dit proefschrift en als begeleider van mij in deze universiteitsstad wil ik jou met name danken. Ter completering en vervolmaking heb je me geweldig ondersteund. Als ervaren cardio-anesthesioloog en als wetenschappelijk adviseur heb ik je visie erg gewaardeerd. Maastricht heeft mijns inziens een hoogleraar en afdelingshoofd met groot talent binnen haar muren. Dank voor je open houding, je stijlvolle begeleiding en je heldere raad. 
Prof.dr. Maessen, prof.dr. Crijns, prof.dr. Roekaerts, prof.dr. Scharnhorst en prof.dr. Stolker, dank u allen voor uw aandeel in deze promotiecommissie en de tijd en inspanning die $u$ hebt geïnvesteerd in de beoordeling van dit proefschrift. $U$ hebt allen uw kritische blik geworpen op deze thesis en de inhoud ervan van commentaar voorzien. Daardoor weet ik dat u met uw ervaring op eigen gebied en relaterend aan dit onderwerp, een waardevolle bijdrage hebt willen en kunnen geven aan mijn boodschap. Hartelijk dank.

Dr. Bouman, beste Arthur, als collega anesthesioloog ben je na onze eerste persoonlijke kennismaking vanuit de Vrije Universiteits kliniek in Amsterdam naar onze club in Eindhoven gekomen. Aanvankelijk leek je ons slechts een kort bezoek te brengen, maar al snel bleek de kennismaking een gevolg te krijgen in je verhuizing naar Eindhoven. Het vertrek van één van onze hoogleraren liet een hiaat achter, hetgeen jij nu opvult. Je wetenschappelijke visie en je enthousiaste houding maakt je tot een uitstekende begeleider van promovendi. Dat heb ik ook mogen ervaren. Dank je voor je goede adviezen.

Drs. Kreeftenberg, beste Herman, het advies van jou om maar eens te starten met het halen van mijn vliegbrevet getuigt van visie en heb ik opgevolgd. Tot op de dag van vandaag heb ik daar geen spijt van gekregen en vrijwel dagelijks mag en kan ik mijn vliegervaringen met je bespreken. Echter de voortgang van deze promotie moest voorrang krijgen. Op de IC ken ik je als een uitstekende collega internist-intensivist met een goed geheugen. De bespiegelingen op de omgeving en de visie op het vak tijdens de koffie na de ochtendronde op de IC in jouw aanwezigheid zijn altijd louterend. Dank voor je steun en hulp in de afgelopen jaren. Laten we nog vele jaren deze IC bevolken en besturen.

Dr. Bindels, beste Alexander, het leven in zijn vele facetten hebben we vaak besproken. Met name de zinvolle bijdrage van de geneeskunde aan het welbevinden van de mens was daarbij een terugkerend onderwerp. Opvallend vaak waren we het eens over de wijze waarop we als intensivisten de patiënten moeten en kunnen bijstaan. Dank voor je hulp en advies bij de totstandkoming van een der artikelen in dit proefschrift. Laten we onze IC tot de beste in zijn soort maken.

Collegae intensivisten IC Catharina Ziekenhuis, beste collega Ingeborg Herold, Femke Intven, Vesna Svircevic, Marc Buise, Dick Koning, Erik Korsten, Arnoud Roos en Luc Ottenspoor dank voor jullie steun en bijval om door te gaan met schrijven, welk een extra investering heeft gevergd naast het dagelijkse werk. 
Collegae anesthesiologen van de Coöperatieve Vereniging Catharina Anesthesiologie Intensive Care en Pijngeneeskunde Groot Eindhoven U.A., dank voor jullie ondersteuning. Wij zijn recentelijk behoorlijk in samenstelling veranderd en met name de laatste paar jaren gemiddeld jonger geworden. De ambitie en werklust die uit deze groep straalt geeft me een trots gevoel en ik hoop nog jaren met jullie te mogen werken.

Esther en Francine, zonder jullie was de afdeling Research \& Development van het Hartcentrum van het Catharina ziekenhuis niet zo voortvarend geweest in haar werk. Jullie wil ik danken voor de immer vrolijke bereidwilligheid me bij te staan in allerlei administratieve handelingen aangaande wetenschappelijk werk. Zonder mensen zoals jullie gaat het niet.

Verpleegkundigen van de intensive care en operatiekamers van het Catharina Ziekenhuis, vele uren heb ik met jullie overdag en veelal 's avonds en 's nachts doorgebracht ten behoeve van de patiëntenzorg. Op zich kan ik daar al een boek over schrijven. Wat hebben we veel mee gemaakt in al die jaren en dankzij jullie ondersteuning gaf dat mij altijd weer een voldaan gevoel. We hebben een prachtig vak. Door de goede onderlinge verstandhouding en gezamenlijke inzet kan ik alleen maar dankbaar zijn dat ik met jullie heb mogen werken.

Alle nurse practitioners en physician assistants van de Intensive Care en van de CTC afdeling wil ik graag hier bedanken voor hun aandeel in het klinische werk. Jullie behulpzame inzet in vele onderzoeken, processen en de extra klussen die zo ongemerkt er even bijgedaan worden in het dagelijkse werk zijn zeer gewaardeerd. Met name Frank Verstappen wil ik danken voor zijn inzet in de praktijk en zijn werk aan het protocol en uitvoering van de bloedbesparing op de operatiekamer. De tegenwoordige kliniek wordt met name door jullie aanwezigheid en werk vorm gegeven. Dat zal in de toekomst van grote waarde blijken. Bedankt.

Sofie den Ouden, beste Sofie, jou wil ik danken voor de plezierige samenwerking en je visie bij de totstandkoming van dit boek. Als kenner ben je in staat geweest om een mooi design te creëren met oog voor de details. Het resultaat is helder, scherp en professioneel, kwaliteiten die passen bij ons vak.

Marcel Bastiaans, beste Marcel, jou vroeg ik een schilderij te maken, welke facetten uit mijn leven bevat. Het resultaat is een prachtige en kleurrijke creatie geworden met diverse verwijzingen naar ons bestaan. Dank voor je bereidwilligheid en je inzet om met je geweldig kunstzinnige gevoel hier invulling aan te geven. Op deze wijze blijft mijn herinnering aan deze tijd levend en zal ik met plezier kunnen terugdenken aan het proces van het schrijven van een thesis bij het zien van dit schilderij. 
Frans van Meltvoort, beste Frans, jou ken ik als vliegenier, maar vooral als deskundige op het gebied van drukwerk en ambachtelijk vakmanschap. Dankjewel voor je visie en adviezen bij de keuzes die men moet maken bij het fabriceren van een boek. Ik heb je deskundigheid en aandacht erg gewaardeerd.

Alle co-auteurs van mijn manuscripten wil ik danken voor hun zinvolle en heldere commentaren op de inhoud en vormgeving en voor de plezierige samenwerking.

Esther en Daniëlle, mijn beide lieve dochters, dank voor jullie steun als paranimfen bij deze voor mij belangrijke dag. Ik ben trots op het feit dat jullie na je academische opleiding beide een mooie baan hebben gevonden en ambitieus in het leven staan. Een mens is nooit uitgeleerd in zijn leven en weet dat er nog mooie verassingen in de toekomst zullen zijn, door met een open houding en optimistische kijk je weg in je werkzame leven te vervolgen.

Rutger, mijn zoon, je nieuwsgierige houding aangaande de voortgang van mijn werk heeft me altijd steun gegeven. Je bereidheidwillige houding aangaande de medemens om je heen en je investering in die relaties zal je veel waardering brengen. Doorzettingsvermogen en werklust zullen je zeker verder helpen in het leven. Dank voor de organisatie en je inzet als ceremoniemeester op het feest na de verdediging van deze promotie.

Lieve pa en ma, jullie wil ik danken voor de steun in mijn opleiding en verdere leven. Jullie waren altijd bereid me van advies te dienen in een breed scala aan vragen gedurende het proces van volwassen worden in mijn studietijd. Nu, na vele jaren ben ik heel blij dat jullie allebei redelijk gezond deze dag mogen en kunnen meemaken. Laten we het leven nog jaren mogen vieren.

Yvonne, mijn lieve vrouw, met jouw overweldigende steun en altijd weer aanwezige luisterende oor ben je mijn rust en liefde. Hoe kan ik het in mijn drukke leven volhouden zonder je liefdevolle immer aanwezige steun. Je bent mijn trouwe levensmaatje en eeuwig ben ik je dankbaar voor alle begrip, aandacht en liefde die je me geeft. Zonder jou was dit proefschrift er niet gekomen. 


Abbrevations 


\section{Abbreviations}

\begin{tabular}{|c|c|}
\hline $\mathrm{ABO}$ & A, B $\bigcirc$ blood group types \\
\hline$A F$ & Atrial fibrillation \\
\hline AKI & Classification Acute Kidney injury network \\
\hline AKIN & Acute kidney Injury \\
\hline AoX & Aortic cross-clamping time \\
\hline ASD & Atrial septum defect \\
\hline$A \cup C$ & Area under the ROC curve \\
\hline BMI & Body mass Index \\
\hline BSA & Body Surface Area \\
\hline CABG & Coronary artery bypass graft(ing) \\
\hline CBS & Central Bureau of Statistics \\
\hline $\mathrm{Cl}$ & Confidence Interval \\
\hline CKD & Chronic Kidney Disease \\
\hline CPB & Cardio Pulmonary Bypass \\
\hline COPD & Chronic Obstructive Pulmonary Disease \\
\hline $\mathrm{CrCl}$ & Creatinine Clearance \\
\hline CRP & C-reactive protein \\
\hline CVA & Cerebrovascular accident \\
\hline CVVH & Central veno-venous hemofiltration \\
\hline CVD & Cardio vascular disease \\
\hline ECC & Extra-corporeal circulation \\
\hline ECG & Electro cardiogram \\
\hline EF & Ejection Fraction \\
\hline EurOSCORE & European System for cardiac Operative Risk Evaluation \\
\hline FFP & Fresh frozen Plasma \\
\hline $\mathrm{Hb}$ & Hemoglobin \\
\hline HIV & Human immunodeficiency virus \\
\hline $\mathrm{HR}$ & Hazard ratio \\
\hline IABP & Intra-aortic balloon pump \\
\hline ICU & Intensive Care Unit \\
\hline KIU & Kallikrein-inactivating units \\
\hline LAD & Left ascending coronary artery \\
\hline LITA & Left internal thoracic artery \\
\hline LVEF & Left- ventricular Ejection Fraction \\
\hline MDRD & Modification of diet in renal disease \\
\hline $\mathrm{Ml}$ & Myocardial infarction \\
\hline
\end{tabular}




$\begin{array}{ll}\text { MORROW } & \text { Myomectomy according to Morrow } \\ \text { NERC } & \text { No elective Red cells } \\ \text { OPCAB } & \text { Off-pump coronary artery bypass } \\ \text { OR } & \text { Odds Ratio } \\ \text { PACU } & \text { Post Anesthesia Care Unit } \\ \text { PALL } & \text { Peak Arterial Lactate Level } \\ \text { PCI } & \text { Percutaneous Coronary Intervention } \\ \text { Periop MI } & \text { Perioperative Myocardial Infarction } \\ \text { RBC } & \text { Red Blood Cells } \\ \text { RIFLE } & \text { Classification Risk Injury Failure Loss end stage renal disease } \\ \text { Redo } & \text { Re-operation (previous cardiac surgery) } \\ \text { RRT } & \text { Renal replacement Therapy } \\ \text { PVD } & \text { Peripheral Vascular Disease } \\ \text { PVISO } & \text { Pulmonary Vein Isolation } \\ \text { ROC } & \text { Receiver Operating Characteristics } \\ \text { SD } & \text { Standard deviation } \\ \text { SPSS } & \text { Statistical Product and Services Solutions }\end{array}$




